In cooperation with the New Jersey Department of Environmental Protection

\title{
Development of the Hydroecological Integrity Assessment Process for Determining Environmental Flows for New Jersey Streams
}

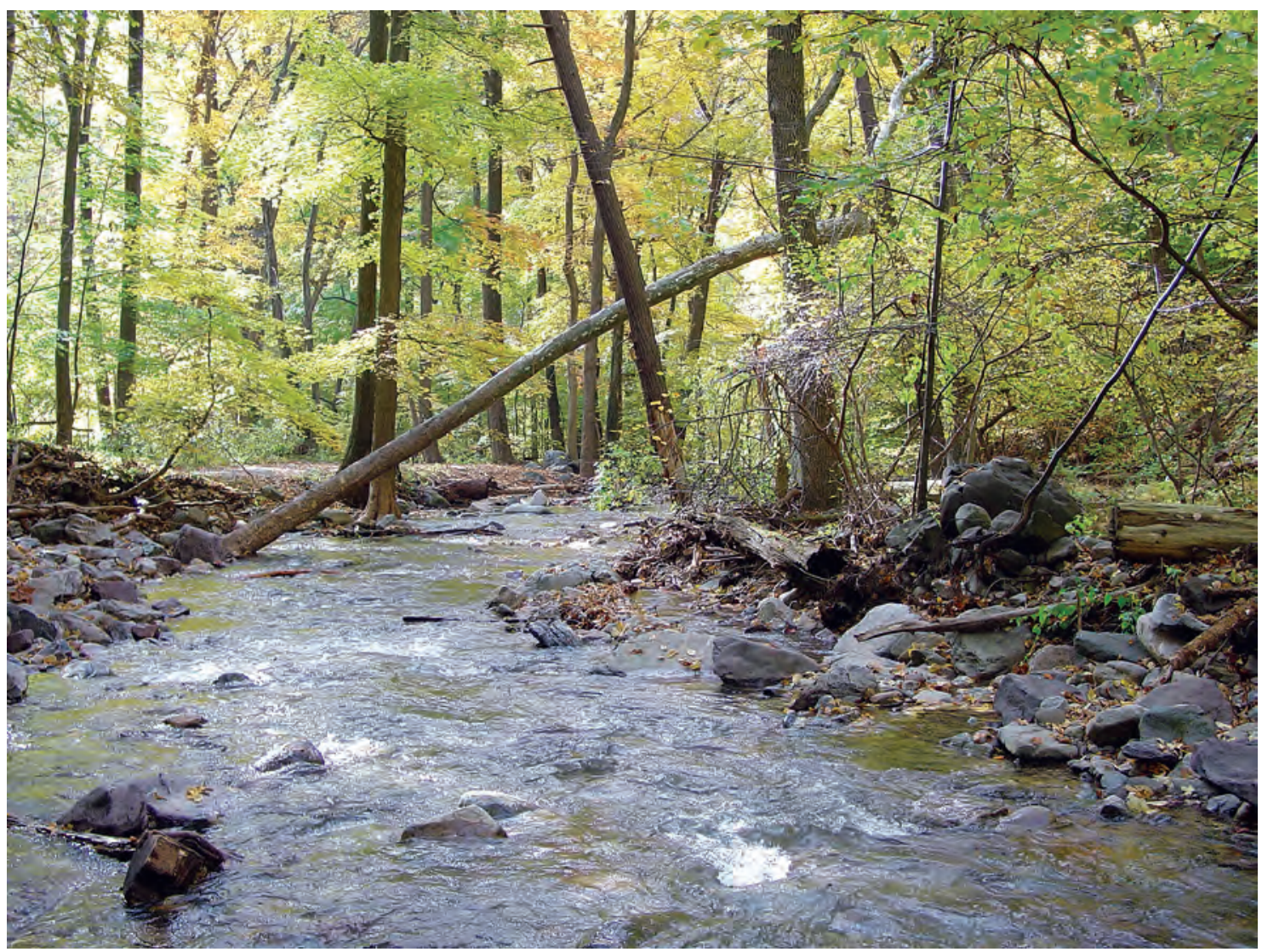

Scientific Investigations Report 2007-5206 
Cover. Dunnfield Creek in the Delaware Water Gap National Recreation Area, Warren County, New Jersey. Photograph by Jason Lewis, U.S. Geological Survey. 


\section{Development of the Hydroecological Integrity Assessment Process for Determining Environmental Flows for New Jersey Streams}

By Jonathan G. Kennen, James A. Henriksen, and Steven P. Nieswand

In cooperation with the New Jersey Department of Environmental Protection

Scientific Investigations Report 2007-5206 


\section{U.S. Department of the Interior DIRK KEMPTHORNE, Secretary}

\section{U.S. Geological Survey \\ Mark D. Myers, Director}

\section{U.S. Geological Survey, Reston, Virginia: 2007}

For product and ordering information:

World Wide Web: http://www.usgs.gov/pubprod

Telephone: 1-888-ASK-USGS

For more information on the USGS--the Federal source for science about the Earth, its natural and living resources, natural hazards, and the environment:

World Wide Web: http://www.usgs.gov

Telephone: 1-888-ASK-USGS

Any use of trade, product, or firm names is for descriptive purposes only and does not imply endorsement by the U.S. Government.

Although this report is in the public domain, permission must be secured from the individual copyright owners to reproduce any copyrighted materials contained within this report.

Suggested citation:

Kennen, J.G., Henriksen, J.A., and Nieswand, S.P., 2007, Development of the Hydroecological Integrity Assessment Process for Determining Environmental Flows for New Jersey Streams: U.S. Geological Survey Scientific Investigations Report 2007-5206, 55 p. 


\section{Contents}

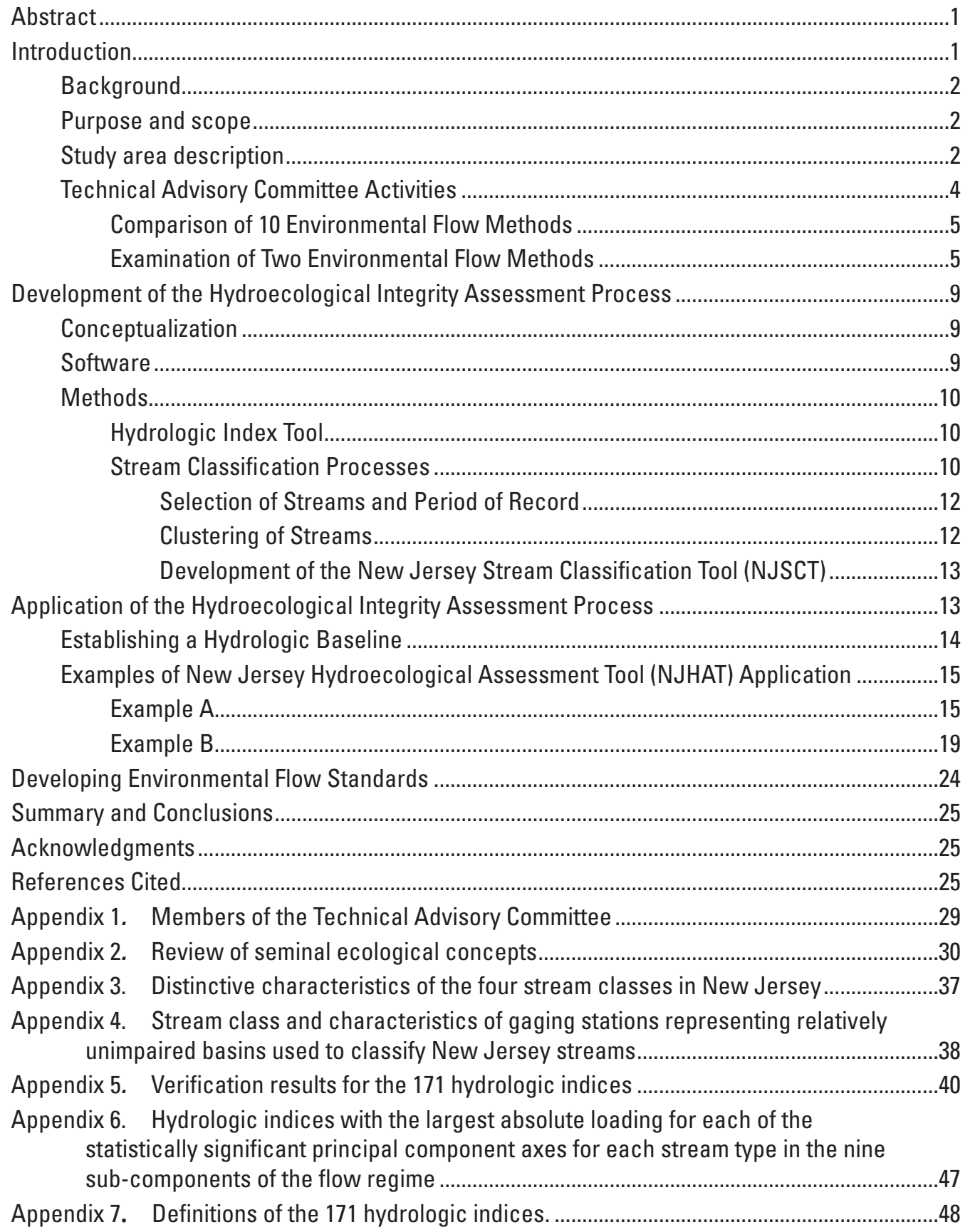




\section{Figures}

1. Maps showing location of physiographic regions and streamflow sites used to classify the primary stream classes in New Jersey.

2. Graph showing time series of daily flow, minimum flow, and 25th- and 75th-percentile flow ranges for the South Branch Raritan River (USGS station 01396500), New Jersey, with flows for three environmental flow methods: Aquatic Base Flow (ABF), Range of Variation Approach (RVA), and 7-day, 10-year low flow (7010).....

3. Diagram showing steps taken to develop and apply the Hydroecological Integrity

Assessment Process (HIP).

4-19. Graphs showing-

4. Monthly maximum daily mean streamflow for time periods before and after regionalization of a wastewater facility, water years 1964-2003...

5. Monthly mean streamflow for time periods before and after regionalization of a wastewater facility, water years 1964-2003.

6. Monthly minimum daily mean streamflow for time periods before and after regionalization of a wastewater facility, water years 1964-2003.

7. Maximum monthly streamflow for time periods before and after regionalization of a wastewater facility, water years 1964-2003.

8. Median monthly streamflows for time periods before and after regionalization of a wastewater facility, water years 1964-2003.

9. Minimum monthly streamflows for time periods before and after regionalization of a wastewater facility, water years 1964-2003.

10. The calculated value and the 25th- and 75th-percentile values of selected hydrologic indices pre- and post-regionalization

11. Monthly maximum daily mean streamflow for water years 1924-2003

12. Monthly mean streamflow for water years 1924-2003...

13. Monthly minimum daily mean streamflow for water years 1924-2003.

14. Hydrograph showing two diversion scenarios with baseline daily flow conditions for water year 2000 (diversions of 5 and $50 \mathrm{ft}^{3}$ with an environmental passing flow of $\left.25 \mathrm{ft}^{3}\right)$

15. Hydrograph showing two diversion scenarios with baseline daily flow conditions for water year 2000 (diversions of 25 and $50 \mathrm{ft}^{3}$ with environmental passing flows of 25 and $10 \mathrm{ft}^{3}$, respectively)

16. Maximum monthly flows for four flow-diversion scenarios for water years 1924-2003.

17. Median monthly flows for four flow-diversion scenarios for water years 1924-2003

18. Minimum monthly flows for four flow-diversion scenarios for water years 1924-2003

19. Mean, 25th, and 75th percentiles of 10 principal hydrologic indices for baseline conditions and four streamflow-diversion scenarios 


\section{Tables}

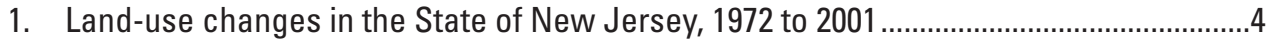

2. Information used by Technical Advisory Committee to evaluate and compare 10 instream flow methods for potential application in New Jersey......................................

3. Hydrologic indices with the largest absolute loading on each of the four or five significant principal component axes for each group in each of the 10 subcomponents of flow for four New Jersey stream classes.

4. Comparison of pre- and post-regionalization values of selected hydrologic indices ....17

5. Comparison of the 10 principal hydrologic indices for baseline conditions and four water-diversion scenarios ............................................................................................ 


\section{Acronyms and abbreviations used in this report:}

\begin{tabular}{|c|c|}
\hline Abbreviation & Description \\
\hline $\mathrm{ABF}$ & Aquatic Base Flow \\
\hline DFA & Discriminant Function Analysis \\
\hline EFG & Ecological Flow Goals \\
\hline GIS & Geographic Information System \\
\hline HIP & Hydroecological Integrity Assessment Process \\
\hline HIT & Hydrologic Indices Tool \\
\hline HAT & Hydrologic Assessment Tool \\
\hline HRIs & Hydroecologically Relevant Indices \\
\hline IDH & Intermediate-Disturbance Hypothesis \\
\hline IHA & Indicators of Hydrologic Alteration \\
\hline NJDEP & New Jersey Department of Environmental Protection \\
\hline NJHAT & New Jersey Hydrologic Assessment Tool \\
\hline NJSCT & New Jersey Stream Classification Tool \\
\hline NWIS & National Water Information System \\
\hline PCA & Principal Components Analysis \\
\hline POR & Period of Record \\
\hline $\mathrm{RCC}$ & River Continuum Concept \\
\hline RVA & Range of Variability Approach \\
\hline SCT & Stream Classification Tool \\
\hline $\mathrm{TAC}$ & Technical Advisory Committee \\
\hline UPGMA & Unweighted Pair Group Method using Arithmetic Averages \\
\hline USEPA & U.S. Environmental Protection Agency \\
\hline USGS & U.S. Geological Survey \\
\hline 7Q10 & 7-day, 10-year low-flow statistic \\
\hline $\mathrm{ft}$ & feet \\
\hline $\mathrm{ft}^{3} / \mathrm{s}$ & cubic feet per second \\
\hline$>$ & greater than \\
\hline$<$ & less than \\
\hline$\geq$ & greater than or equal to \\
\hline$\leq$ & less than or equal to \\
\hline
\end{tabular}




\title{
Development of the Hydroecological Integrity Assessment Process for Determining Environmental Flows for New Jersey Streams
}

\author{
By Jonathan G. Kennen, James A. Henriksen, and Steven P. Nieswand
}

\section{Abstract}

The natural flow regime paradigm and parallel stream ecological concepts and theories have established the benefits of maintaining or restoring the full range of natural hydrologic variation for physiochemical processes, biodiversity, and the evolutionary potential of aquatic and riparian communities. A synthesis of recent advances in hydroecological research coupled with stream classification has resulted in a new process to determine environmental flows and assess hydrologic alteration. This process has national and international applicability. It allows classification of streams into hydrologic stream classes and identification of a set of non-redundant and ecologically relevant hydrologic indices for 10 critical sub-components of flow. Three computer programs have been developed for implementing the Hydroecological Integrity Assessment Process (HIP): (1) the Hydrologic Indices Tool (HIT), which calculates 171 ecologically relevant hydrologic indices on the basis of daily-flow and peak-flow streamgage data; (2) the New Jersey Hydrologic Assessment Tool (NJHAT), which can be used to establish a hydrologic baseline period, provide options for setting baseline environmentalflow standards, and compare past and proposed streamflow alterations; and (3) the New Jersey Stream Classification Tool (NJSCT), designed for placing unclassified streams into pre-defined stream classes. Biological and multivariate response models including principal-component, cluster, and discriminant-function analyses aided in the development of software and implementation of the HIP for New Jersey. A pilot effort is currently underway by the New Jersey Department of Environmental Protection in which the HIP is being used to evaluate the effects of past and proposed surfacewater use, ground-water extraction, and land-use changes on stream ecosystems while determining the most effective way to integrate the process into ongoing regulatory programs. Ultimately, this scientifically defensible process will help to quantify the effects of anthropogenic changes and development on hydrologic variability and help planners and resource managers balance current and future water requirements with ecological needs.

\section{Introduction}

Maintaining and restoring the ecological integrity of streams - that is, native biodiversity and physiochemical processes that result in self-sustaining productivity - is an elusive goal for State water- and land-use regulatory and planning programs. Although many State water-quality programs are well developed, most existing State laws, regulations, and policies addressing the quantity of water in a stream are insufficient to enable meaningful flow management (Annear and others, 2004).

Furthermore, State agencies with authority and responsibility to protect and manage stream resources are confronted with four troublesome issues when they attempt to develop or apply standards or requirements for environmental flow (that is, a flow regime of a particular magnitude, duration, frequency, timing, and rate of change which is necessary to ensure that a river system remains ecologically, environmentally, economically, and socially healthy; also called instream flow). Proponents of water development may assume that:

- The environmental flow necessary to protect stream resources, commonly described using terms such as aquatic habitat, fishery resources, aquatic communities, or ecological integrity, is known or easily quantified by the State regulatory agency for every stream reach within its authority.

- Regardless of the extent of previous hydrologic alterations of the flow (that is, cumulative impact on streamflow), a sufficient quantity remains available for an additional water use.

- The environmental-flow standard developed by a State regulatory agency is simple and compliance with the standard can easily be attained.

- Streamflow alteration results primarily from direct diversion (for example, municipal water supply) or regulation of flow (for example, hydropower), not from land-use change. In other words, water develop- 
ment and land use are not perceived to be competing for the same water resources.

Most such assumptions are incorrect.

\section{Background}

The New Jersey Department of Environmental Protection (NJDEP) has broad responsibilities through its various regulatory and planning programs for managing water and land resources, while concurrently protecting and restoring stream resources. Several divisions within the NJDEP have regulatory, management, and (or) monitoring responsibilities that directly or indirectly concern streamflow: Division of Land Use Regulation, Fish and Wildlife, Water Supply, Water Quality, and Watershed Management. The primary streamflow regulatory standard that historically has been used by the Division of Water Supply has been a "minimum passing-flow" requirement as a condition for a water-use permit. This environmental-flow requirement typically is a low-flow statistic, such as the 7-day, 10-year low flow (7Q10); however, other low-flow statistics are occasionally used. The NJDEP recognized that a flow requirement that focuses on only the low-flow portion of the stream hydrograph does not adequately address the full scope of stream resources and fails to protect the ecological integrity of streams. There is no direct relation between the 7Q10 and aquatic-life protection, and many suggest that this statistic should not be used as a basis for flow recommendations (Annear and others, 2004). Equally important was the recognition by the NJDEP that other regulatory agencies were not specifically establishing environmental-flow requirements for activities that could potentially alter streamflows.

To address these concerns, the U.S. Geological Survey (USGS) in cooperation with the NJDEP undertook a project - to identify or develop a methodology for establishing environmental-flow standards for regulatory and planning purposes that will sustain stream communities in New Jersey. This project was called the Ecological Flow Goals (EFG) project. Due to the broad scope and potential significance of the task, the agreement required the creation and implementation of a Technical Advisory Committee (TAC) to direct and manage the efforts to achieve this goal.

\section{Purpose and scope}

This report:

1. Describes the initial goal of the Ecological Flow Goals project and the approach the TAC took to help achieve that goal.

2. Compares some established environmental flow methods, reviews important stream ecosystem concepts, and examines the critical hydrologic research that represents the framework for the environmental flow process presented herein.
3. Describes the development of a new environmental flow assessment process - the Hydroecological Integrity Assessment Process (HIP). Application of the HIP includes a hydrologic classification of streams in New Jersey, and the development of software tools for classifying unclassified streams (the New Jersey Stream Classification Tool (NJSCT)) and for establishing a baseline (reference) time period, comparing and contrasting past and proposed streamflow alterations, and providing options for setting environmental-flow standards at the reach scale (the New Jersey Hydrologic Assessment Tool (NJHAT)).

4. Provides example management applications using the NJSCT and the NJHAT for an analysis of land-use changes that are known to alter streamflow, and a series of scenarios of direct surface-water withdrawals from an unregulated stream.

\section{Study area description}

New Jersey covers approximately $8,100 \mathrm{mi}^{2}$. This area has a population of more than 8.6 million people and includes some of the most densely populated metropolitan areas in the United States (U.S. Census Bureau, 2005). New Jersey is composed of four physiographic provinces-the Valley and Ridge, New England, Piedmont (all north of the Fall Line), and the Coastal Plain (which is south of the Fall Line) (fig. 1).

In general, the provinces north of the Fall Line consist of sedimentary rock (for example, shale and sandstone) and crystalline rock. South of the Fall Line is unconsolidated gravel, sand, silt, and clay. The Valley and Ridge physiographic province is characterized by a series of parallel ridges and valleys trending northeast-southwest, with mountainous topography that commonly reaches elevations of more than 1,600 ft. The New England physiographic province consists of broad, flat-topped highlands and long, narrow valleys that range in elevation from 500 to $1,500 \mathrm{ft}$. The Piedmont physiographic province consists of northwestward-dipping sedimentary rocks that form broad, gently sloping lowlands and rolling hills, where elevations typically reach only $400 \mathrm{ft}$. About 55 percent of the study area is in the Coastal Plain physiographic province and is characterized by flat to gently rolling topography and unconsolidated sedimentary deposits. (For a detailed description of New Jersey's physiography, refer to Wolfe (1977).) Streamflow characteristics differ greatly among the physiographic provinces. Streamflow in the Piedmont province tends to be highly variable (flashy) due to minimal ground-water recharge. In the Coastal Plain, however, groundwater recharge is high and streamflow is relatively stable. In the New England and Valley and Ridge provinces, streamflow tends to fall somewhere between the flashy flows of the Piedmont and the more stable ground-water-supported flows of the Coastal Plain. Ground water contributes from 65 to 95 percent of the base flow in the Coastal Plain. North of the Fall Line, the ground-water contribution to base flow ranges 

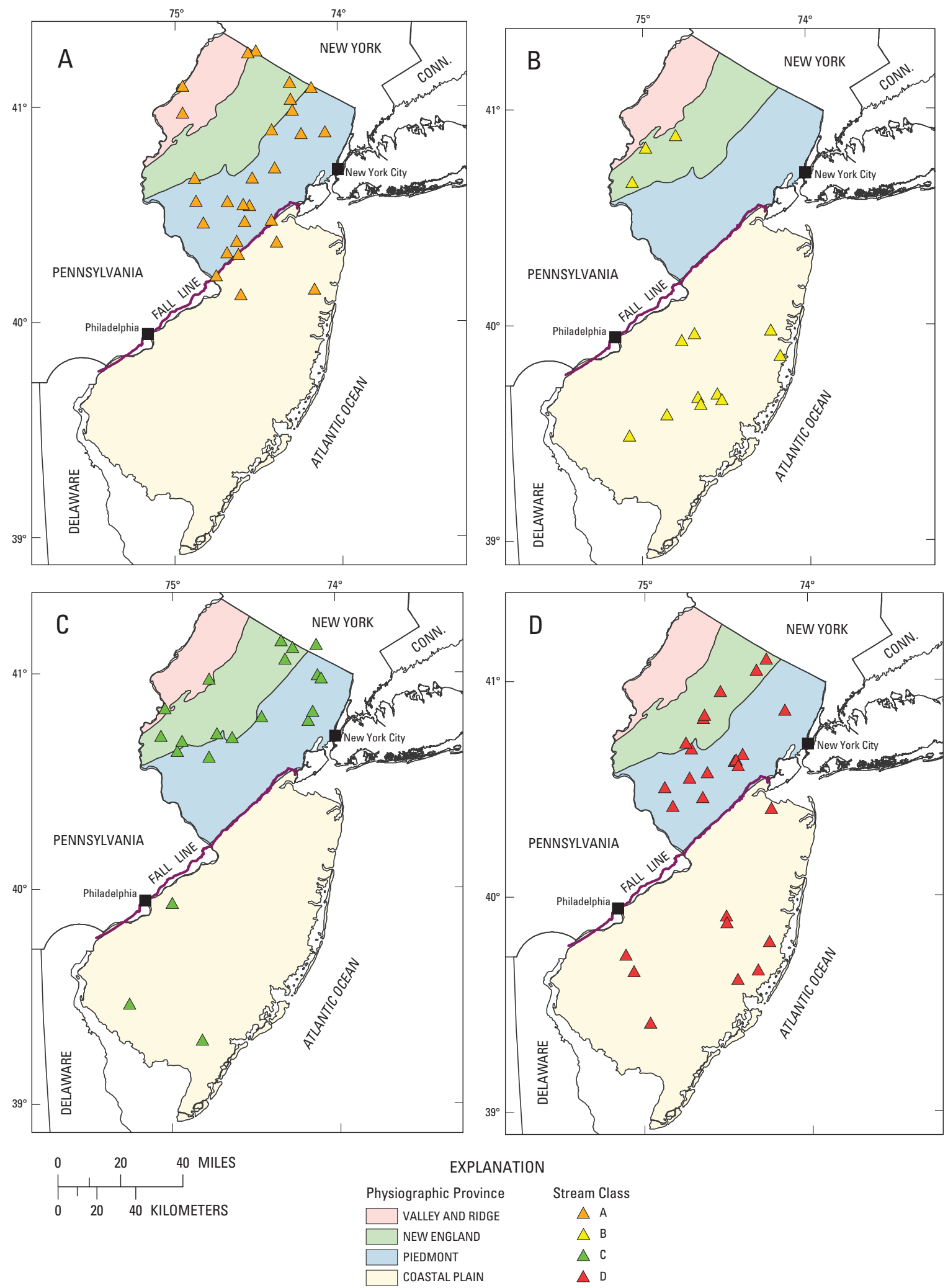

Figure 1. Location of physiographic regions and streamflow sites used to classify the primary stream classes in New Jersey. (Each symbol represents a U.S. Geological Survey streamflow-gaging station and is color coded to indicate a stream class as referenced in appendix 4.) 
from approximately 22 to 88 percent (Watt, 2001). In general, streamflow in the northern part of the study area is dominated by surface runoff; in the Coastal Plain, it is dominated by flow from ground-water sources.

Since the 1970s, the landscape in the study area has experienced extensive disturbances associated with the conversion of forested and agricultural land to urban and suburban developments and concomitant changes in the hydrologic regime (Kennen and Ayers, 2002). As a consequence of these largescale changes in population and land use, very few streams remaining are not affected by some form of flow regulation or water development (for example, water diversions, wastewater discharges, dams, and reservoirs). Estimated land use in the study area over the 30-year period from 1972 to 2001 is shown in table 1. During this period, developed land has increased more than 66 percent, with a concurrent decrease in forest and wetlands. As a result of these changes, most of northeastern New Jersey and the corridor between New York City and Philadelphia consist of heavily urbanized and, therefore, relatively impervious areas that yield runoff rapidly. Surfacewater and ground-water withdrawals have reduced base flow in streams in some areas. Water-supply systems in the study area are highly connected and transfer of water across drainage divides and among basins is common. For example, nearly 100 million gallons per day is transferred from the Delaware River to the Raritan River Basin via the Delaware and Raritan Canal (Ayers and others, 2000).

\section{Technical Advisory Committee Activities}

A TAC was assembled by the NJDEP to direct the effort to address the project's goals. The TAC consisted of 40 members representing six agencies: NJDEP, USGS, New Jersey
Pinelands Commission, New Jersey Water Supply Authority, Philadelphia Academy of Natural Sciences, and Pennsylvania Fish and Boat Commission. Individual members of the TAC and their affiliations are listed in appendix 1.

The initial goal of the EFG project was to identify or develop a method that will provide environmental streamflow standards necessary to sustain or restore ecological integrity of the stream communities. Ecological integrity - that is, native biodiversity and physiochemical processes - results in selfsustaining productivity. In addition, three guidelines regarding the goal of the project were established by the cooperative agreement: (1) application of the method selected or developed to determine environmental flows would not require long-term project or stream-specific field studies; (2) the development of the method would utilize, if possible, the results of NJDEP's Watershed Indicator Study (Kennen and others, in press), which focused on a State-wide benthic invertebrate community impairment assessment; and (3) the method would, ideally, be useable by all regulatory and planning programs within the NJDEP. The TAC was directed not to consider any consequences or policy issues potentially related to any new method developed as part of the EFG project. This directive allowed the TAC to select the most effective method for managing streamflows regardless of implementation or policy considerations.

The TAC undertook two primary tasks. First, a review of existing environmental-flow methods was conducted, and 10 documented environmental-flow methods were chosen for comparison. Second, based on the results of this review, the TAC identified two applicable methods that potentially would meet the goal of the EFG project. The two selected methods were compared to the established 7Q10 environmental-flow standard that historically has been used by the NJDEP in the regulatory process. A third task, undertaken after comple-

Table 1. Land-use changes in the State of New Jersey, 1972 to 2001.

\begin{tabular}{|c|c|c|c|c|c|}
\hline Land use & \multicolumn{4}{|c|}{ Acres } & $\begin{array}{l}\text { Percent change } \\
\text { 1972-2001 }\end{array}$ \\
\hline Developed - urban & 888,848 & $1,204,958$ & $1,427,359$ & $1,483,205$ & 66.9 \\
\hline Cultivated/grassland & 999,372 & $1,007,012$ & 883,618 & 850,027 & -14.9 \\
\hline Upland forest & $1,673,164$ & $1,465,727$ & $1,421,105$ & $1,388,984$ & -17.0 \\
\hline Coastal wetland & 220,726 & 208,287 & 201,575 & 200,172 & -9.3 \\
\hline Inland wetland & 925,329 & 788,896 & 737,033 & 734,051 & -20.7 \\
\hline Unconsolidated shore & 12,311 & 47,162 & 45,882 & 46,811 & 280.2 \\
\hline Water & 517,716 & 516,587 & 514,975 & 514,859 & -0.6 \\
\hline
\end{tabular}

Data source: Classification and analysis of Landsat satellite image data performed at the Grant F.Walton Center for Remote Sensing \& Spatial Analysis, Rutgers, The State University of New Jersey, New Brunswick, New Jersey. Data are available on the World Wide Web at http://www.crssa.rutgers.edu/ project $N / l d$ 
tion of tasks 1 and 2, was a general review of seminal stream ecological concepts and recent hydroecological research. This information is presented in appendix 2 .

\section{Comparison of 10 Environmental Flow Methods}

The TAC reviewed Annear and others (2002), which was published by the Instream Flow Council, an organization that represents the interests of state and provincial fish and wildlife management agencies in the United States and Canada and is dedicated to improving the effectiveness of instream-flow programs. The comprehensive list of environmental-flow methods presented was evaluated and a subset was identified that potentially could meet the goal of the EFG project. Specifically, the 29 "Instream Flow Assessment Tools" (methods) presented in Annear and others (2002, chap. 7) were evaluated to determine which, if any, met the EFG project guidelines presented above. Based on this review, 10 methods were selected for a thorough examination and comparison to the historically used 7Q10 standard.

Twenty-eight criteria in four categories were selected to aid in the comparison of the 10 flow methods (table 2). The "Background" category in table 2 summarizes where the method was developed and geographically where the method has been or is being implemented. "Beecher Elements" are from Beecher (1990), which indicates that an unambiguous instream-flow standard requires addressing five critical elements to: (1) establish a goal, such as maintenance of or no net loss in a resource; (2) identify the resource(s) of value, such as fish or recreation; (3) use a unit of measurement that is restricted to the resource itself, for example flow or habitat; (4) set a benchmark time period for the resource level, typically current conditions (historic conditions can be used as a benchmark time period if current conditions are unacceptable); and (5) derive a "protection statistic." Beecher (1990) points out that using a mean or median as a protection statistic may not protect the resource at its historical mean or median level. Beecher (1990) also notes that the "upper extremes of a distribution are important to maintaining an average condition" and that "it may be necessary to protect an upper extreme in order to maintain an average condition." The "Components" category (table 2) identifies physical (for example, hydrology) and biological (for example, fish or invertebrates) stream components that the method purportedly addresses. The "Application" category (table 2) addresses size (drainage area or stream order), what the method is applicable to, level of effort required to apply the method, and the type of method (incremental, standard, or planning). See Annear and others (2004, p. 133, table 6-3) for a summary of assessment tools.

The TAC reached a consensus that no single method was sufficiently holistic to specifically meet the stated goal of or guidelines for the EFG project. This conclusion was based primarily on three points. First, most of the methods (8 of 10) addressed only one or two of the components explicitly identified in the goal statement for the EFG project. Second, some methods appeared to arbitrarily select hydrologic measures or unintentionally select redundant measures and typically failed to address all of the five critical components of flow (magnitude, frequency, duration, timing, and rate of change) identified by Poff and others (1997) as being important to maintaining biological integrity in stream systems. Third, some of the methods were applicable only to specific streams (for example, Pennsylvania trout streams) or applicable to all the streams without differentiating among stream types (for example, Range of Variability Approach (RVA)). Some of the flow methods presented in table 2 , however, had attributes that could be used as building blocks for a method that met the goals of the EFG project. Therefore, the TAC undertook a more through examination of two well-established flow methods: the New England Aquatic Base Flow (ABF) standard (Larsen, 1981; Lang, 1999), which is based on hydrology in the New England area; and the Range of Variability Approach (Richter and others, 1997), which is an extension of the Indicators of Hydrologic Alteration (IHA) method (Richter and others, 1996).

\section{Examination of Two Environmental Flow Methods}

The Aquatic Base Flow (ABF) standard was developed as part of the U.S. Fish and Wildlife Service's (FWS) New England Flow Policy (Larsen, 1981). The method uses measures of central tendency (for example, median monthly flows) as a surrogate for the amount of available aquatic habitat. Specifically, the $\mathrm{ABF}$ standard recommends the median August flow (calculated from a period of record with minimum anthropogenic alteration) as a minimum instantaneous flow requirement unless additional, seasonal flows are needed (for example, to protect fish spawning and incubation). During the spring and fall/winter periods, the recommendations are the April/May and February median flow, respectively. Median monthly flows are derived from a period of record (POR) with minimum anthropogenic alteration or from established ratios of cubic feet per second per square mile of drainage area in representative unregulated streams. The relation of aquatic habitat to seasonal flows was established by professional opinion and typically focuses on the low-flow summer period and general seasonal needs for spawning and incubation in spring and fall. The principal underlying assumption of the ABF standard is that because aquatic life evolved and adapted to the natural flow regime, emulating critical parts (for example, seasonal high and low flow pulses) of that flow regime should provide an adequate level of protection. The intended purpose of the $\mathrm{ABF}$ method, however, is to protect fish spawning and incubation. There is no stated objective to address the dynamic physical processes, especially the movement of water and sediment within the channel and between the channel and the floodplain (that is, stream and floodplain connectivity), typically associated with rejuvenation and creation of aquatic habitat or processes related to the maintenance of biodiversity.

The Range of Variability Approach (RVA) developed by The Nature Conservancy addresses all five critical components of the flow regime by using 67 hydrologic attributes 
Table 2. Information used by Technical Advisory Committee to evaluate and compare 10 instream flow methods for potential application in New Jersey.

[PA, Pennsylvania; MD, Maryland; 7Q10, 7-day, 10-year low flow; RVA, Range of Variation Approach, \%, percent; ADF, Average Daily Flow; Adm., Administration; Max., Maximum; (ft³/s)/mi² , cubic feet per second per square mile; Q, discharge; NS, not specified; Sept., September; SRBC, Susquehanna River Basin Commission; TNC, The Nature Conservancy; AAD, Average Annual Discharge; ADF, Average Daily Flow; Dev., Development; Dept. Nat. Res., Department of Natural Resources; OR, Oregon, MT, Montana; US, United States; \#, number; >, greater than; <, less than]

\begin{tabular}{|c|c|c|c|c|c|c|c|c|c|c|}
\hline \multirow[b]{2}{*}{ Evaluation criterion } & \multicolumn{10}{|c|}{ INSTREAM FLOW METHOD } \\
\hline & PA & $\begin{array}{c}\text { Wetted } \\
\text { perimeter }\end{array}$ & 7010 & $\begin{array}{c}\text { MD Most com- } \\
\text { mon flow }\end{array}$ & $\begin{array}{c}\text { Aquatic base } \\
\text { flow } \\
\end{array}$ & RVA & Texas method & Georgia method & Georgia method & Georgia method \\
\hline \multicolumn{11}{|c|}{ Background } \\
\hline Reference & $\begin{array}{r}\text { Denslinger and } \\
\text { others, } 1998\end{array}$ & Collings, 1974 & Unknown & $\begin{array}{l}\text { Water Resource } \\
\text { Adm. }\end{array}$ & $\begin{array}{r}\text { US Fish \& } \\
\text { Wildlife }\end{array}$ & $\begin{array}{l}\text { Richter and } \\
\text { others, } 1997\end{array}$ & $\begin{array}{c}\text { Water Dev. } \\
\text { Board }\end{array}$ & Dept. Nat. Res. & Dept. Nat. Res. & Dept. Nat. Res. \\
\hline Development location & PA & Unknown & Unknown & Maryland & New England & US & Texas & Georgia & Georgia & Georgia \\
\hline Current use & $\mathrm{PA}$ & OR, MT & Several states & Maryland & New England & Many locations & Texas & Georgia & Georgia & Georgia \\
\hline \multicolumn{11}{|c|}{ Beecher Elements ${ }^{1}$} \\
\hline Resource & Trout & Invertebrates & Water quality & Stream biota & Aquatic habitat & $\begin{array}{c}\text { Biodiversity/ } \\
\text { integrity }\end{array}$ & $\begin{array}{l}\text { Aquatic } \\
\text { resources }\end{array}$ & Aquatic life & Aquatic life & Aquatic life \\
\hline Goal & Protect & Protect & Protect & Protect & Protect & Protect & Protect & Protect & Protect & Protect \\
\hline Unit of measurement & Habitat & Wetted area & Flow & Flow & Flow & Flow & Flow & Flow & Flow & Flow \\
\hline Benchmark time period & Past & Present & Present & Present & Past & Past & Past & Past & Past & Present \\
\hline Protection statistic & $\% \mathrm{ADF}$ & $\begin{array}{l}\text { Max. wetted } \\
\text { area }\end{array}$ & 7Q10 & $\begin{array}{l}50 \text { to } 85 \% \\
\quad \text { Exceedence }\end{array}$ & $\left(\mathrm{ft}^{3} / \mathrm{s}\right) / \mathrm{mi}^{2}$ & $\begin{array}{l}67 \text { Flow } \\
\text { parameters }\end{array}$ & $\begin{array}{l}\% \text { Median } \\
\text { monthly }\end{array}$ & $30 \% \mathrm{AAD}$ & Sept. median Q & 30 to $60 \%$ AAD \\
\hline \multicolumn{11}{|c|}{ Components Explicitly Addressed } \\
\hline Hydrology & No & No & No & No & No & Yes & Yes & No & No & No \\
\hline Channel form & No & No & No & No & No & Yes & No & No & No & No \\
\hline Sediment transport & No & No & No & No & No & Yes & No & No & No & No \\
\hline Water quality & No & No & Yes & No & No & Yes & No & No & No & No \\
\hline Temperature & No & No & No & No & No & Yes & No & No & No & No \\
\hline Connectivity & No & No & No & No & No & Yes & No & No & No & No \\
\hline Riparian zone & No & No & No & No & No & Yes & No & No & No & No \\
\hline Fish species & Yes & No & No & No & No & Yes & Yes & No & Trout & No \\
\hline Fish community & No & No & No & No & No & Yes & Yes & No & No & No \\
\hline Invertebrate species & No & No & No & No & No & Yes & No & No & No & No \\
\hline Invertebrate community & No & Yes & No & No & No & Yes & No & No & No & No \\
\hline Aquatic "health" & No & No & No & Yes & Yes & Yes & No & Yes & Yes & Yes \\
\hline \# Components addressed & 1 & 1 & 2 & 1 & 1 & 12 & 3 & 1 & 2 & 1 \\
\hline \multicolumn{11}{|c|}{ Application } \\
\hline $\begin{array}{l}\text { Stream order } \\
\quad \text { (Drainage area) }\end{array}$ & $<100 \mathrm{mi}^{2}$ & NS & NS & NS & $>50 \mathrm{mi}^{2}$ & NS & Below reservoirs & NS - Warm & NS - Trout & NS - All \\
\hline Office analysis & Yes & No & Yes & Yes & Yes & Yes & Yes & Yes & Yes & Yes \\
\hline Field data required & No & Yes & No & No & No & No & No & No & No & No \\
\hline Impact analysis & Yes & No & No & No & No & Yes & No & No & No & No \\
\hline Level of effort ${ }^{2}$ & Low & Moderate & Low & Low & Low & Moderate & Low & Low & Low & Low \\
\hline Scale $^{3}$ & Segment & Segment & Segment & NS & NS & Segment & Segment & Segment & Segment & Segment \\
\hline $\begin{array}{l}\text { Category (type of } \\
\text { method) }\end{array}$ & Incremental & Standard setting & Planning & Standard setting & Standard setting & Standard setting & $\begin{array}{l}\text { Standard setting/ } \\
\text { planning }\end{array}$ & Standard setting & Standard setting & Standard setting \\
\hline
\end{tabular}


(33 hydrologic indices and 34 environmental flow components) to assess the degree of hydrologic alteration attributable to human influence (The Nature Conservancy, 2006). The degree of alteration is evaluated by comparing the values of the hydrologic indices calculated from daily flow records for any pre-project condition to a post-project condition (for example, flow prior to and after installation of a hydroelectric dam). A range calculated around the mean index value of either \pm 1 standard deviation or the 25 th to 75 th percentile of flow is used to define flow-management targets. If a postproject flow alteration moves the mean outside the range of the pre-project flow condition for any of the flow indices, it is considered a significant change. The objective of the method is "conservation of native aquatic biodiversity and protection of natural ecosystem functions" (Richter and others, 1997). The critical element of this approach is that it is derived from aquatic ecological theory, which recognizes the importance of hydrologic variability and all five critical components of the flow regime (magnitude, frequency, duration, timing, and rate of change) in sustaining aquatic ecosystem integrity (Poff, 1996; Richter and others, 1997). Poff and others (1997) established that hydrologic variability is strongly correlated with many physiochemical characteristics of rivers and is considered a "master variable" that affects, directly and indirectly, the distribution and abundance of riverine species and thus, the ecological integrity of rivers.

Two concerns arose regarding the RVA. First, there appeared to be a potential for some level of redundancy among the hydrologic parameters. For example, 3 of the 67 parameters are based on the annual minimum 1-day mean, annual minimum 3-day mean, and annual minimum 7-day mean. Many of these parameters tend to be highly intercorrelated. The RVA was not explored, however, beyond identifying parameter redundancy, nor was an evaluation conducted to determine whether any of the implicit redundancy affected the interpretation of the hydrologic relations. Olden and Poff (2003) provide a comprehensive evaluation of this redundancy. Most flow methods utilizing hydrologic indices that include annual minima and maxima are highly likely to include some level of implicit redundancy. More importantly, however, it was recognized that the RVA did not specifically address differences among stream types. Streamflow regimes are known to show distinct regional patterns (Poff and Ward, 1989; Poff, 1996; Olden and Poff, 2003), which are driven by geographic variation in climate, geology, topography, and vegetation. NJDEP water managers routinely recognize general hydrogeomorphic differences in stream characteristics among the four physiographic provinces of New Jersey (Valley and Ridge, New England, Piedmont, and Coastal Plain). Any methodology that does not explicitly consider differences in streams based on known geophysical characteristics including geology, geography, or physiography would be of limited use in New Jersey.

Data for several pilot streams were selected to compare the ABF and the RVA to the 7Q10. Because the comparisons were similar among all of the pilot streams identified for this study, however, only one example is presented here. The South Branch of the Raritan River near High Bridge in north-central New Jersey (USGS streamflow-gaging station 01396500) was selected because anthropogenic alteration of flow in the upper part of the basin is limited. A time-series plot of median daily flows, minimum daily flows, and the 25th- to 75th-percentile range for the daily flows for a 23-year POR (water years 1978-2000) are shown in figure 2. Values calculated using the ABF, RVA (mean monthly flow), and 7Q10 methods are superimposed on the daily-flow values. The 7Q10, applied as a minimum-flow standard, allows a flow less than the minimum daily flow ever recorded for approximately 150 days of the year, which the TAC found to be unacceptable. Similarly, implementing the $\mathrm{ABF}$ as a minimum-flow standard would allow complete utilization of the available water resource for nearly 2.5 months of the year. The TAC concluded that the $7 \mathrm{Q} 10$ and the ABF produced unrealistically low standards for some periods and would probably fail to adequately protect some critical stream-resource components, such as invertebrates, the stream bank, and riparian habitat.

Application of the RVA to the South Branch Raritan River raised additional methodological concerns beyond that noted for the ABF method. The RVA is described by Richter and others (1997) as an impact analysis tool in application, in contrast to the ABF, which was developed to establish an environmental-flow standard. The RVA analysis is accomplished by comparing pre- and post-project hydrologic conditions. A typical application requires that all 67 pre-project hydrologic indices be compared to the 67 post-project indices using the same POR. Alternatively, the analysis could be done using a simulated post-project hydrograph. Of the 67 indices, only those for which the mean moves outside \pm 1 standard deviation, or the 25th- to 75th-percentile range, are considered as significant alterations for which "management targets" (moving the post-project mean back into the pre-project standard deviation or percentile range) would be developed. Twelve of the parameters used in RVA - that is, the mean monthly value for each calendar month-are plotted in figure 2. Although this interpretation was not proposed by Richter and others (1997), a user could infer that the 25th-percentile values for all 67 RVA indices could be applied as the maximum allowable alteration.

The TAC determined that neither of these two methods was sufficiently comprehensive to meet the goal of the EFG project. Consequently, the focus was shifted from examining environmental-flow methods to a review of seminal stream-ecology concepts as a fundamental building block to understanding the relation between flow variation and stream ecosystem integrity (see appendix 2 for a general review of seminal stream-ecology concepts). 


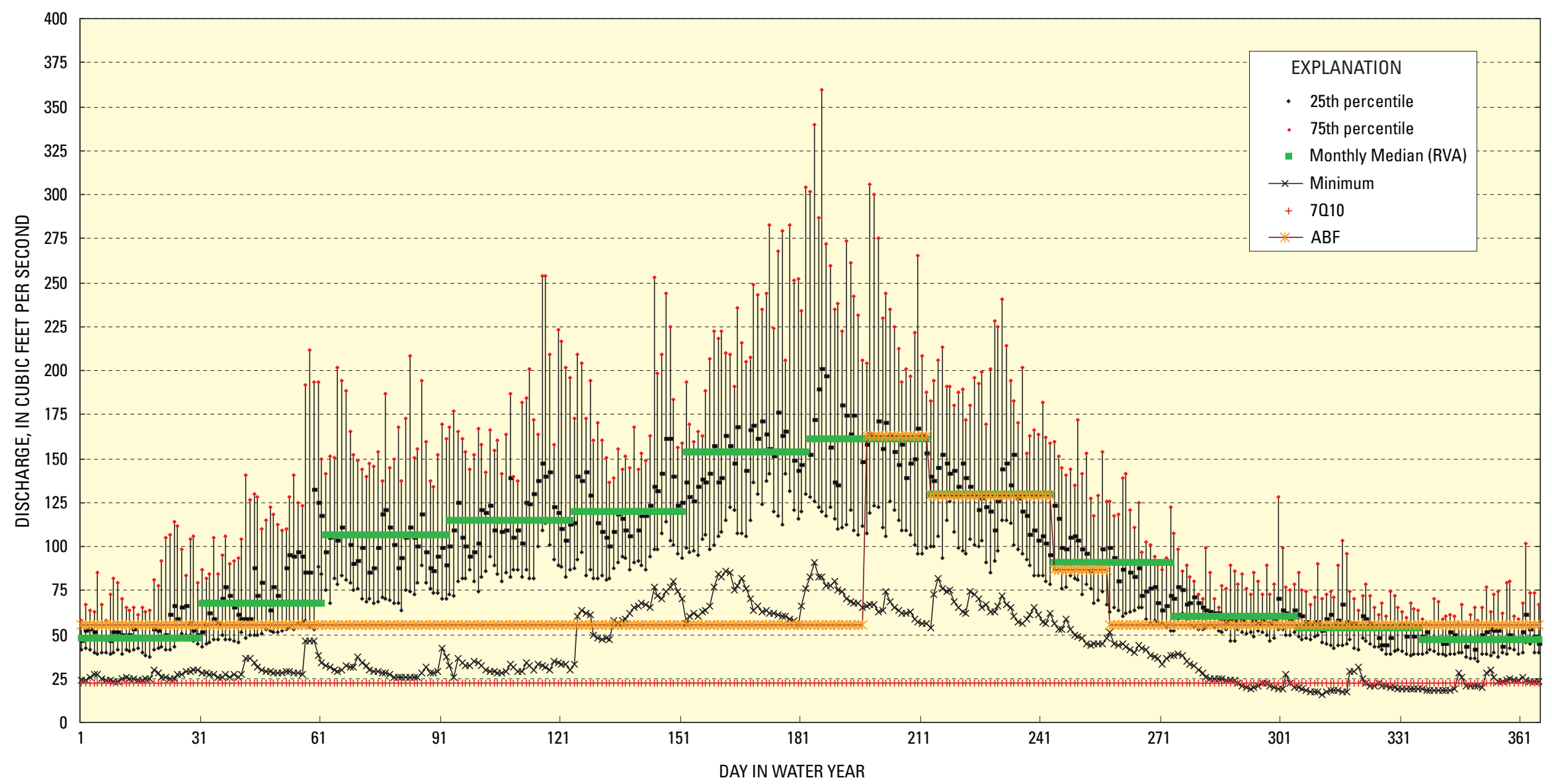

Figure 2. Time series of daily flow, minimum flow, and 25th- and 75th-percentile flow ranges for the South Branch Raritan River (USGS streamflow-gaging station 01396500), New Jersey, with flows for three environmental flow methods: Aquatic Base Flow (ABF), Range of Variation Approach (RVA), and 7-day, 10-year low flow (7010). 


\section{Development of the Hydroecological Integrity Assessment Process}

\section{Conceptualization}

The Hydroecological Integrity Assessment Process (HIP) is based on the large body of research linking hydrologic variability and aquatic ecosystem integrity. This research strongly supports the natural flow paradigm - that is, "the full range of natural intra- and inter-annual variation of hydrological regimes, and associated characteristics of magnitude, frequency, duration, timing, and rate of change, are critical in sustaining the full diversity and integrity of aquatic ecosystems" (Poff and others, 1997). Streamflow is strongly related to many critical physiochemical components of rivers, such as dissolved-oxygen concentration, channel geomorphology, and water temperature, and can be considered a "master variable" that limits the distribution, abundance, and diversity of many aquatic plant and animal species (Resh and others, 1988; Poff and others, 1997). The need for applicable management tools that incorporate this connection and assist in the establishment of flow standards protective of aquatic ecosystem integrity was one of the primary reasons the HIP was developed.

The HIP can be used by any federal, state, provincial, regional, national, or international agency or a non-governmental entity that has a responsibility for or interest in the management and (or) regulation of streams with an objective to address ecological integrity at the reach scale. In addition, the HIP can assist researchers by identifying critical streamtype-specific hydrologic indices that adequately characterize the five critical components of the flow regime by using 10 non-redundant indices (see Olden and Poff, 2003).

Development of the Hydroecological Integrity Assessment Process requires four major steps (fig. 3):

1. Perform a hydrologic classification of streams in a geographic area using long-term gaging-station records for relatively unmodified streams. Calculate 171 hydroecologically relevant indices (HRIs) for each station (Olden and Poff, 2003). Employ an unweighted pair group method using arithmetic averages (UPGMA) (McCune and Medford, 1999; McCune and Grace, 2002), or a comparable hierarchical-clustering method, to group streams into area-specific stream classes.

2. Identify statistically significant, non-redundant HRIs (surrogate indices are also identified) associated with the five critical flow components (a total of 10 primary indices) of the flow regime for each stream class using principal components analysis (SAS Institute Inc., 1989). This suite of HRIs should adequately characterize the flow regime for each stream class (Olden and Poff, 2003).

3. Develop an area-specific Stream Classification (computer software) Tool (SCT) for placing unclassified streams

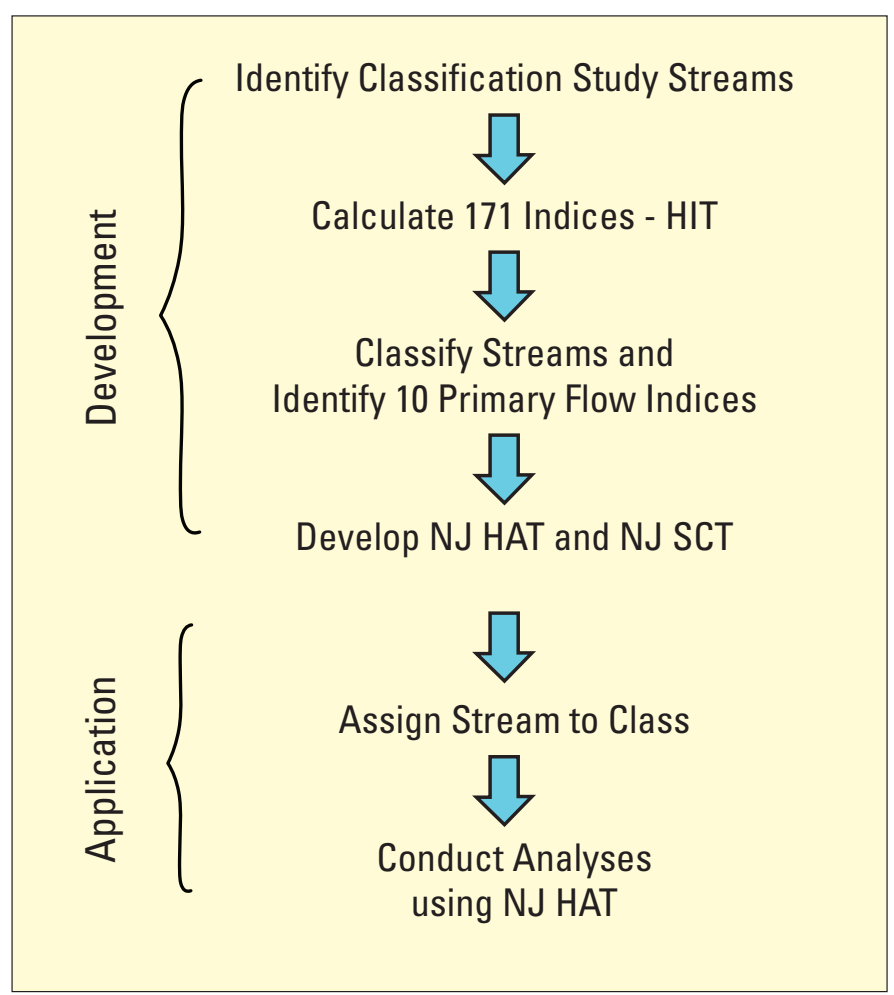

Figure 3. Steps taken to develop and apply the Hydroecological Integrity Assessment Process (HIP).

(that is, streams not placed into a specific stream class as part of the initial classification analysis) into one of the identified stream classes. The SCT software uses multiple discriminant function analyses (SYSTAT Software Inc., 2004) to match a stream with one of the four specified stream classes based on the level of concordance among a suite of significant hydrologic parameters identified during the initial classification analysis.

4. Develop an area-specific Hydrologic Assessment Tool (HAT). This software can be used to (a) establish a hydrologic baseline (that is, a reference time period), (b) provide options for setting environmental-flow standards, and (c) evaluate past and proposed hydrologic modifications for a stream reach. The HAT software uses 10 streamclass-specific indices chosen from an available 171.

\section{Software}

Three computer software tools were developed for implementation of the New Jersey HIP:

- Hydrologic Index Tool-Version 1.0 (HIT)-The HIT is used to calculate the 171 HRIs for the stream-classification analysis. The program is designed to import USGS daily-mean and peak-flow discharges from the 
National Water Information System (NWIS) database (http://waterdata.usgs.gov/nwis/sw). Simulated data can also be used; however, the format should be consistent with the USGS NWIS format. HIT can be used for any gaging site and is not specific to New Jersey.

- New Jersey Stream Classification Tool-Version 1.0 (NJSCT)-The NJSCT classifies a stream as belonging to one of four stream classes by comparing specific HRI values for an unclassified stream with indices defining each of the four previously identified stream classes. The four classes of streams (table 3 ) identified in New Jersey are characterized by the relative degree of skewness of daily flows (low $=$ stable flow, high $=$ flashy flow) and frequency of low-flow events (low = high base flow, high = low base flow). Thus, streams belonging to stream class A are semiflashy with moderately low base flow, class B streams are stable with high base flow, class $\mathrm{C}$ streams are moderately stable with moderately high base flow, and class D streams are flashy with low base flow. The characteristics of the four classes of streams in New Jersey are shown in appendixes 3 and 4 .

- New Jersey Hydrologic Assessment Tool-Version 3.0 (NJHAT)-The NJHAT is used to evaluate the hydrologic baseline (that is, a reference period of flow used as a basis for comparison), provide options for establishing environmental-flow standards, and assess past and proposed hydrologic modifications of streams in New Jersey. It accomplishes this by using flow statistics, trend assessment (that is, evaluating possible changes in streamflow over a specified period), and 10 primary stream-class-specific indices (that is, the first hydrologic index listed in table 3 for each of the flow components) chosen from the available 171 HRIs.

A national HAT-Version 3.0 (NATHAT) has also been developed. This tool is based on a hydrologic classification conducted by Poff (1996) using 420 sites across the contiguous United States. NATHAT has the same capabilities as NJHAT, but contains six stream classes. Until such time that area-specific classification results in greater discrimination among stream classes, and correspondingly, a refined identification of critical HRI values in other states, provinces, or regions, NATHAT can be used to establish a hydrologic baseline (reference period), to establish environmental-flow standards, and to evaluate past and proposed hydrologic modification for the six stream classes.

\section{Methods}

\section{Hydrologic Index Tool}

HIT is a stand-alone program that calculates 171 HRIs by using daily-mean and peak-flow discharge values. The USGS conducted tests to verify that the computer code in the Hydroecological Integrity Assessment Process computer programs (HIT and NJHAT) correctly applies the definitions and the formulas for the calculation of the $171 \mathrm{HRIs}$. The results of these tests are presented in appendix 5 . The HIT is primarily used in conjunction with the classification analysis of any geographic area; however, it is not specifically used in conjunction with NJSCT or NJHAT. Prior to using the HIT, a researcher would select all stream-gaging stations within a geographic area of interest using the POR that provides the least altered streamflow record. These station records should have a POR that is a minimum of 10 years in length, with 25 years preferred (Interagency Advisory Committee on Water Data, 1981). Daily-mean discharge and peak-flow data (if available) would be processed using the HIT; that is, the program would calculate the 171 indices for each stream. If peak-flow data are not available, then eight HIT indices (FH11, DH22, DH23, DH24, TA3, TH3, TL3, and TL4) are not calculated. The daily-mean discharge values could also be acquired by simulating dailyflow data (for example, Kennen and others (in press)).

Daily-mean discharges and peak annual flows are necessary to run a complete HIT analysis. These data can be downloaded from the USGS web site NWIS Web Data for the Nation at http://waterdata.usgs.gov/nwis/. Simulated data can also be used, but the format has to be consistent with that of USGS continuous streamflow records.

\section{Stream Classification Processes}

A series of procedural steps can be followed to identify a set of minimally impaired New Jersey streams and group these streams into distinct stream classes based on hydroecologically relevant indices. This approach includes the calculation of 171 HRIs for a minimally impaired period of record for 94 streams and a statistical process to reduce the amount of redundancy among the hydrologic indices. The reduced set of indices is used to cluster the streams into four primary stream classes, and principal components analysis (PCA) is used to identify the most significant hydrologic indices for each of the four stream classes. The HRIs characterize the magnitude of flow events, frequency of flow events, duration of flow events, timing of flow events, and rate of change of flow events (for example, table 3 ). The primary indices from these stream classes are then used to build a discriminant model that is used to predict the class in which an unclassified stream would be placed based on a level of concordance with HRIs of a specific stream class. 
Table 3. Hydrologic indices with the largest absolute loading on each of the four or five significant principal component axes for each group in each of the 10 subcomponents of flow for four New Jersey stream classes. (Refer to appendix 7 for definitions of hydrologic indices.)

\begin{tabular}{|c|c|c|c|c|c|}
\hline \multirow[b]{2}{*}{ Flow component } & \multicolumn{4}{|c|}{ CLASS } & \multirow[b]{2}{*}{ All streams } \\
\hline & A & B & C & D & \\
\hline \multicolumn{6}{|c|}{ Magnitude of flow events: } \\
\hline Average flow conditions & $M_{A} 18, M_{A} 39, M_{A} 26, M_{A} 37$ & $M_{A} 9, M_{A} 15, M_{A} 33, M_{A} 32$ & $\begin{array}{l}\mathrm{M}_{\mathrm{A}} 24, \mathrm{M}_{\mathrm{A}} 11, \mathrm{M}_{\mathrm{A}} 43, \mathrm{M}_{\mathrm{A}} 40 \\
\quad \mathrm{M}_{\mathrm{A}} 45\end{array}$ & $\begin{array}{l}\mathrm{M}_{\mathrm{A}} 39, \mathrm{M}_{\mathrm{A}} 13, \mathrm{M}_{\mathrm{A}} 44, \mathrm{M}_{\mathrm{A}} 40 \\
\quad \mathrm{M}_{\mathrm{A}} 9\end{array}$ & $\mathrm{M}_{\mathrm{A}} 20, \mathrm{M}_{\mathrm{A}} 37, \mathrm{M}_{\mathrm{A}} 34, \mathrm{M}_{\mathrm{A}} 40$ \\
\hline Low-flow conditions & $M_{L} 6, M_{L} 13, M_{L} 13, M_{L} 16$ & $\mathrm{M}_{\mathrm{L}} 20, \mathrm{M}_{\mathrm{L}} 4, \mathrm{M}_{\mathrm{L}} 21, \mathrm{M}_{\mathrm{L}} 16$ & $\begin{array}{l}M_{L} 3, M_{L} 19, M_{L} 20, M_{L} 3 \\
\quad M_{L} 13\end{array}$ & $\begin{array}{l}M_{L} 20, M_{L} 20, M_{L} 13, M_{L} 15 \\
\quad M_{L} 21\end{array}$ & $M_{L} 8, M_{L} 19, M_{L} 13, M_{L} 15$ \\
\hline High-flow conditions & $M_{H} 5, M_{H} 16, M_{H} 20, M_{H} 18$ & $M_{H} 24, M_{H} 4, M_{H} 18, M_{H} 26$ & $\begin{array}{l}M_{H} 14, M_{H} 17, M_{H} 12, M_{H} 13 \\
\quad M_{H} 16\end{array}$ & $\begin{array}{l}M_{H} 16, M_{H} 2, M_{H} 21, M_{H} 3, \\
\quad M_{H} 1\end{array}$ & $\mathrm{M}_{\mathrm{H}} 20, \mathrm{M}_{\mathrm{H}} 3, \mathrm{M}_{\mathrm{H}} 20, \mathrm{M}_{\mathrm{H}} 23$ \\
\hline \multicolumn{6}{|c|}{ Frequency of flow events: } \\
\hline Low-flow conditions & $\mathrm{F}_{\mathrm{L}} 3, \mathrm{~F}_{\mathrm{L}} 3, \mathrm{~F}_{\mathrm{L}} 1, \mathrm{~F}_{\mathrm{L}} 1$ & $\mathrm{~F}_{\mathrm{L}} 3, \mathrm{~F}_{\mathrm{L}} 2, \mathrm{~F}_{\mathrm{L}} 1, \mathrm{~F}_{\mathrm{L}} 1$ & $\mathrm{~F}_{\mathrm{L}} 1, \mathrm{~F}_{\mathrm{L}} 3, \mathrm{~F}_{\mathrm{L}} 3, \mathrm{~F}_{\mathrm{L}} 2, \mathrm{~F}_{\mathrm{L}} 3$ & $\mathrm{~F}_{\mathrm{L}} 3, \mathrm{~F}_{\mathrm{L}} 1, \mathrm{~F}_{\mathrm{L}} 1, \mathrm{~F}_{\mathrm{L}} 2, \mathrm{~F}_{\mathrm{L}} 3$ & $\mathrm{~F}_{\mathrm{L}} 3, \mathrm{~F}_{\mathrm{L}} 3, \mathrm{~F}_{\mathrm{L}} 1, \mathrm{~F}_{\mathrm{L}} 2$ \\
\hline High-flow conditions & $\mathrm{F}_{\mathrm{H}} 4, \mathrm{~F}_{\mathrm{H}} 3, \mathrm{~F}_{\mathrm{H}} 1, \mathrm{~F}_{\mathrm{H}} 9$ & $\mathrm{~F}_{\mathrm{H}} 4, \mathrm{~F}_{\mathrm{H}} 10, \mathrm{~F}_{\mathrm{H}} 1, \mathrm{~F}_{\mathrm{H}} 10$ & $\mathrm{~F}_{\mathrm{H}} 7, \mathrm{~F}_{\mathrm{H}} 3, \mathrm{~F}_{\mathrm{H}} 3, \mathrm{~F}_{\mathrm{H}} 4, \mathrm{~F}_{\mathrm{H}} 11$ & $\mathrm{~F}_{\mathrm{H}} 3, \mathrm{~F}_{\mathrm{H}} 9, \mathrm{~F}_{\mathrm{H}} 5, \mathrm{~F}_{\mathrm{H}} 10, \mathrm{~F}_{\mathrm{H}} 11$ & $\mathrm{~F}_{\mathrm{H}} 7, \mathrm{~F}_{\mathrm{H}} 3, \mathrm{~F}_{\mathrm{H}} 9 . \mathrm{F}_{\mathrm{H}} 2$ \\
\hline \multicolumn{6}{|c|}{ Duration of flow events: } \\
\hline Low-flow conditions & $\mathrm{D}_{\mathrm{L}} 4, \mathrm{D}_{\mathrm{L}} 12, \mathrm{D}_{\mathrm{L}} 16, \mathrm{D}_{\mathrm{L}} 6$ & $\mathrm{D}_{\mathrm{L}} 15, \mathrm{D}_{\mathrm{L}} 1, \mathrm{D}_{\mathrm{L}} 16, \mathrm{D}_{\mathrm{L}} 12$ & $\mathrm{D}_{\mathrm{L}} 16, \mathrm{D}_{\mathrm{L}} 14, \mathrm{D}_{\mathrm{L}} 5, \mathrm{D}_{\mathrm{L}} 9, \mathrm{D}_{\mathrm{L}} 17$ & $\mathrm{D}_{\mathrm{L}} 4, \mathrm{D}_{\mathrm{L}} 16, \mathrm{D}_{\mathrm{L}} 16, \mathrm{D}_{\mathrm{L}} 11, \mathrm{D}_{\mathrm{L}} 7$ & $\mathrm{D}_{\mathrm{L}} 3, \mathrm{D}_{\mathrm{L}} 12, \mathrm{D}_{\mathrm{L}} 16, \mathrm{D}_{\mathrm{L}} 6$ \\
\hline High-flow conditions & $\mathrm{D}_{\mathrm{H}} 2, \mathrm{D}_{\mathrm{H}} 13, \mathrm{D}_{\mathrm{H}} 20, \mathrm{D}_{\mathrm{H}} 8$ & $\mathrm{D}_{\mathrm{H}} 12, \mathrm{D}_{\mathrm{H}} 2, \mathrm{D}_{\mathrm{H}} 20, \mathrm{D}_{\mathrm{H}} 24$ & $D_{H} 11, D_{H} 14, D_{H} 1, D_{H} 9, D_{H} 23$ & $\begin{array}{l}\mathrm{D}_{\mathrm{H}} 14, \mathrm{D}_{\mathrm{H}} 2, \mathrm{D}_{\mathrm{H}} 17, \mathrm{D}_{\mathrm{H}} 12, \\
\mathrm{D}_{\mathrm{H}} 23\end{array}$ & $\mathrm{D}_{\mathrm{H}} 11, \mathrm{D}_{\mathrm{H}} 2, \mathrm{D}_{\mathrm{H}} 15, \mathrm{D}_{\mathrm{H}} 8$ \\
\hline \multicolumn{6}{|c|}{ Timing of flow events: } \\
\hline Low-flow conditions & $\mathrm{T}_{\mathrm{L}} 4, \mathrm{~T}_{\mathrm{L}} 4, \mathrm{~T}_{\mathrm{L}} 1, \mathrm{~T}_{\mathrm{L}} 1$ & $\mathrm{~T}_{\mathrm{L}} 4, \mathrm{~T}_{\mathrm{L}} 3, \mathrm{~T}_{\mathrm{L}} 2, \mathrm{~T}_{\mathrm{L}} 1$ & $\mathrm{~T}_{\mathrm{L}} 3, \mathrm{~T}_{\mathrm{L}} 3, \mathrm{~T}_{\mathrm{L}} 2, \mathrm{~T}_{\mathrm{L}} 1, \mathrm{~T}_{\mathrm{L}} 2$ & $\mathrm{~T}_{\mathrm{L}} 4, \mathrm{~T}_{\mathrm{L}} 2, \mathrm{~T}_{\mathrm{L}} 2, \mathrm{~T}_{\mathrm{L}} 1, \mathrm{~T}_{\mathrm{L}} 4$ & $\mathrm{~T}_{\mathrm{L}} 4, \mathrm{~T}_{\mathrm{L}} 3, \mathrm{~T}_{\mathrm{L}} 3, \mathrm{~T}_{\mathrm{L}} 1$ \\
\hline High-flow conditions & $\mathrm{T}_{\mathrm{H}} 2, \mathrm{~T}_{\mathrm{H}} 2, \mathrm{~T}_{\mathrm{H}} 2, \mathrm{~T}_{\mathrm{H}} 3$ & $\mathrm{~T}_{\mathrm{H}} 2, \mathrm{~T}_{\mathrm{H}} 2, \mathrm{~T}_{\mathrm{H}} 1, \mathrm{~T}_{\mathrm{H}} 3$ & $\mathrm{~T}_{\mathrm{H}} 2, \mathrm{~T}_{\mathrm{H}} 2, \mathrm{~T}_{\mathrm{H}} 3, \mathrm{~T}_{\mathrm{H}} 4, \mathrm{~T}_{\mathrm{H}} 3$ & $\mathrm{~T}_{\mathrm{H}} 1, \mathrm{~T}_{\mathrm{H}} 3, \mathrm{~T}_{\mathrm{H}} 2, \mathrm{~T}_{\mathrm{H}} 3, \mathrm{~T}_{\mathrm{H}} 3$ & $\mathrm{~T}_{\mathrm{H}} 3, \mathrm{~T}_{\mathrm{H}} 2, \mathrm{~T}_{\mathrm{H}} 2, \mathrm{~T}_{\mathrm{H}} 3$ \\
\hline $\begin{array}{l}\text { Rate of change in flow } \\
\text { events: }\end{array}$ & $\mathrm{R}_{\mathrm{A}} 3, \mathrm{R}_{\mathrm{A}} 7, \mathrm{R}_{\mathrm{A}} 8, \mathrm{R}_{\mathrm{A}} 5$ & $R_{A} 7, R_{A} 1, R_{A} 6, R_{A} 2$ & $\mathrm{R}_{\mathrm{A}} 6, \mathrm{R}_{\mathrm{A}} 3, \mathrm{R}_{\mathrm{A}} 1, \mathrm{R}_{\mathrm{A}} 2, \mathrm{R}_{\mathrm{A}} 4$ & $R_{A} 7, R_{A} 3, R_{A} 8, R_{A} 1, R_{A} 6$ & $\mathrm{R}_{\mathrm{A}} 6, \mathrm{R}_{\mathrm{A}} 3, \mathrm{R}_{\mathrm{A}} 8, \mathrm{R}_{\mathrm{A}} 2$ \\
\hline
\end{tabular}

${ }^{1}$ Some indices can appear more than once in a table cell because they may be the most highly loaded variable on PCA axis one, two, three, and so forth, for a given index. 


\section{Selection of Streams and Period of Record}

The steps used to select New Jersey streams for use in the HIP eliminated streams that either were not representative of "least impaired" conditions or did not have a continuous period of record long enough to be considered appropriate for analysis. These steps included a site-selection process that incorporated visual and statistical procedures as well as professional judgment. First, all candidate New Jersey streams $(\mathrm{N}=114)$ with a minimum POR of 20 years were identified. Second, the flow records were used to establish a minimum background flow profile based on the available POR. The flow profile was used to visually identify any flow-related anomalies and determine whether any major changes in flow processes occurred over the established POR. Least impaired sites - that is, sites that had minimal flow regulation or a POR reflecting a time period prior to major flow alteration-were identified. This included New Jersey streams with a POR that in many cases did not include the 1960s drought of record and had minimal (<25 percent) catchment urbanization. In addition, streams with a catchment size exceeding $400 \mathrm{mi}^{2}$ were eliminated to reduce the influence of dams and reservoirs commonly established on larger river systems (for example, the Delaware River) in New Jersey. Professional judgment based on more than 40 years of accumulated knowledge and experience was used to identify some New Jersey streams that initially did appear to meet the minimum requirements for inclusion, but later were found to be anomalous due to changes in flow associated with water withdrawals, inter-basin water transfers, or other flow-regulation processes. In many cases, trend analysis between split periods of the flow record was necessary to fully establish whether differences in flow occurred over a given timeframe and whether these changes were a result of water-development processes in the basin or of long-term climatic variation (for example, Watson and others (2005)). This process reduced the number of streams suitable for inclusion in the HIP from 114 to 94.

\section{Clustering of Streams}

Stream classes in New Jersey were defined by classifying the 94 stream sites that met the minimum criteria established above - that is, a sufficiently long POR (about 20 years) with minimal anthropogenic disturbance in the catchment. In this analysis, the 94 streams chosen were assumed to represent the "least impaired" portion of the gaging record and were subsequently analyzed using the HIP to generate 171 ecologically relevant indices (Richter and others, 1997; Olden and Poff, 2003) for each stream. By focusing on streams with a least impaired POR, the resulting HRIs are thought to be indicative of what would be expected for a relatively unmodified aquatic system. The results of these HIT analyses were validated against available published USGS streamflow records and by a series of validation techniques outlined in Henriksen and others (2006). (See also appendix 5.) All 171 HRIs were calculated for the 94 streams.
Principal components analysis (SAS Institute Inc., 1989) in combination with collinearity assessment (Spearman's rho) was used to reduce the number of HRIs and to isolate a subset of indices that accounted for the greatest proportion of variance while minimizing redundancy. PCA is well suited to decreasing the dimensionality of complex data sets (Digby and Kempton, 1987; Manly, 1994) and was used to minimize HRI intercorrelation. Distributions of all HRIs were evaluated for normality and standardized when necessary. PCA was conducted on the correlation matrix and the significance of principal components was evaluated using the broken stick method (Jackson, 1993). The broken stick method is used to determine statistically significant principal component axes by comparing the observed eigenvalues to the eigenvalues from random data. In addition, use of the correlation matrix ensured that all HRIs contributed equally to the PCA and that the contributions were scale-independent (Legendre and Legendre, 1998; Olden and Poff, 2003). Loadings (the level of correlation between the HRIs and principal components) of the HRIs on each significant principal component were used to identify indices explaining the dominant patterns of variation among a full suite of intercorrelated indices. Indices with the strongest loadings (minimum cutoff was set at 0.6000 ) along significant primary components were retained for additional analysis. Spearman's correlations were then used to further diminish redundancy and the combination of these two approaches reduced the number of significant HRIs from 171 to 70 .

The reduced set of HRIs was then used to classify the 94 streams using the unweighted pair group method using arithmetic averages (UPGMA), a clustering technique that is also known as average linkage or group average, into distinct stream classes. UPGMA is a hierarchical clustering technique in which the similarity between clusters is calculated using the average of all Euclidean distances for all pairs of individuals (McCune and Grace, 2002). Prior to the cluster analysis, HRIs were normalized to reduce the effect of scale and the UPGMA was carried out using PRIMER 6 (Clarke and Gorley, 2006). The UPGMA cluster analysis separated the 94 streams based on the strength of the associations among the 70 indices into four distinct stream classes (app. 3; fig. 1). A fifth group that represented the largest catchment areas (for example, the Delaware River sites) was found to be an outlier and was omitted from further analysis. The remaining four stream classes were found to be highly distinct and the sensitivity of the clusters was validated using a jackknifing procedure (for example, Ibarra and Stewart, 1989; Kennen and others, 2002). This analysis requires a sequential deletion of sites and calculation of percent persistence of each cluster division. This analysis indicated 80- to 95-percent persistence for the four primary divisions.

Following the cluster analysis, PCA was conducted to identify the HRIs that best exemplify the 10 sub-components of the flow regime (magnitude-low, average, high; frequencylow, high; duration-low, high; timing-low, high; rate of change-average (table 3)) for each of the four stream classes. 
A matrix was produced by identifying, for each stream class, the indices that are most significant for each of the 10 critical components of the flow regime. Significant indices were derived by assessing the loading pattern on significant principal components. Loadings of the hydroecological indices on each significant principal component were used to identify indices that explain dominant patterns of hydrologic variation. Because principal component axes by definition are orthogonal, indices from significant secondary and tertiary principal component axes also were selected to ensure that the chosen indices are relatively independent from one another and to identify surrogate indices for subsequent comparisons (Olden and Poff, 2003). (Surrogate indices represent other indices within each component that are collinear with the indices of interest (Henriksen and others, (2006).) The primary and surrogate indices for each stream class are listed in table 3. The four stream classes in New Jersey are referred to here as stream classes A, B, C, and D (fig. 1; app. 3). Each of these stream classes has predominant hydrologic traits. For example, class A streams are semiflashy with moderately low base flow and are typically located north of the Fall Line; class B streams are generally more stable, have high base flow, and are located primarily in the Coastal Plain; class C streams are moderately stable with moderately high base flow and are commonly in glaciated areas; and class D streams are smaller, flashy streams (catchments generally $<10 \mathrm{mi}^{2}$ ) with low base flow, and are distributed throughout New Jersey (fig. 1). Additional information on the distinguishing characteristics of the four stream classes in New Jersey is found in appendixes 3 and 4 .

\section{Development of the New Jersey Stream Classification Tool (NJSCT)}

Linear discriminant function analysis (DFA) was used to derive parsimonious multivariate models that best separated the means of the four New Jersey stream classes based on the calculated flow indices. Several steps were taken to select variables for the final model. (1) Backward elimination of variables (based on an F-ratio P-value of 0.15) in separate DFAs was performed using the 70 variables identified from the PCA for each of the five critical flow components (magnitude, frequency, duration, timing, and rate of change) (table 3). (2) This analysis produced a reduced set of variables that were then considered simultaneously in another DFA using backward elimination of variables. The philosophy of this approach was to try to further reduce variable redundancy while allowing all five critical flow components to potentially contribute to the final model. The final model included 20 flow-magnitude variables (MA9, MA13, MA18, MA24, MA37, MA40, ML4, ML6, ML13, ML15, ML16, ML20, ML21, MH4, MH5, MH13, MH14, MH16, MH18, MH20), 7 frequency-of-flow variables (FL1, FL2, FL3, FH1, FH3, FH5, FH7), 8 durationof-flow variables (DL4, DL5, DL7, DL15, DL16, DH13, DH14, DH17), and 2 timing-of-flow variables (TA1, TL2). This model had an overall jackknifed classification accuracy of 63 percent (raw optimistic classification accuracy was 98 percent) based on the final DFA with the 37 variables on 94 streams. Prior probabilities in the classification function were based on relative sample sizes of the four stream classes.

To validate the DFA model, three test cases based on minimums, means, and maximums for these 37 variables were constructed in the statistical package SYSTAT version 11 (SYSTAT Software Inc., 2004) to compare the statistical model classification of these new observations with the classification functions included in this software. They agreed. The NJSCT software was programmed based on the discriminatory power of this model, and any given stream representing flow attributes that are in concordance with a specific stream class would be automatically placed into that stream class (see Henriksen and others, 2006).

During the development of the software tools it became apparent that the process could concurrently be developed for the six national stream types classified by Olden and Poff (2003) (app. 6). Olden and Poff's (2003) national classification identified only two stream types in New Jersey (see also Poff, 1996), whereas when the HIP was developed for New Jersey, four stream classes were identified. Identification of additional stream classes is expected to occur as a refinement in the classification when the HIP is developed and implemented specifically for other geographic areas (for example, states, provinces, or sub-regions). Finally, Olden and Poff (2003, p. 109, Table III) (app. 6) identified nine sub-components of flow for each stream type in the national classification. Our analysis indicated that more specific comparisons could be made by dividing the timing of flow events into two sub-components of flow, average timing of low- and high-flow events (table 3).

\section{Application of the Hydroecological Integrity Assessment Process}

The natural flow regime paradigm (Poff and others, 1997) is the conceptual basis for the HIP (Henriksen and others, 2006). As implemented here, it evaluates the degree of alteration of 10 or more statistically significant hydrologic indices (out of a total of 171) that address the five critical components of streamflow (Richter and others, 1997; Olden and Poff, 2003). Commonly, however, the "natural flow regime" is assumed to require a lengthy flow record pre-dating any anthropogenic water or land-use alteration. Such a period of record is rarely available, and usually is not necessary to apply the HIP tools. In most cases, the user will be limited to either an existing streamflow record or a synthesized period of record (which can be derived through flow modeling; for example, Kennen and others, 2007) documenting the flow history. In addition, regardless of what POR is recommended (for example, Poff and others, 1997), the user should determine whether a stream's biotic integrity can be considered "healthy" or "acceptable" in its current condition or at some prior point 
in time for the available POR. If stream biotic integrity (user defined) is found to be acceptable, then the recent historic POR (alternatively, a timeframe in the POR when the stream's integrity was considered acceptable) can be used as the baseline (reference) condition. Ultimately, the biotic condition of a stream reach should be derived from biological metrics from monitoring programs (for example, New Jersey's Ambient Biological Monitoring Network-see also Kennen and Ayers, 2002) or rapid stream assessment tools (for example, the U.S. Environmental Protection Agency's Rapid Assessment Protocols for Use in Streams and Wadeable Rivers: Periphyton, Benthic Macroinvertebrates, and Fish-see Barbour and others, 1999). Hereafter, the term "baseline hydrologic condition" will be used as a surrogate for the natural flow regime.

The primary purpose of the NJHAT (or any version developed for a specific state, province, or geographic area) is to assist decision makers (water-resource managers, planners, or regulatory agencies) with the comparison of baseline conditions to either current conditions or proposed hydrologic changes through the evaluation of HRIs. HRIs account for characteristics of streamflow variability that are known to be "biologically relevant" - that is, they are important in shaping ecological processes in streams (Olden and Poff, 2003; Richter and others, 1997). The basic premise is that if one or more stream-class-specific indices is significantly altered due to past or proposed streamflow alterations, the alteration will have a significant impact, directly or indirectly, on biodiversity, physical processes (habitat), and (or) production. It is anticipated that this process will be used by regulatory agencies to establish ecologically based environmental-flow standards and criteria that will be used to protect, maintain, or restore stream biotic integrity.

NJHAT can be applied to an unlimited number of flow scenarios, but all have one thing in common-that the flow regime of the stream system being assessed has been or is going to be altered. The most likely application of NJHAT would be the assessment of a proposed or existing diversion (for example, water-treatment-facility intake, reservoir, or ground-water extraction) in a watershed. For a proposed diversion, the goal would be to establish environmental-flow standards that address all 10 sub-components of flow. In the case of an existing diversion, the purpose would be to determine whether or not the agency-established standard is being violated for any of the stream-class-specific flow indices (for example, table 3). For either case, adaptive management (a type of natural-resource management that implies making decisions as part of an ongoing process) of environmental flows can be effectively applied for determining the ecologically compatible withdrawal rate necessary to protect biotic integrity (Richter and others, 2006).

NJHAT can be used to compare a variety of waterdevelopment or hydrologic-infrastructure scenarios by directly varying the streamflow and (or) the project's operating procedures. For example, if a proposed water-development project consists of an intake on stream (x) and the facilities require (y) amount of water per day, an environmental-flow standard could be established to meet the most stringent level (worstcase scenario) or be adjusted monthly or seasonally to set flows during the most ecologically sensitive time of the year (for example, during fish spawning or migration periods). The proposed diversion could also be adjusted to meet seasonal demands or the project could be revised to include storage that reduces reliance on diversions during specific times of the year.

Another application of the NJHAT would be to evaluate the effects of anthropogenic changes that have occurred over a long period of time for a given stream. If a streamflow POR is available or can be developed for a fairly long period of time (for example, $>20$ years), NJHAT can be used to evaluate the effects that historical hydrologic alteration associated with land-use changes may have had during that timeframe. This would provide managers and decision makers with the ability to compare the effects of differing approaches for proposed water-development projects, which may facilitate optimal management choices if restoration is warranted. NJHAT also can be used to evaluate trends in streamflow for the entire POR or for segments of the record. Again, such an analysis can give the user a more comprehensive understanding of the variability in flow characteristics for the stream being investigated.

\section{Establishing a Hydrologic Baseline}

It is important to determine the appropriate baseline hydrologic conditions so that the extent of alteration to the hydrology is accurate and that environmental-flow standards can be established. A hydrologic baseline represents the "relatively unimpaired" or "natural" conditions that embody natural flow variability (Poff and others, 1997) and represent the foundation of environmental-flow management. In this document we take a two-pronged approach that incorporates visual and statistical evaluation of stream hydrographs to identify least impaired streams or portions of the hydrograph that represent the least impaired time period. In addition, professional judgment was used to identify specific time periods or overlooked water-development processes (withdrawals, dams, diversions, inter-basin transfers, etc.) in the POR that would affect the baseline conditions or skew the results of statistical comparisons. This method worked well for this study although many other statistical processes and hydrologic criteria can be used to establish baseline hydrographs. Such approaches could include simulating flow-duration curves (Seelbach and Wiley, 1997; Wiley and others, 1998), quantile regression (Cade and Noon, 2003), hydrologic trends, the use of simulated hydrographs (Kennen and others, 2007), or regression approaches (Sanborn and Bledsoe, 2006; Stuckey, 2006) to identify hydrograph anomalies, hydrologic inflection points, statistical differences in trend-line slopes, back-projected baseline conditions using hydrologic modeling, or predicted stream baselines, respectively. 


\section{Examples of New Jersey Hydroecological Assessment Tool (NJHAT) Application}

Two examples are presented in this section to illustrate some of the basic functions of NJHAT. The data for each example are taken from USGS stream-gaging stations located in New Jersey. The first example is an analysis that characterizes the hydrologic changes that have occurred in a watershed over a 40-year period; the second is an analysis based on a proposed water diversion from a relatively unaltered stream. Although based on real streams, these examples are for illustration purposes only. Although example A represents historical data, example B should not be misinterpreted to represent any specific current or ongoing water-development project in New Jersey. Therefore, in an effort to avoid any potential misunderstanding or confusion, the names of the streams are not revealed.

\section{Example A}

Example $\mathrm{A}$ is an analysis of a watershed that had undergone continuous urban development, resulting in the discharge of increasing amounts of treated wastewater from several wastewater-treatment facilities to the stream. The watershed is $17 \mathrm{mi}^{2}$ and is in the Coastal Plain. In the late 1980s, a regional wastewater facility that aggregated all of the sewage from within the watershed and discharged to a location outside the watershed began operation. To evaluate the subsequent changes in flow, the streamflow record was divided into two periods, one before and one after sewer regionalization. Monthly maximum daily mean streamflow, monthly mean streamflow, and monthly minimum daily mean streamflow for pre-and post-regionalization are shown in figures 4,5 , and 6 , respectively. These figures were generated with the NJHAT software based on a specific stream class (table 3). A visual inspection of the graphs of monthly mean (fig. 5) and monthly minimum (fig. 6) streamflow shows a slight decrease in streamflow at the time of regionalization of the sewerage system (1988). There is no discernible difference, however, between the two periods for monthly maximum (fig. 4). This is a predictable result given that the sewage flow comprises a much smaller percentage of high flows than of low or mean flows.

Three additional indices - median of monthly flows (MA12-23), median of minimum monthly flows (ML1-12), and median of maximum monthly flows (MH1-12) - were calculated by determining the respective monthly value for the

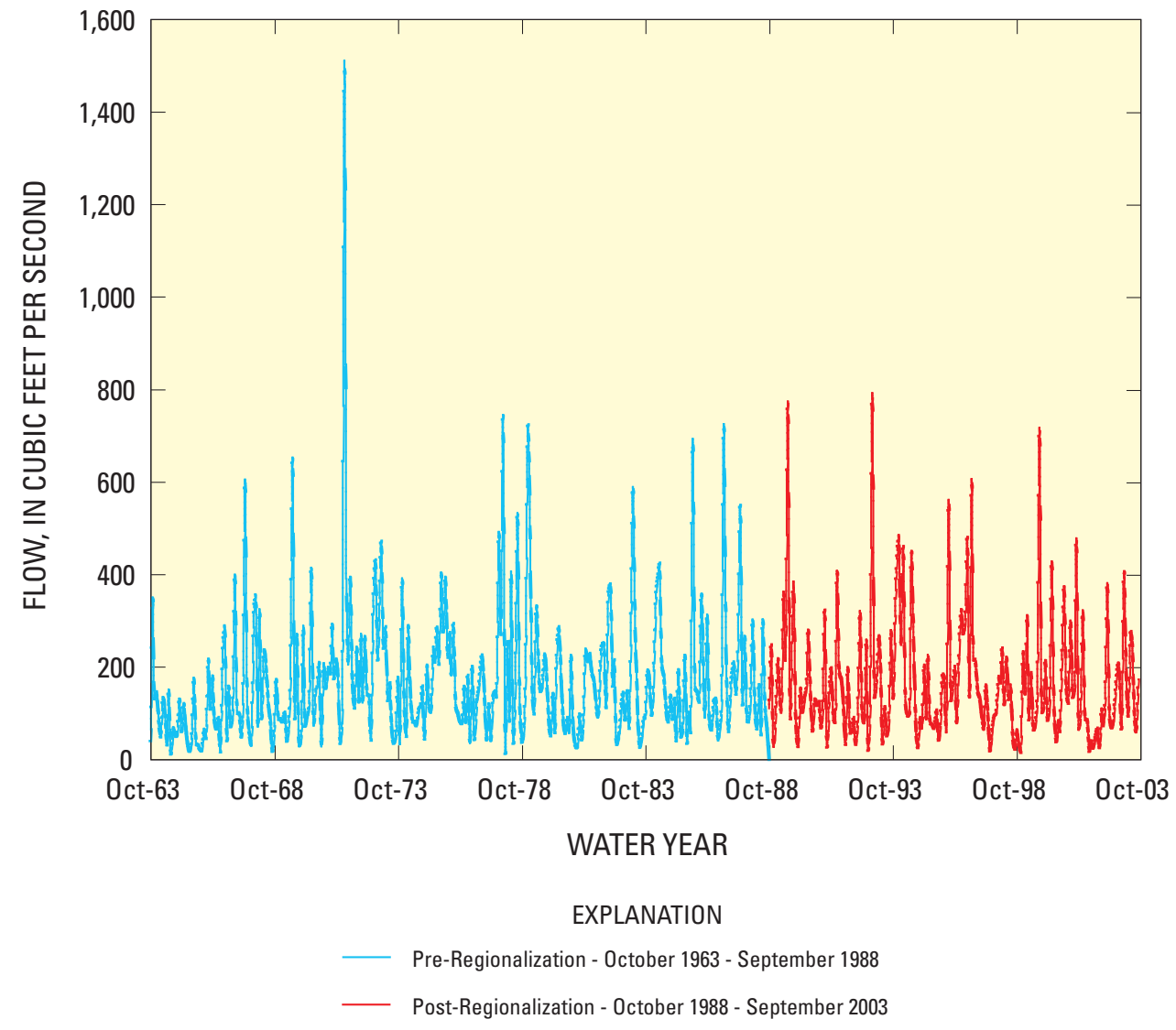

Figure 4. Monthly maximum daily mean streamflow for time periods before and after regionalization of a wastewater facility, water years 1964-2003. 


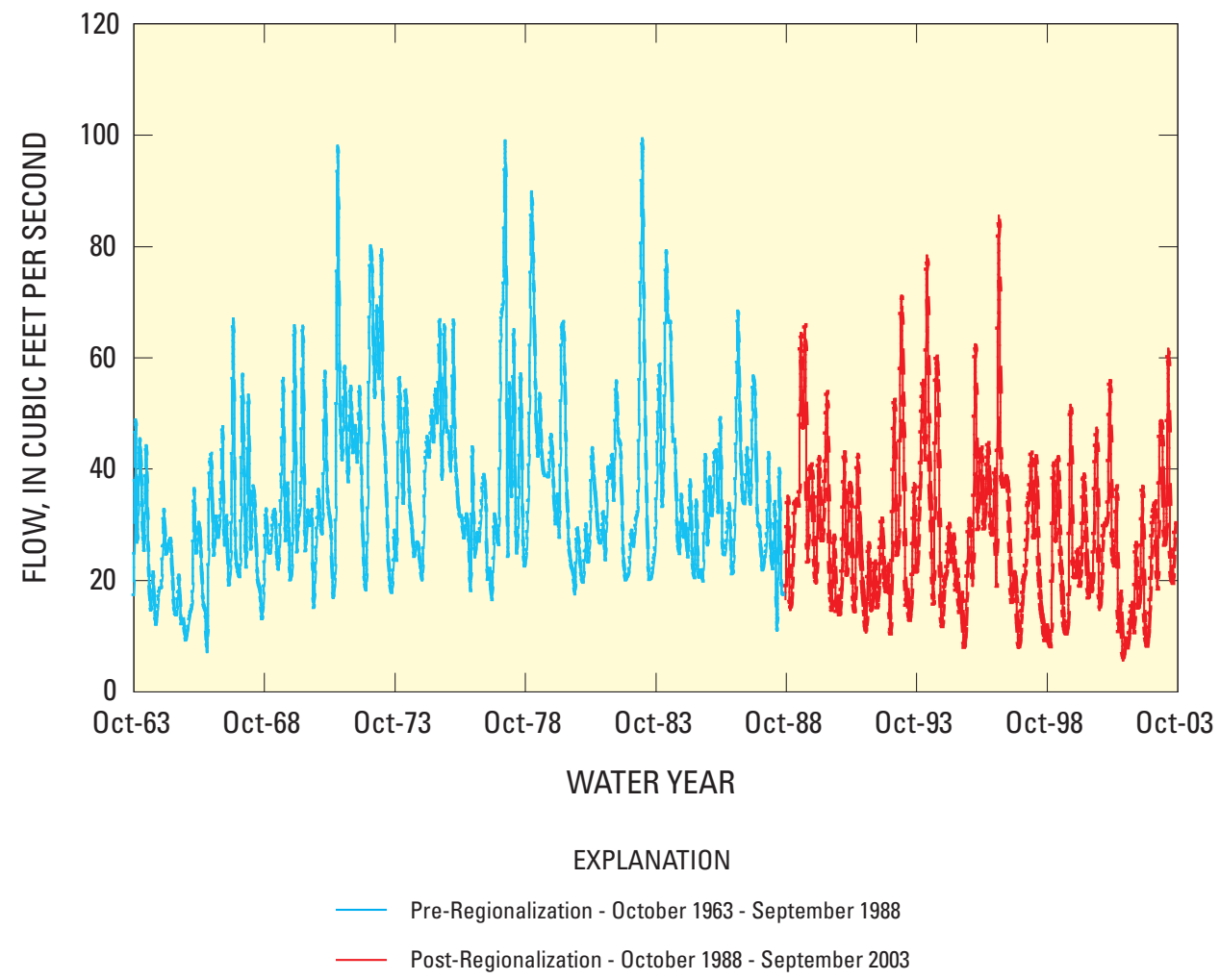

Figure 5. Monthly mean streamflow for time periods before and after regionalization of a wastewater facility, water years $1964-2003$.

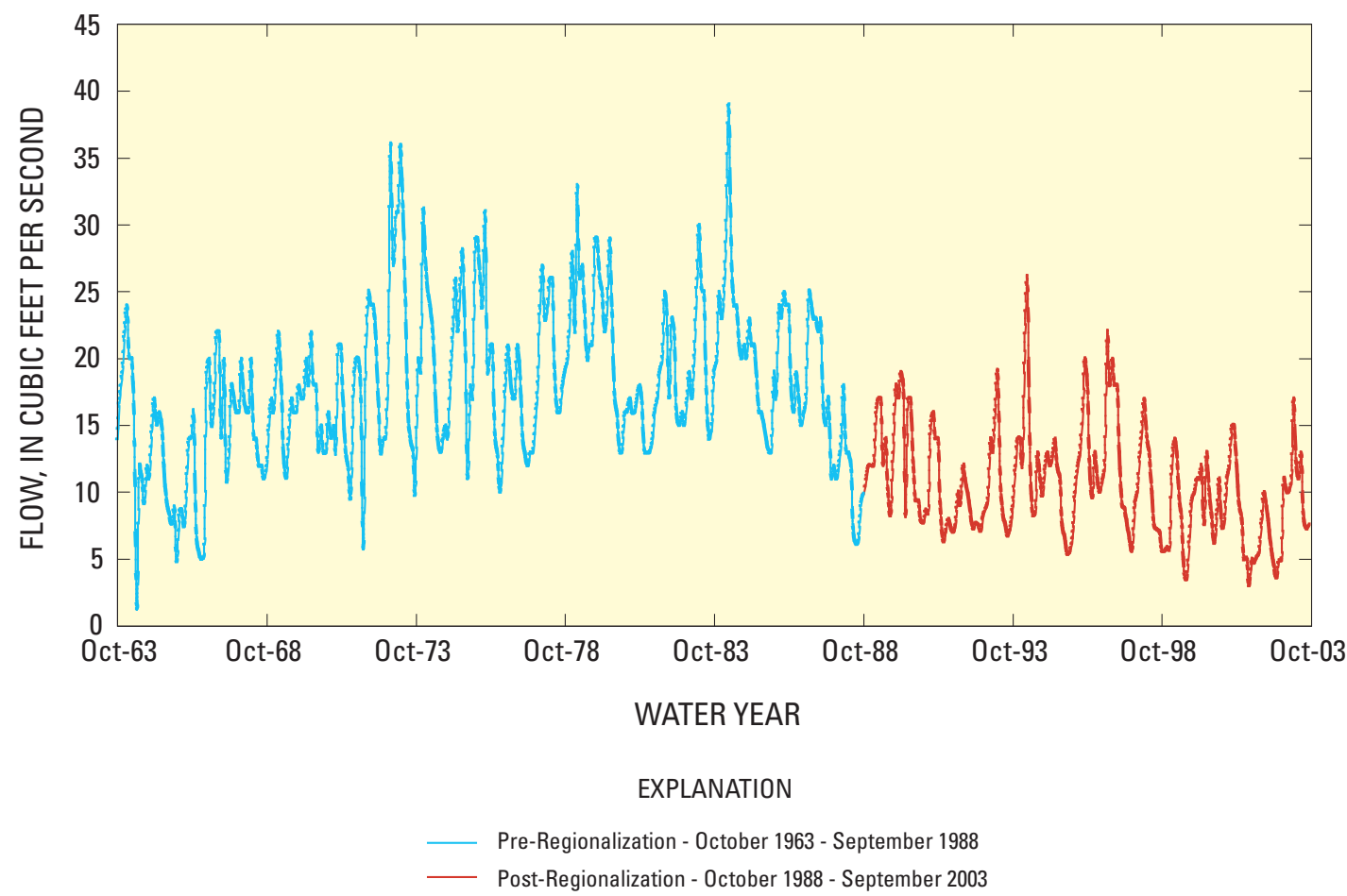

Figure 6. Monthly minimum daily mean streamflow for time periods before and after regionalization of a wastewater facility, water years 1964-2003. 
flow record and then determining the median for each month (app. 7). For example, ML1 is the median of the minimum daily mean flows for all Januarys for each flow record (preregionalization and post-regionalization). These indices are shown for the two flow records in figures 7,8 , and 9 . These figures also show the 25th and 75th percentiles of the preregionalization range of the indices. As above, the maximum monthly flows for both flow records are similar and do not fall outside the pre-regionalization 25 th or 75 th percentiles, whereas the median and minimum monthly flows show differences between the pre- and post-wastewater-regionalization periods and, in some cases, fall outside the 25th- and 75thpercentile ranges (figs. 8 and 9).

The 10 principal HRIs are shown for pre- and postregionalization of the watershed in table 4 (NJHAT-calculated values) and figure 10 (values normalized to pre-regionalization indices). For some indices, the 25th- and 75th-percentile values are based on data for stream class C (app. 3); in those cases, the calculated value of the baseline or, in this case, the two periods of record could fall outside the established range (for example, figure 10, index TH3).

For this stream, however, a synthesized daily flow record would be required because no pre-alteration (baseline) period of record exists. The POR for this site began in 1964, after development and operation of wastewater-treatment facilities. In this example, indices ML3, MH14, FH7, DH11, and TL2 show a distinct difference between the two time periods. The values for ML3, MH14, FH7, and DH11 for the post-regionalization period clearly fall outside the respective 25th- and 75th-percentile pre-regionalization values (table 4 ), whereas the value for TL 2 falls between the pre-regionalization 25thand 75 th-percentile values. Regionalization of the sewerage system may not be the sole cause of the hydrologic changes that occurred in this watershed; however, a significant difference in flow processes between these two time periods clearly exists. Additional investigation is always warranted, as other factors including climate, increased water diversions, and increases in impervious cover due to urban development may have influenced these changes as well.

Table 4. Comparison of pre- and post-regionalization values of selected hydrologic indices.

[Indices outside the 25th- to 75th-percentile range are shown in bold; refer to appendix 7 for index definitions]

\begin{tabular}{lcccc}
\hline Index & \multicolumn{3}{c}{ Pre-regionalization } & Post- \\
\cline { 2 - 4 } & $\begin{array}{c}\text { 25th } \\
\text { percentile }\end{array}$ & Value & $\begin{array}{c}\text { 75th } \\
\text { percentile }\end{array}$ & $\begin{array}{c}\text { Pegionalization } \\
\text { rennn}\end{array}$ \\
\hline MA24 & 48.716 & 71.491 & 108.631 & 101.849 \\
\hline ML3 & 18.5 & 22 & 24.5 & $\mathbf{1 5}$ \\
\hline MH14 & 12.899 & 16.857 & 24.454 & $\mathbf{2 7 . 1 3 3}$ \\
\hline FL1 & 8 & 16 & 23 & 14 \\
\hline FH7 & 4 & 6 & 9 & $\mathbf{1 2}$ \\
\hline DL16 & 3.607 & 5.333 & 6.167 & 4.826 \\
\hline DH11 & 12.396 & 19.855 & 26.208 & $\mathbf{3 1 . 9 6 4}$ \\
\hline TL2 & 29.362 & 42.497 & 40.797 & 35.823 \\
\hline TH3 & 0.108 & 1.003 & 0.431 & 1.003 \\
\hline RA6 & 0.074 & 0.204 & 0.647 & 0.369 \\
\hline
\end{tabular}

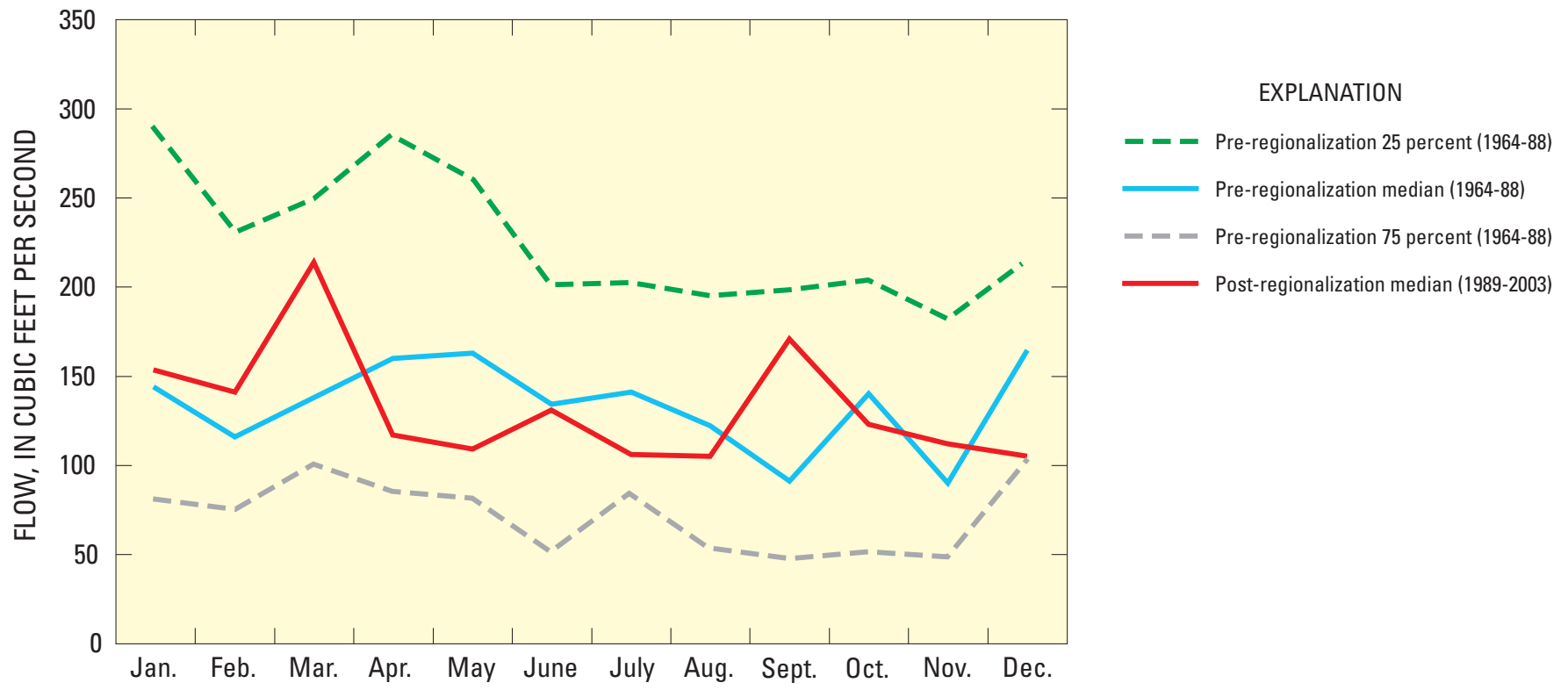

Figure 7. Maximum monthly streamflow for time periods before and after regionalization of a wastewater facility, water years 1964-2003. 


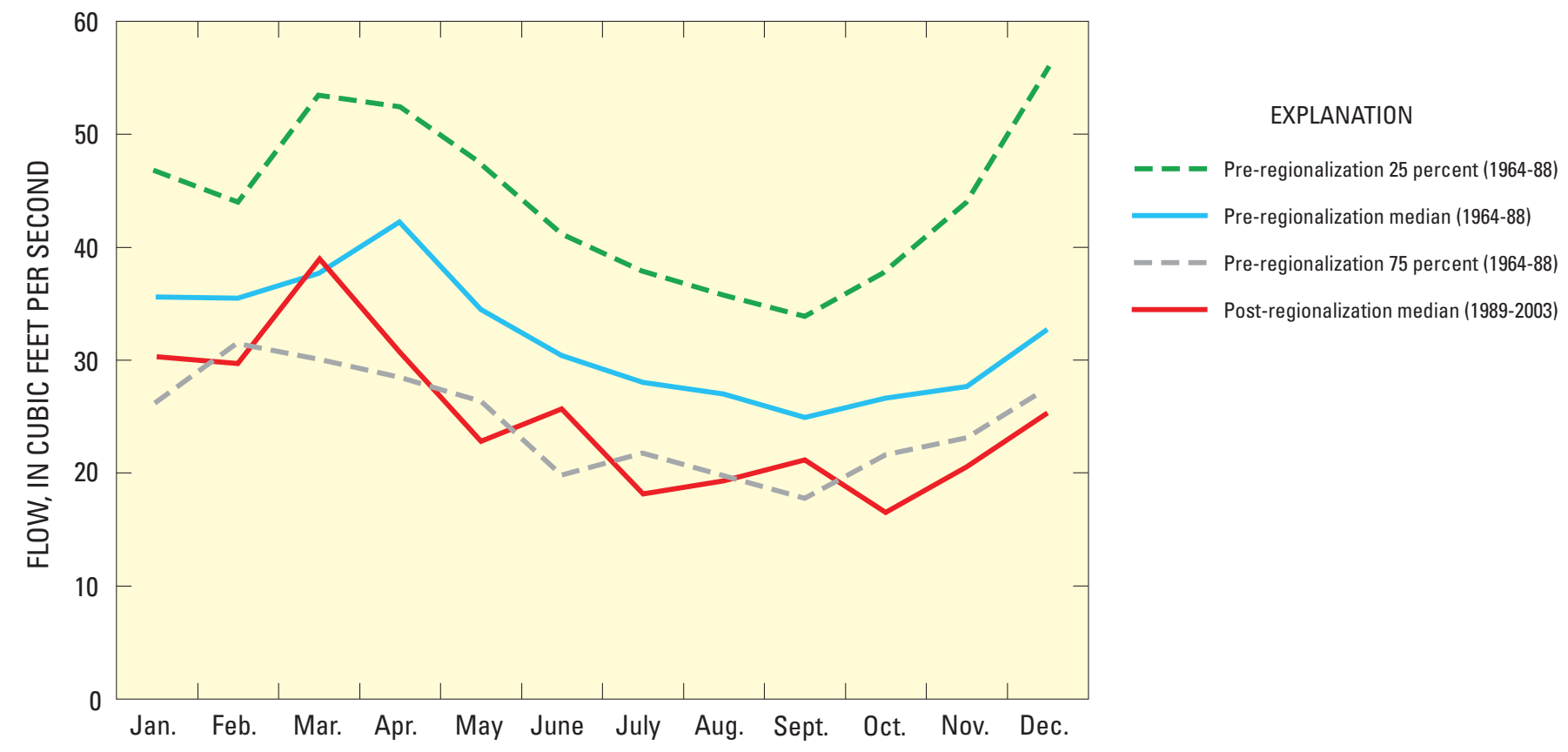

Figure 8. Median monthly streamflows for time periods before and after regionalization of a wastewater facility, water years 19642003.

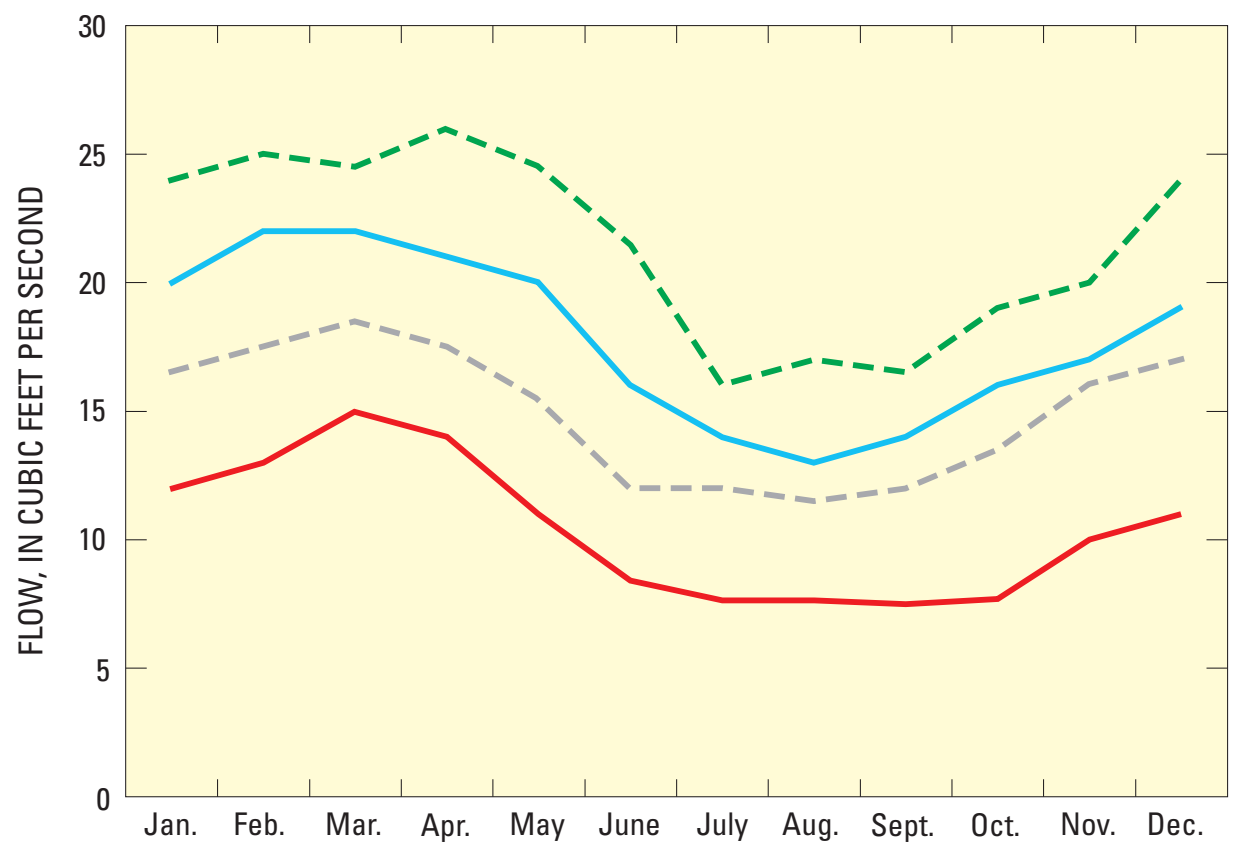

EXPLANATION

- - - Pre-regionalization 25 percent (1964-88)

- Pre-regionalization median (1964-88)

- - - Pre-regionalization 75 percent (1964-88)

Post-regionalization median (1964-2003)

Figure 9. Minimum monthly streamflows for time periods before and after regionalization of a wastewater facility, water years 1964-2003. 


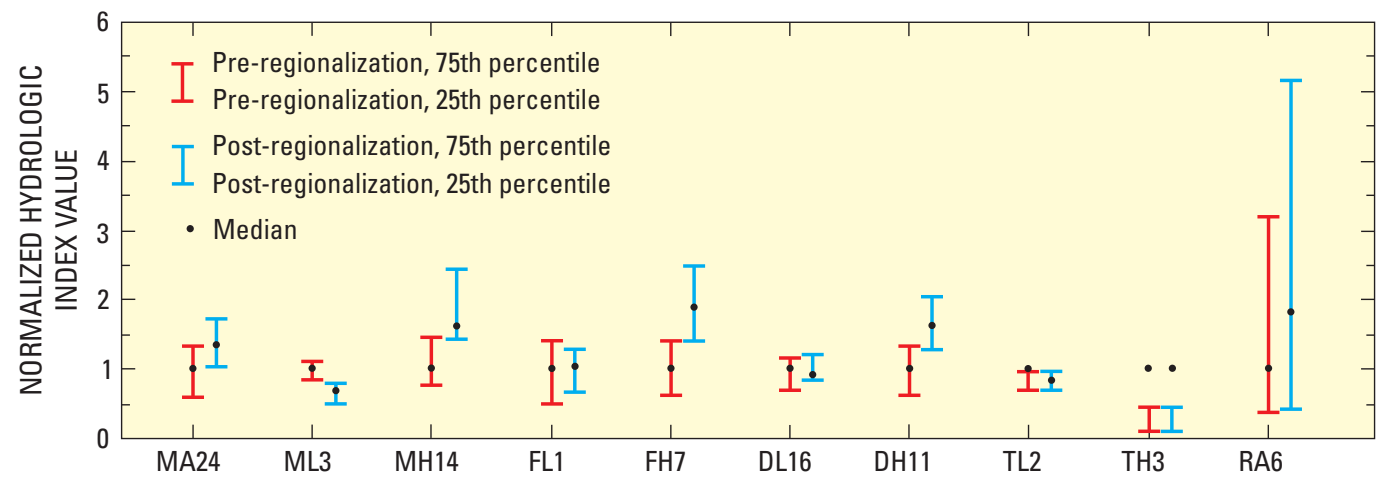

Figure 10. The calculated value and the 25th- and 75th-percentile values of selected hydrologic indices pre- and post-regionalization. (Indices have been normalized to the pre-regionalization indices for easy comparison.)

\section{Example B}

Example B is an analysis of a watershed that has an extensive streamflow record and is considered to be relatively unaltered hydrologically. This watershed is $64 \mathrm{mi}^{2}$ in size and is in northwestern New Jersey. Because the streamflow and the watershed are relatively unaltered, the entire stream-gaging record (1924-2003) was used as a baseline for this evaluation. A theoretical surface-water diversion and several alternatives are examined to illustrate the use of NJHAT to analyze a new water-diversion project. The amount of the diversion and the required environmental flow (amount of streamflow required before the diversion would be allowed) were varied to determine the amount of water that hypothetically could be diverted without violating the 25 th- and 75 th-percentile range standard applied to the baseline flow indices for stream class A (table 3, fig. 1).

The monthly maximum, monthly mean, and monthly minimum daily flows for the period 1924-2003 are shown in figures 11,12 , and 13 , respectively. No changes are discern-

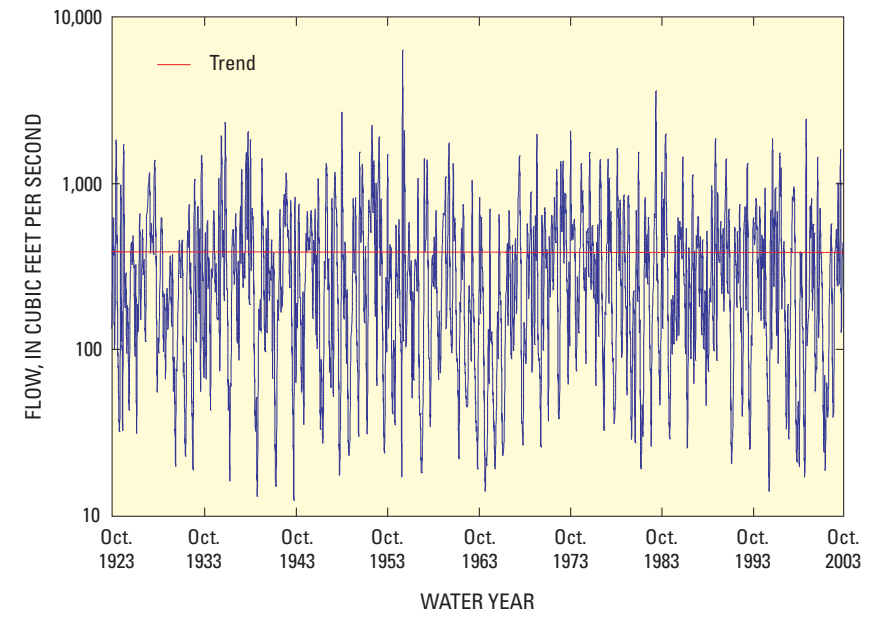

Figure 11. Monthly maximum daily mean streamflow for water years 1924-2003.

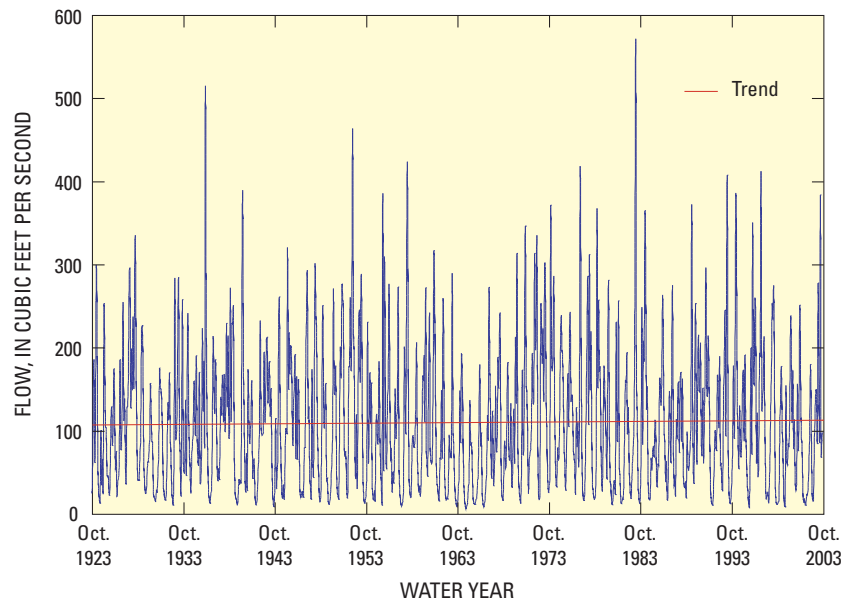

Figure 12. Monthly mean streamflow for water years 1924-2003.

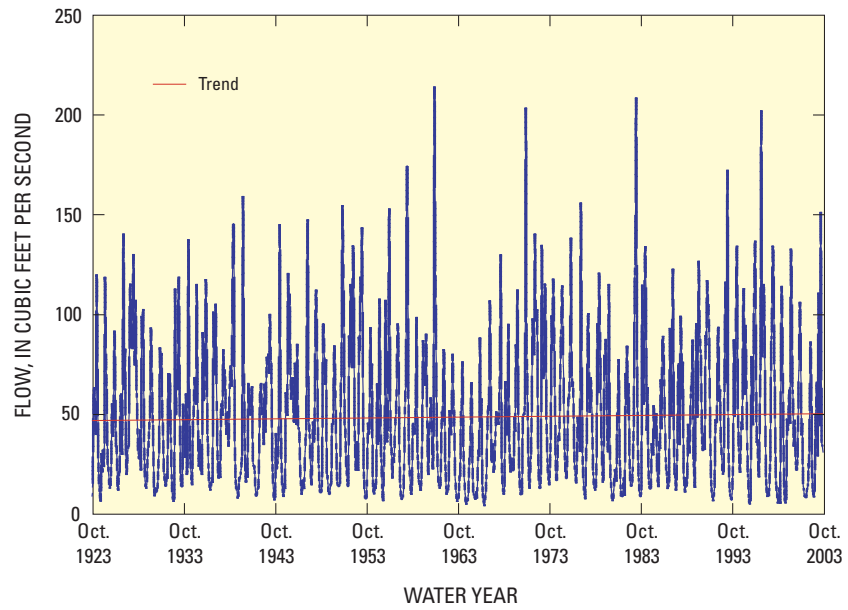

Figure 13. Monthly minimum daily mean streamflow for water years 1924-2003. 
able for the entire POR, which would be expected for this relatively unaltered watershed. Visible in these hydrographs are typical high and low flows that are related to annual variability in climate, and some longer term variations related to droughts (in the mid 1960s) and a fairly wet decade (the 1970s); there is, however, no evidence of anthropogenic change that was sufficiently significant to affect the natural hydrologic regime of this watershed. (Note that NJHAT generates the trend line shown in figures 11,12 , and 13 by a linear regression calculation, but does not currently provide a significance test for the line. This analysis can be done outside the NJHAT program using an appropriate inferential statistical test.)

Four diversion scenarios are considered. The scenarios consist of flow diversions of $5,50,25$, and $50 \mathrm{ft}^{3} / \mathrm{s}$ with environmental passing flows of $25,25,25$, and $10 \mathrm{ft}^{3} / \mathrm{s}$, respectively. The stream hydrographs for water year 2000 (October 1, 1999, through September 30, 2000) for the first two scenarios are shown in figure 14; the hydrographs for the second two scenarios are shown in figure 15. Flat sections of the hydrographs represent periods during which the diversion was decreased to meet the environmental flow requirement. If the baseline flow falls below the established environmental flow standard, the diversion would cease and the streamflow would be the natural unaltered flow; however, this condition did not occur in water year 2000. If the diversion or the environmental flow were increased, the amount of time that the diversion could operate would decrease.

The maximum monthly (MH 1-12), mean monthly (MA 12-23), and minimum monthly flows (ML 1-12) are shown in figures 16,17 , and 18, respectively, with the 25th and 75 th percentiles for the baseline streamflow record. Each of the diversion alternatives shown falls below the natural flow median for each flow condition, and the $50-\mathrm{ft}^{3} / \mathrm{s}$ alternatives show several months in which the streamflow falls below the 25 th percentile for the mean and minimum monthly flows (figs. 17 and 18). The $5-\mathrm{ft}^{3} / \mathrm{s}$ diversion has the smallest overall impact on streamflow and is consistently within the 25th- and 75 th-percentile range for all months and all flow conditions (figs. 16, 17, and 18).

Statistics for the 10 principal HRIs (based on stream classification A, table 3, fig. 1) for the four diversion scenarios are listed in table 5 and shown in figure 19. The values of two or more of the HRIs for the latter three flow-diversion scenarios are outside the 25th- to 75 th-percentile range of the baseline streamflow, whereas those for the $5-\mathrm{ft}^{3} / \mathrm{s}$ diversion appear to be, for the most part, within the 25th- to 75th-percentile range of the baseline flow indices, with the exception of indices TL1 and TH1, whose values closely match the baseline. This is

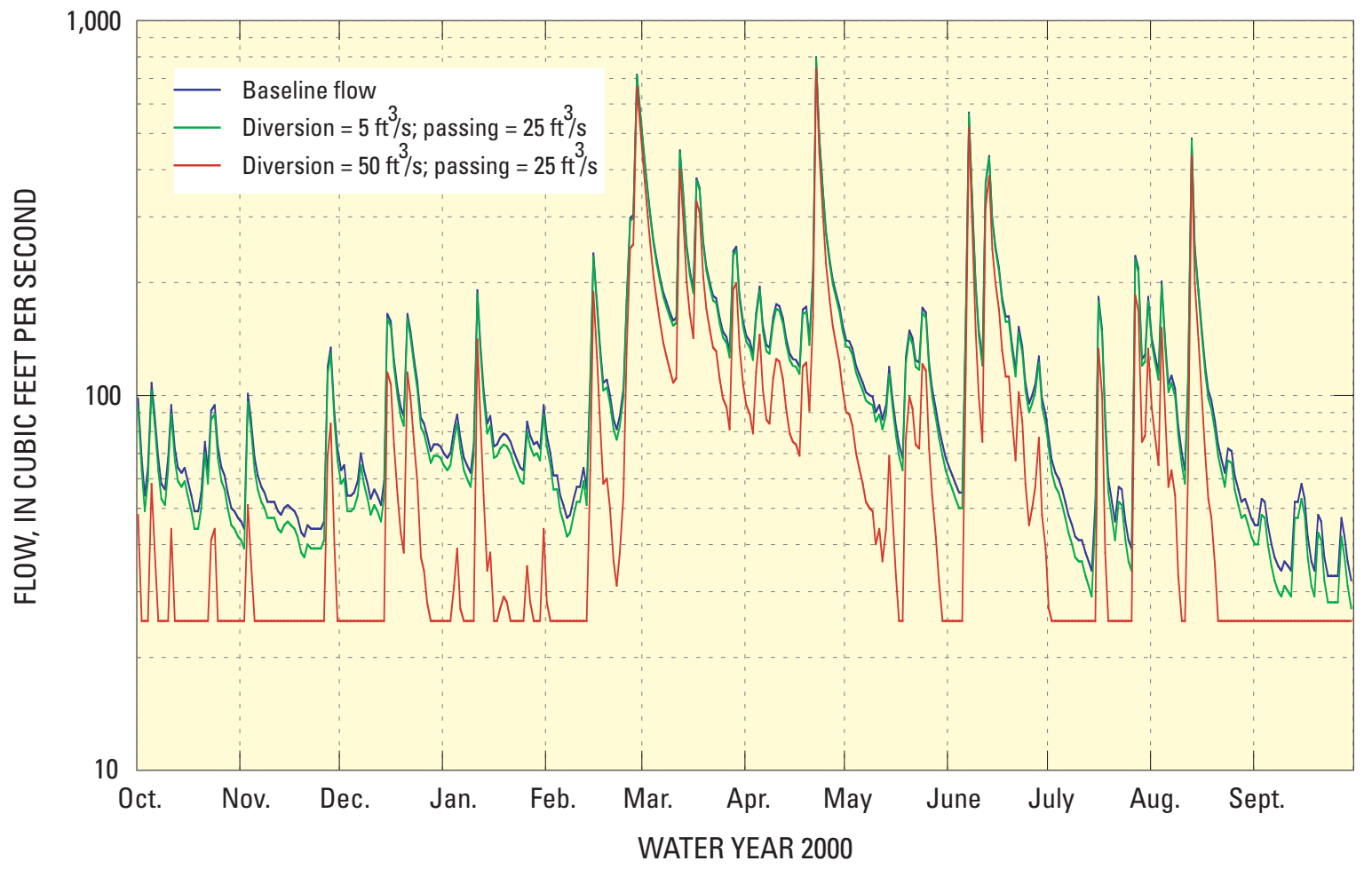

Figure 14. Hydrograph showing two diversion scenarios with baseline daily flow conditions for water year 2000. (In this example, 5 and $50 \mathrm{ft}^{3} / \mathrm{s}$ are removed from the stream with an environmental passing flow of $25 \mathrm{ft}^{3} / \mathrm{s}$.) 


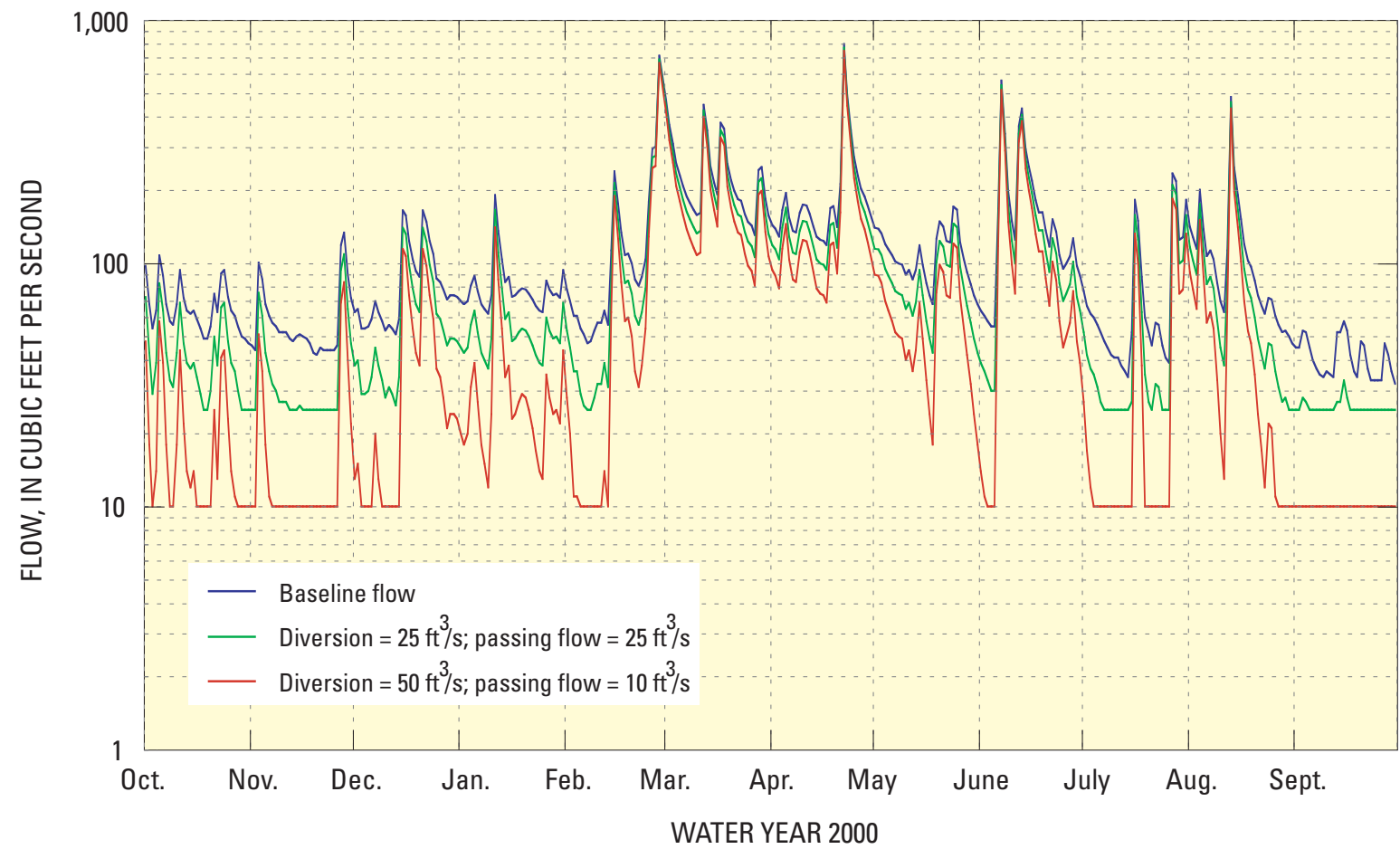

Figure 15. Hydrograph showing two diversion scenarios with baseline daily flow conditions for water year 2000. (In this example, 25 and $50 \mathrm{ft}^{3} / \mathrm{s}$ are removed from the stream with environmental passing flows of 25 and $10 \mathrm{ft}^{3} / \mathrm{s}$, respectively.)

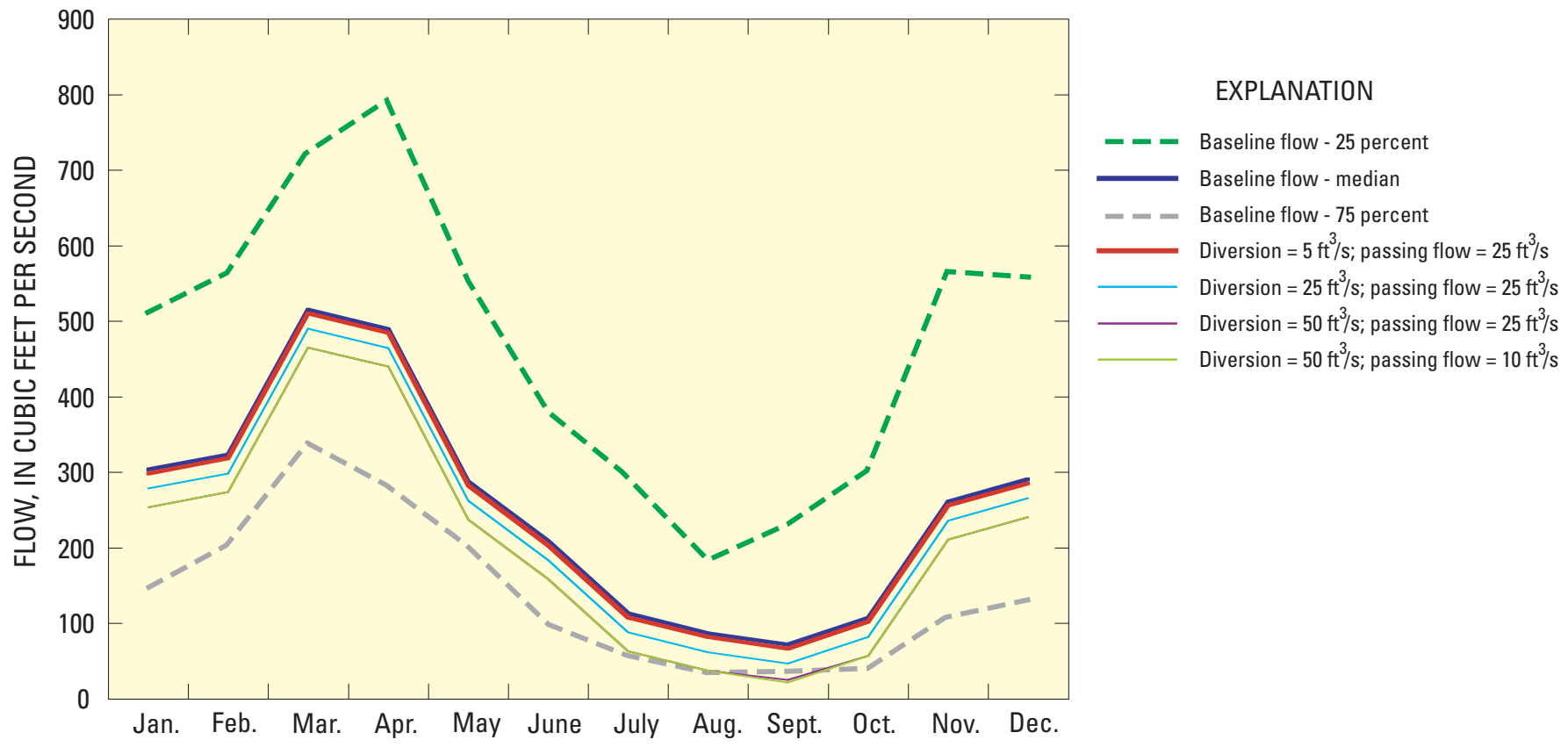

Figure 16. Maximum monthly flows for four flow-diversion scenarios for water years 1924-2003. 


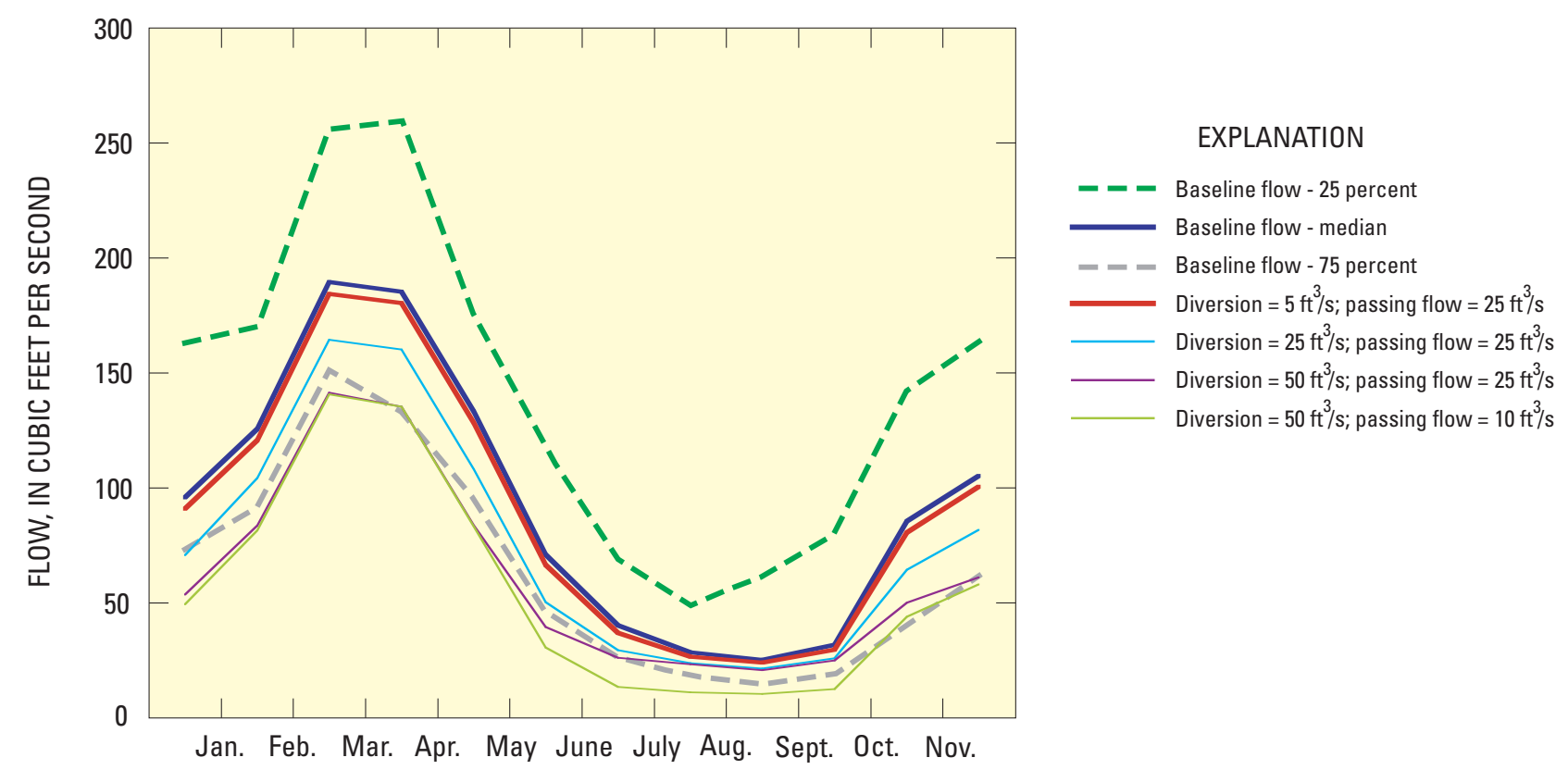

Figure 17. Median monthly flows for four flow-diversion scenarios for water years 1924-2003.

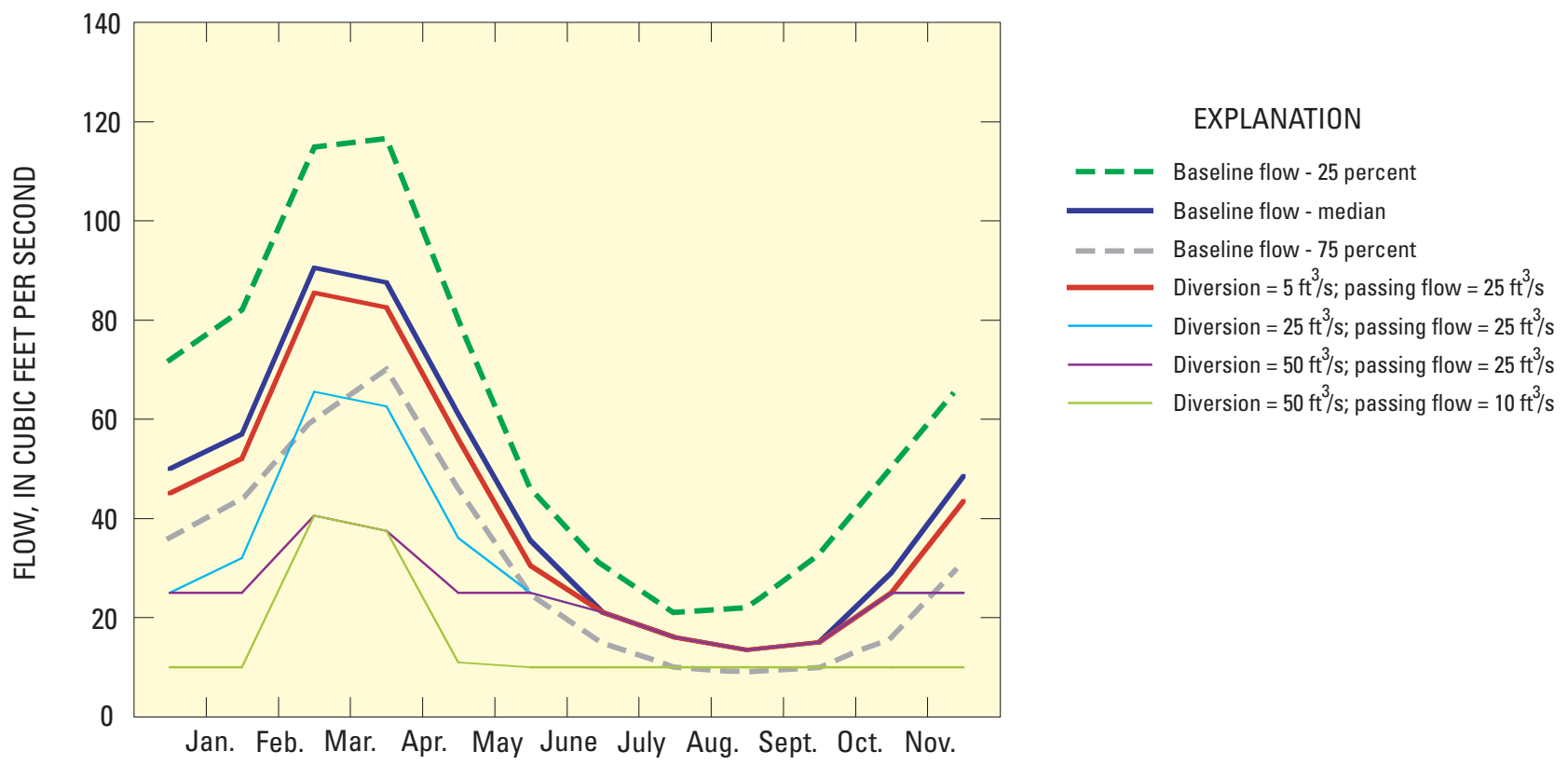

Figure 18. Minimum monthly flows for four flow-diversion scenarios for water years 1924-2003. 
because the range of some indices is based on using a mean or median value for all streams in the stream class (Henriksen and others, 2006); therefore, the calculated values for these two indices for the baseline and for all diversion scenarios appear to fall outside the 25 th to 75 th percentiles. Depending upon the management criteria selected, the $5-\mathrm{ft}^{3} / \mathrm{s}$ diversion could be the only scenario considered to be acceptable because of its minimal alteration of the natural flow regime and assumed concomitant minimal effect on the stream biota. The results for the alternatives with a $25-\mathrm{ft}^{3} / \mathrm{s}$ and $50-\mathrm{ft}^{3} / \mathrm{s}$ diversion and a $25-\mathrm{ft}^{3} / \mathrm{s}$ environmental flow did not meet the criteria necessary to have no minimal effect on the flow regime, as the FH4 value is clearly outside the 25 th- to 75 th-percentile range of the baseline (fig. 19). Diversion scenario four $\left(50-\mathrm{ft}^{3} / \mathrm{s}\right.$ diversion and a $10-\mathrm{ft}^{3} / \mathrm{s}$ environmental flow) had the overall greatest impact on the flow regime, as the HRI values MA18, ML6, FL1, FH4, and DL4 all fell outside the 25th- to 75thpercentile range of the baseline (table 5, fig. 19).

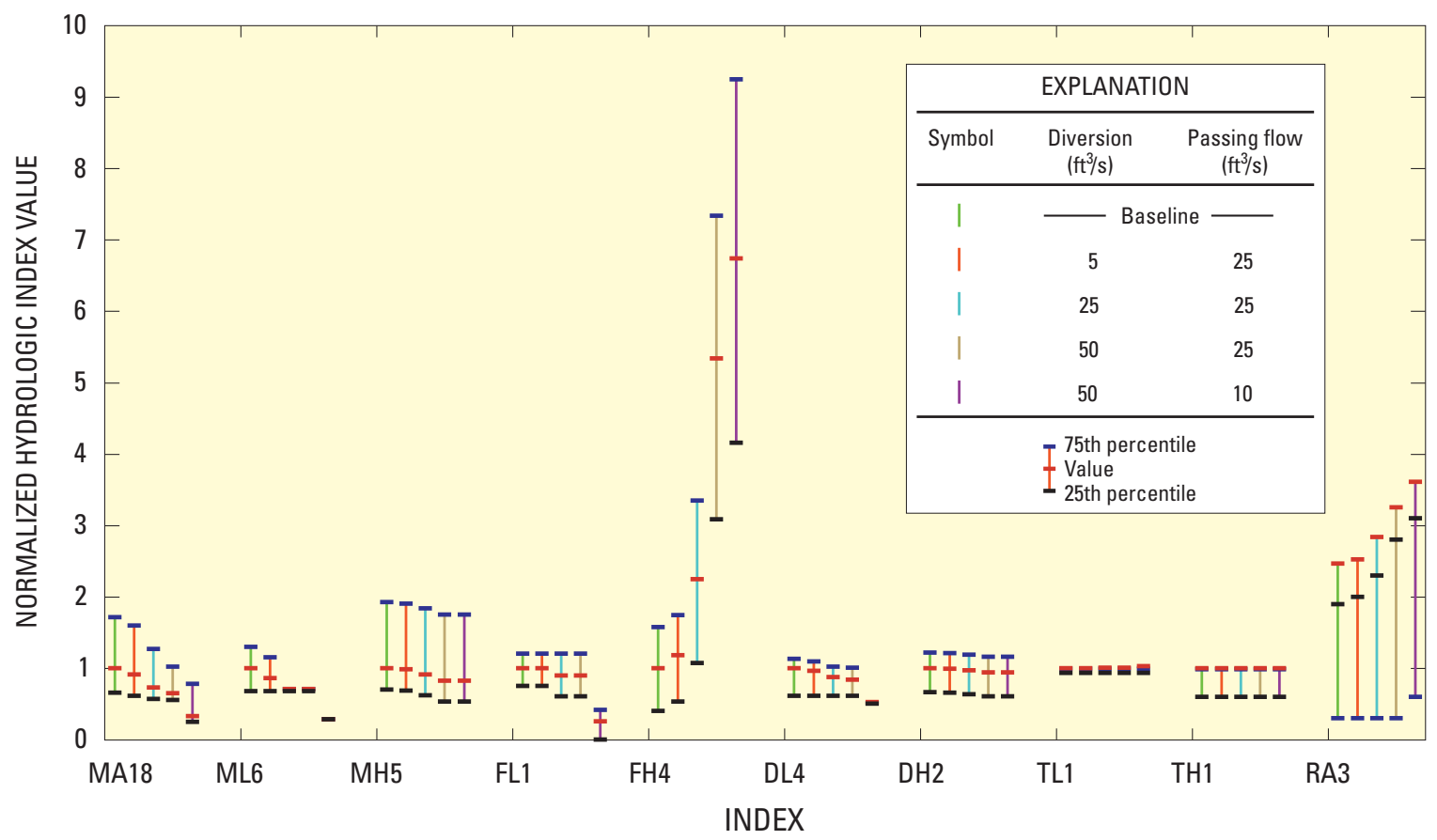

Figure 19. Mean, 25th, and 75th percentiles of 10 principal hydrologic indices for baseline conditions and four streamflow-diversion scenarios. (Indices have been normalized to the baseline indices for easy comparison; $\mathrm{ft}^{3} / \mathrm{s}$, cubic feet per second)

Table 5. Comparison of the 10 principal hydrologic indices for baseline conditions and four water-diversion scenarios.

[Values in bold are those outside the 25 th- to 75 th-percentile range for a given withdrawal scenario; refer to appendix 7 for index definitions; $\mathrm{ft}^{3} / \mathrm{s}$, cubic feet per second]

\begin{tabular}{|c|c|c|c|c|c|c|c|}
\hline \multirow[b]{2}{*}{ Index } & \multicolumn{3}{|c|}{ Baseline } & \multirow{2}{*}{$\begin{array}{c}5-\mathrm{ft}^{3} / \mathrm{s} \text { diversion } \\
25-\mathrm{ft}^{3} / \mathrm{s} \text { passing flow }\end{array}$} & \multirow{2}{*}{$\begin{array}{c}25-\mathrm{ft}^{3} / \mathrm{s} \text { diversion } \\
25-\mathrm{ft}^{3} / \mathrm{s} \text { passing flow }\end{array}$} & \multirow{2}{*}{$\begin{array}{c}50-\mathrm{ft}^{3} / \mathrm{s} \text { diversion } \\
25-\mathrm{ft}^{3} / \mathrm{s} \text { passing flow }\end{array}$} & \multirow{2}{*}{$\begin{array}{c}50-\mathrm{ft}^{3} / \mathrm{s} \text { diversion } \\
10-\mathrm{ft}^{3} / \mathrm{s} \text { passing flow }\end{array}$} \\
\hline & $25^{\text {th }}$ percentile & Value & $75^{\text {th }}$ percentile & & & & \\
\hline MA18 & 26.21 & 40.145 & 68.855 & 36.742 & 29.226 & 26.048 & 13.274 \\
\hline MH5 & 202.25 & 287.5 & 553 & 282.5 & 262.5 & 237.5 & 237.5 \\
\hline FL1 & 5 & 6 & 8 & 6 & 6 & 6 & 0 \\
\hline DL4 & 12.028 & 16.283 & 22.133 & 16.268 & 16.168 & 16.168 & 10 \\
\hline DH2 & 563.833 & 830.167 & 1035.583 & 825.167 & 805.167 & 780.167 & 780.167 \\
\hline TL1 & 246.837 & 264.792 & 262.492 & 264.792 & 266.588 & 265.863 & 271.866 \\
\hline TH1 & 42.796 & 71.355 & 70.441 & 71.355 & 71.355 & 71.355 & 71.355 \\
\hline
\end{tabular}




\section{Developing Environmental Flow Standards}

Research in the field of environmental flows has resulted in more than 207 methods that have been grouped into four categories: hydrologic rules, hydraulic rating methods, habitat simulation methods, and holistic methodologies (Tharme, 2003). Many of these methods address arbitrary "minimum" flows and are recognized as being inadequate to protect freshwater biodiversity and maintain essential goods and services (Naiman and others, 2002; Postel and Richter, 2003). The HIP is established on the basis of the principles of hydroecology and the natural flow regime paradigm (Poff and others, 1997), and to maintain biodiversity and overall stream integrity, it takes into account natural flow variability. This is achieved by addressing the magnitude, frequency, duration, timing, and rate of change of streamflow. However, translating hydrologicecological principles and knowledge into specific environmental-flow standards remains a challenge (Poff and others, 2003).

Adaptive management is an example of a collaborative approach that has been used to address scientific uncertainties by implementing carefully planned long-term adaptive-management experiments and developing appropriate management actions (for example, Grand Canyon flow release (Rubin and others, 2002); Snowy River flow-restoration program (Pigram, 2000)). In addition, adaptive-management procedures have been successfully used in environmental-flow restoration of impounded rivers with substantial flow control (Richter and others, 2006; The Nature Conservancy, 2007). It is yet to be seen, however, whether adaptive-management processes can be used for management of short-term water-development projects or whether there is enough time in such circumstances to implement strategic, incremental actions to reduce policy uncertainties. Water managers are more commonly faced with a situation in which no additional experimentation is possible (due to funding limitations), because regulatory control of most flow processes except low flow is limited, and, once the proposed water-development project is approved, the possibility of retracting or amending the decision through either incremental revision or stakeholder participation is impractical. Due to the high risk of being unable to restore stream biodiversity and stream integrity once management options are foregone, and because in most situations time is limited, the implementation of scientifically defensible environmentalflow standards could maximize the likelihood of maintaining or restoring stream integrity. Fortunately, a few approaches have been put forth to bridge the gap between simplistic hydrologic low-flow standards and long-term, empirically developed environmental-flow assessments.

As discussed in the "Application of the Hydroecological Integrity Assessment Process" section of this report, the first step for instituting environmental-flow standards is to establish whether the stream reach of interest is in a non-impaired "healthy" or impaired condition. Ideally, stream biotic condition can be evaluated by using long-term biomonitoring or rapid assessment methods that address the status of key aquatic communities, instream habitat, and geomorphological processes. Once established, the management objective would be to protect, maintain, or restore the stream to a desired condition. Accordingly, the manager would use the 10 primary (or secondary) HRIs from the HIP that are associated with a specific stream class. The 10 primary indices, however, may be supplemented or substituted with surrogate hydrologic indices that have been identified and in some cases validated with empirical biological data. For example, Kennen and Ayers (2002) established that hydrologic instability associated with urban development was significantly related to impairment of fish, invertebrate, and algal communities in New Jersey streams across the four stream classes identified in New Jersey. Specifically, the 2-year peak-flow event was identified as accounting for a significant proportion of the variability in aquatic community structure (Kennen and Ayers, 2002). Thus, index FH11 (frequency of high-flow events) could potentially be substituted for one of the 10 evaluation indices for stream classes A and B even though it was not previously listed in NJHAT as a primary or secondary index (table 3 ). Likewise, FH11 is identified as a secondary index for stream classes C and D in NJHAT (table 3) and, therefore, based on empirical results, could justifiably be used to replace the primary indices FH7 and FH3, respectively.

Richter and others (1997) recommend that environmental flow standards address hydrologic variability (using ecologically relevant hydrologic indices) and require that mean or median flow (depending on the index in question) remain within the 25th- to 75th-percentile range for all of the selected "standard" indices. The 25th- to 75th-percentile range is viewed as allowing some management flexibility to accommodate human uses while still maintaining stream biotic integrity. A water regulatory agency, however, has the option of using more stringent standards to provide a higher level of protection for streams classified as being of "high value" (for example, streams with threatened or endangered species). For example, a 40th- to 60th-percentile range would be narrower and, therefore, would represent a more restrictive standard. Some HRIs available in NJHAT may have even broader regulatory applicability if the standards take into consideration dry, average, and wet water seasons or years. Hoffman and Rancan (2007) recommend a variety of possible statistics generated by the NJHAT as guidelines for setting passing flows. For example, the statistics associated with MA12-23 (median monthly flow values) provide information on median monthly flows. The 25th-percentile value represents a median flow that occurs in one year out of four. These values could be used to set monthly flow standards. A flow standard based on median monthly flows would be very protective of streamflows and thus require frequent reduction in withdrawals. In contrast, the statistics associated with ML1-12 (monthly low-flow values) provide information on lowest monthly flows in that stream. Using one of these statistics as a standard (for example, the 25th-percentile value of ML1-12) would be less protective of streamflows but would require less frequent 
withdrawal reductions. The NJHAT provides for novel and innovative approaches to selecting alternative indices (beyond the 10 primary indices identified in NJHAT) that allow water managers to apply meaningful regulatory standards that take into consideration inherent natural hydrologic variability. This application requires, however, that the water managers analyze tradeoffs between reliability of the stream as a water source and protection of streamflows.

Recently, a holistic flow-management approach that incorporates essential aspects of the natural flow variability shared among stream classes was published by Arthington and others (2006). This approach can be used to validate thresholds for individual ecologically relevant hydrologic indices using empirical biological data from natural or "reference" streams and flow-altered streams. Flow-ecological response relations are developed for each ecological index across the gradient of reference flow regimes to modified flow regimes for each streamflow variable and stream class. The HIP approach described in this report is based on the identification of specific stream classes in New Jersey and is highly consistent with the recommendations proposed by Arthington and others (2006) for classifying streams based on key attributes of flow variability. The HIP approach attempts to balance the need for managing streams based on the unique hydrologic variability of specific stream classes and on generalized ecological attributes (described herein as stream-class-specific HRIs). Arthington and others (2006) describe a series of steps for characterizing streams and provide two critical "risk levels" or "benchmarks" that can be used to establish or guide the setting of environmental flow standards. This approach shows much promise in (1) validating the indices used to assess hydrologic alteration, and (2) refining the threshold and benchmark (risk-level) standard.

\section{Summary and Conclusions}

This report documents the development of the Hydroecological Integrity Assessment Process (HIP), which includes a hydroecological classification of streams in New Jersey and the development of three software tools: the Hydrologic Indices Tool (HIT), for calculating 171 hydroecologically relevant indices (HRIs) to aid in stream classification; the New Jersey Stream Classification Tool (NJSCT), for classifying unclassified streams; and the New Jersey Hydrologic Assessment Tool (NJHAT) for evaluating baseline (reference) periods, conducting hydrologic-alteration analyses, evaluating past and proposed hydrologic modifications of streams, and establishing environmental-flow standards. The HIP was specifically designed to assist state and watershed resource planners in making sound and scientifically defensibly management decisions by providing reference points that can be used as a basis for comparing pre- and post-watershed conditions or evaluating the effects of planned water-development projects.
Two hypothetical examples taken from USGS streamgaging stations located in New Jersey are presented to highlight some of the basic functions and flexibility of the HIP: (1) an analysis that characterizes the hydrologic changes that have occurred in a watershed over a 40-year period after implementation of a regional wastewater facility; and (2) an analysis based on a proposed water diversion from a relatively unaltered stream. In the latter example, the amount of the diversion and the required environmental flow were varied to determine the amount of water that hypothetically could be diverted without violating the 25th- and 75th-percentile range standard applied to the baseline flow indices for a selected stream class. The HIP methodology is robust and can be applied in any state, region, or province where improved flow-based management processes are needed; however, this methodology relies on a hydroecological stratification of stream classes and the recognition that hydrology is the "master variable" that directly and (or) indirectly affects the distribution and abundance of riverine species.

\section{Acknowledgments}

The authors thank Julian Olden and LeRoy Poff for providing the data sets and formulations used to verify index calculations and for the essential role their research played in the development of the software and approach used in the Hydroecological Integrity Assessment Process. Scientific guidance from numerous members of the Technical Advisory Committee, especially Jeffrey Hoffman, Andrew Didun, Robert Kecskes, Marjorie Kaplan, Michelle Putnam, and Kevin Berry of the NJDEP and Robert Schopp of the USGS, was greatly appreciated. Thanks also to Ward Hickman of the USGS for his assistance with the index validation process. The authors thank David Hamilton and Murphy Laubhan of the USGS for their continued support of this project. Ward Hickman and Dale Simmons of the USGS and Jeff Hoffman of the NJDEP provided many helpful suggestions that greatly improved this report.

\section{References Cited}

Annear, T., Chisholm, I., Beecher, H., Locke, A., and 12 other authors, 2004, Instream flows for riverine resources, revised edition: Cheyenne, Wyo., Instream Flow Council, 268 p.

Annear, T., Chisholm, I., Beecher, H., Locke, A., and 12 other authors, 2002, Instream flows for riverine resources: Cheyenne, Wyo., Instream Flow Council, 411 p.

Arthington, A.H., Bunn, S.E., Poff, N.L., and Naiman, R.J., 2006, The challenge of providing environmental flow rules to sustain river ecosystems: Ecological Applications, v. 16, p. 1311-1318. 
Arthington, A.H., King, J.M., O’Keefe, J.H., Bunn, S.E., Day, J.A., Pusey, B.J., Bluhdorn, D.R., and Thame, R., 1991, Development of an holistic approach for assessing environmental flow requirements of riverine ecosystems, in Pigram, J.J., and Hooper B.A., eds., Water allocation for the environment: Proceedings of an international seminar and workshop: University of New England Armidale (Australia), The Centre for Water Policy Research, p. 69-76

Ayers, M.A., Kennen, J.G., and Stackelberg, P.E., 2000, Water quality in the Long Island-New Jersey Coastal drainages, New York and New Jersey, 1996-98: U.S. Geological Survey Water-Resources Circular 1201, 40 p.

Barbour, M.T., Gerritsen, J., Snyder, B.D., and Stribling, J.B., 1999, Rapid bioassessment protocols for use in streams and wadeable rivers: Periphyton, benthic macroinvertebrates and fish (2d ed.): Washington, D.C., U.S. Environmental Protection Agency, Office of Water, EPA 841-B-99-002.

Baron, J.S., Poff, N.L., Angermeier, P.L., Dahm. C.N., Gleick, P.H., Hairston, N.G., Jackson, R.B., Johnston, C.A., Richter, B.D., and Steinman, A.D., 2002, Meeting ecological and societal needs for freshwater: Ecological Applications, v. 12 , p. $1247-1260$.

Bayley, P.B., 1991, The flood-pulse advantage and the restoration of river-floodplain systems: Regulated Rivers Research and Management, v. 6, p. 75-86.

Beecher, H.A., 1990, Standards for instream flow: Rivers, v. 1, p. $97-109$.

Brinson, M.M., Bradshaw, H.D., Holmes, R.N., Elkins, J.B., Jr., 1980, Litterfall, stemflow, and throughfall nutrient fluxes in an alluvial swamp forest: Ecology, v. 61, p. 827-835.

Bunn, S.E., and Arthington, A.H., 2002, Basic principles and ecological consequences of altered flow regimes for aquatic biodiversity: Environmental Management, v. 30, p. 492-507.

Cade, B.S., and Noon, B.R., 2003, A gentle introduction to quantile regression for ecologists: Frontiers in ecology and the environment, v. 1, p. 412-420.

Castleberry, D.T., Cech, J.J., Jr., Erman, D.C., Hankin, D., Healey, M., Kondolf, G.M., Mangel, M., Mohr, M., Moyle, P.B., Nielsen, J., Speed, T.P., and Williams, J.G., 1996. Uncertainty and instream flow standards: Fisheries, v. 21, p. 20-21.

Clarke, K.R., and Gorley, R.N., 2006, PRIMER v6: User Manual/Tutorial: PRIMER-E Ltd., Plymouth, England, 190 p.

Clausen, B., and Biggs, B.J.F., 1997, Relationships between benthic biota and hydrological indices in New Zealand streams: Freshwater Biology, v. 38, p. 327-342.
Collings, M.R., 1974, Generalization of spawning and rearing discharges for several Pacific salmon species in western Washington: U.S. Geological Survey Open-File Report, $39 \mathrm{p}$.

Colwell, R.K., 1974, Predictability, constancy, and contingency of periodic phenomena: Ecology, v. 55, p. $1148-1153$.

Denslinger, T.L., Gast, W.A., Hauenstein, J.J., Heicher, D.W., Henriksen, J.A., Jackson, D.R., Lazorchick, G.I., McSparran, J.E., Stoe, T.W., and Young, L.M., 1998, Instream flow studies, Pennsylvania and Maryland: Susquehanna River Basin Commission Publication 191, 295 p.

Digby, P.G.N., and Kempton, R.A., 1987, Multivariate analysis of ecological communities: New York, Chapman and Hall, 206 p.

Gosselink, J.G., and Turner, R.E., 1978, The role of hydrology in fresh water wetland systems, in Good, R.E., Whigham, D.F., Simpson, R.L., and Jackson, C.G., Jr., eds., Freshwater wetlands, ecological processes and management potential: New York, Academic Press, p. 63-67

Frissell, C.A., Liss, W.J., Warren, C.E., and Hurley, M.D., 1986, A hierarchical framework for stream habitat classification: Viewing streams in a watershed context: Environmental Management, v. 10, p. 199-214.

Henriksen, J.A., Heasley, J., Kennen, J.G., and Nieswand, S., 2006, Users' manual for the Hydroecological Integrity Assessment Process software (including the New Jersey Assessment Tools): U.S. Geological Survey Open-File Report 2006-1093, 71 p., online at http://www.fort.usgs.gov/ products/publications/21598/21598.pdf

Hill, M.T., Platts, W.S., Beschta, R.L., 1991, Ecological and geomorphological concepts for instream and out-of-channel flow requirements: Rivers, v. 2, p. 198-210.

Hoffman, J.L., and Rancan, H.L.L., 2007, The Hydroecological Integrity Assessment Process in New Jersey and its potential application in water-supply management: Trenton, N.J., New Jersey Department of Environmental Protection, New Jersey Geological Survey, A Sub-Task of the NJ 2006 Water-Supply Plan, 57 p.

Ibarra, M., and Stewart, D.J., 1989, Longitudinal zonation of sandy beach fishes in the Napo River Basin, eastern Ecuador: Copeia, v. 1989, no. 2, p. 364-381.

Interagency Advisory Committee on Water Data, 1981, Guidelines for determining flood flow frequency: U.S. Geological Survey, Office of Water Data Coordination, Bulletin \#17B of the Hydrology Subcommittee, revised September 1981.

Jackson, D., 1993, Stopping rules in principal components analysis: A comparison of heuristical and statistical approaches: Ecology, v. 74, p. 2204-2214. 
Johnson, W.C., Burgess, R.L., Keammerer, W.R., 1976, Forest overstory vegetation and environment on the Missouri River floodplain in North Dakota: Ecological Monographs, v. 46, p. 59-84.

Junk, W. J., Bayley, P.B., and Sparks, R.E., 1989, The flood pulse concept in river-floodplain systems, in Dodge, D.P., ed., Proceedings of the International Large River Symposium, Honey Harbour, Ontario, Canadian Special Publication of Fisheries and Aquatic Sciences 106, p. 110-127.

Kennen, J.G., and Ayers, M.A., 2002, Relation of environmental characteristics to the composition of aquatic assemblages along a gradient of urban land use in New Jersey, 1996-98: U.S. Geological Survey Water-Resources Investigations Report 02-4069, 77 p.

Kennen, J.G., Kauffman, L.J., Ayers, M.A., and Wolock, D.M., in press, Use of an integrated flow modeling approach to estimate ecologically relevant hydrological characteristics at biomonitoring sites in New Jersey: Ecological Modeling.

Lang, V., 1999, Questions and answers on the New England flow policy: Concord, N.H., U.S. Fish and Wildlife Service, 20 p.

Larsen, H.N., 1981, Interim regional policy for New England stream flow recommendations: Boston, Mass., U.S. Fish and Wildlife Service, Region 5, 3 p.

Legendre, P., and Legendre, L., 1998, Numerical ecology (2d English ed.): Amsterdam, The Netherlands, Elsevier Science, $853 \mathrm{p}$.

Lytle, D.H., and Poff, N.L., 2004, Adaptation to natural flow regimes: Trends in Ecology and Evolution, v. 19, p. 94-100.

Manly, B.F.J., 1994, Multivariate statistical methods: A primer (2d ed.): London, Chapman and Hall, 215 p.

McCune, B., and Grace, J.B., 2002, Analysis of ecological communities: Gleneden Beach, Ore., MjM Software Design, 300 p.

McCune, B., and Medford, M. J., 1999, PC-ORD-Multivariate analysis of ecological data Version 4.25: Gleneden Beach, Ore., MjM Software Design.

Monk, W.A., Wood, P.J., Hannah, D.M., Wilson, D.A., Extence, C.A., and Chadd, R.P., 2006, Flow variability and macroinvertebrate community response within riverine systems: River Research and Applications, v. 22, p. 595-615.

Naiman, R.J., Bunn, S.E., Nilsson, C., Petts, G.E., Pinay, G., and Thompson, L.C., 2002, Legitimizing fluvial ecosystems as users of water: An overview: Environmental Management, v. 30, p. 455-467.
Odum, H.T., 1984, Energy analysis of the environmental role in agriculture, in Stanhill, B., ed., Energy and agriculture: Berlin, Springer-Verlag, p. 24-51.

Olden, J.D., and Poff, N.L., 2003, Redundancy and the choice of hydrologic indices for characterizing streamflow regimes: River Research and Applications, v. 19 , p. 101-121.

Pickett, S.T.A., and White, P., eds., 1985, The ecology of natural disturbance and patch dynamics: Orlando, Fla., Academic Press, 472 p.

Pigram, J. J., 2000, Viewpoint-Options for rehabilitation of Australia's Snowy River: An economic perspective: Regulated Rivers, Research and Management, v. 16, p. 363-373.

Poff, N.L., 1996, A hydrogeography of unregulated streams in the United States and an examination of scale-dependence in some hydrological descriptors: Freshwater Biology, v. 36, p. 71-91.

Poff, N.L., Allan, J.D., Bain, M.B., Karr, J.R., Prestegaard, K.L., Richter, B.D., Sparks, R.E., and Stromberg, J.C., 1997, The natural flow regime-A paradigm for conservation and restoration of river ecosystems: BioScience, v. 47, p. 769-784.

Poff, N.L., Allan, J.D., Palmer, M.A., Hart, D.D., Richter, B.D., Arthington, A.H., Rogers K.H., Meyers, J.L., and Stanford, J.A., 2003, River flows and water wars: Emerging science for environmental decision making: Frontiers in Ecology and the Environment, v. 1, p. 298-306.

Poff, N.L., and Allan, J.D., 1995, Functional organization of stream fish assemblages in relation to hydrologic variability: Ecology, v. 76, p. 606-627.

Poff, N.L., and Ward, J.V., 1989, Implications of streamflow variability and predictability for lotic community structure A regional analysis of streamflow patterns: Canadian Journal of Fisheries and Aquatic Sciences, v. 46, p. 1805-1818.

Postel, S., and Richter, B.D., 2003, Rivers for life: Managing water for people and nature: Washington, D.C., Island Press, $211 \mathrm{p}$.

Powers, M.E., Sun, A., Parker, M., Dietrich, W.E., and Wootton, J.T., 1995, Hydraulic food-chain models - An approach to the study of food-web dynamics in large rivers: BioScience. v. 45, 159-167.

Resh, V.H., Brown, A.V., Covich, A.P., Gurtz, M.E., Li, H.W., Minshall, G.W., Reice, S.R., Sheldon, A.L., Wallace, J.B., and Wissmar, R.C., 1988, The role of disturbance in stream ecology: Journal of North American Benthological Society, v. 7, p. 433-455. 
Richter, B.D., Baumgartner, J.V., Powell, J., and Braun, D.P., 1996, A method for assessing hydrologic alteration within ecosystems: Conservation Biology, v. 10, p. 1163-1174.

Richter, B.D., Baumgartner, J.V., Wigington, R., and Braun, D.P., 1997, How much water does a river need: Freshwater Biology, v. 37, p. 231-249.

Richter, B.D., Warner, A.T., Meyer, J.L., and Lutz, K., 2006, A collaborative and adaptive process for developing environmental flow recommendations: River Research and Application, v. 22, p. 297-318.

Rubin, D.M., Topping, D.J., Schmidt, J.C., Hazel, J., Kaplinski, M., and Melis, T.S., 2002, Recent sediment studies refute Glen Canyon Dam hypothesis: EOS, Transactions, American Geophysical Union, v. 83, p. 273-278.

Sanborn, S.C., and Bledsoe, B.P., 2006, Predicting streamflow regime metrics for ungaged streams in Colorado, Washington, and Oregon: Journal of Hydrology, v. 325, p. 241-261.

SAS Institute Inc., 1989, SAS/STAT® users guide, version 6, 4th ed., v. 2: Cary, North Carolina, SAS Institute Inc., 943 p.

Seelbach, P.W., and Wiley, M.J., 1997, Overview of the Michigan Rivers Inventory (MRI) project: Ann Arbor, Michigan, Michigan Department of Natural Resources, Fisheries Technical Report 97-3, 31 p.

Sparks, R.E., 1995, Need for ecosystem management of large rivers and their floodplains: BioScience, v. 45, p. 168-182.

Stanford, J.A., Ward, J.V., Liss, W.J., Frissell, C.A., Williams, R.N., Lichatowich, J.A., and Coutant, C.C., 1996, A general protocol for restoration of regulated rivers: Regulated Rivers: Research and Management, v. 12, p. 391-414.

Stuckey, M.H., 2006, Low-flow, base-flow, and mean-flow regression equations for Pennsylvania streams: U.S. Geological Survey Scientific-Investigations Report 2006-5130, $84 \mathrm{p}$.

SYSTAT Software Inc., 2004, SYSTAT, Version 11: Point Richmond, Cal.

Tharme, R.E., 2003, A global perspective on environmental flow assessment: Emerging trends in the development and application of environmental flow methodologies for rivers: River Research and Applications, v. 19, p. 397-442.

The Nature Conservancy, 2006, Indicators of Hydrologic Alteration, Version 7, User's manual: The Nature Conservancy, 69 p., accessed February 13, 2007, at http://www. nature.org/initiatives/freshwater/files/ihav7.pdf

The Nature Conservancy, 2007, Sustainable Rivers Program: accessed February 13, 2007, at http://www.nature.org/ success/dams.html
Toth, L.A., 1995, Principles and guidelines for restoration of river/floodplain ecosystems - Kissimmee River, Florida, in Cairns, J., ed., Rehabilitating damaged ecosystems (2d ed.): Boca Raton, Fla., Lewis Publishers/CRC Press, p. 49-73.

Tyus, H.M., 1990, Effects of altered stream flows on fisheries resources: Fisheries v. 15, p. 18-20.

Vannote, R.L., Minshall, G.W., Cummins, K.W., Sedell, K.W., Cushing, C.E., 1980, The river continuum concept: Canadian Journal of Fisheries and Aquatic Science, v. 37, p. $130-137$.

Ward, J.V., and Stanford, J.A., 1983, The serial discontinuity concept of lotic ecosystems, in Fontaine, T.D., and Bartell, S.M., eds., Dynamics of lotic ecosystems: Ann Arbor, Mich., Ann Arbor Science, p. 29-42.

Ward, J.V., and Stanford, J.A., 1989, Riverine ecosystems: The influence of man on catchment dynamics and fish ecology: Canadian Special Publication of Fisheries and Aquatic Sciences, v. 106, p. 56-64.

Watson, K.M., Reiser, R.G., Nieswand, S.P., and Schopp, R.D., 2005, Streamflow characteristics and trends in New Jersey, water years 1897-2003: U.S. Geological Survey Scientific Investigations Report 2005-5105, 131 p.

Watt, M.K., 2001, A hydrologic primer for New Jersey watershed management: U.S. Geological Survey WaterResources Investigations Report 00-4140, 116 p., online at http://nj.usgs.gov/publications/WRIR/00-4140/

Wiley, M.J., Seelbach, P.W., and Bowler, S.P., 1998, Ecological targets for rehabilitation of the rouge river: Final report: Ann Arbor, Mich., University of Michigan, School of Natural Resources and Environment, 79 p.

Wolfe, P.E., 1977, The geological landscapes of New Jersey: New York, Crane Russak, 351 p.

Wood, R., 1951, The significance of managed water levels in developing the fisheries of large impoundments: Journal of the Tennessee Academy of Science, v. 26, p. 214-235.

U.S. Census Bureau, 2005, Statistical Abstracts of the United States, Resident Population-States, 1980-2003: accessed July 26, 2005, at http://www.census.gov/prod/www/ statistical-abstract.html 


\section{Appendix 1. Members of the Technical Advisory Committee.}

\begin{tabular}{|c|c|c|}
\hline Name & Agency & Division/Discipline \\
\hline Jeffrey Hoffman (chairperson) & NJDEP & New Jersey Geological Survey \\
\hline Helen Rancan & NJDEP & New Jersey Geological Survey \\
\hline Andrew Didun & NJDEP & Fish and Wildlife \\
\hline Patricia Hamilton & NJDEP & Fish and Wildlife \\
\hline Jeanette Bowers-Altman & NJDEP & Fish and Wildlife \\
\hline Thomas Belton & NJDEP & Science, Research \& Technology \\
\hline Marjorie Kaplan & NJDEP & Science, Research \& Technology \\
\hline Karen Schaffer & NJDEP & Science, Research \& Technology \\
\hline Flavian Stellerine & NJDEP & Water Quality \\
\hline Jan Gheen & NJDEP & Water Supply \\
\hline Michael Bleicher & NJDEP & Water Supply \\
\hline Michelle Putnam & NJDEP & Water Supply \\
\hline Fred Sickels & NJDEP & Water Supply \\
\hline Robert Kecskes & NJDEP & Water Supply \\
\hline Kevin Berry & NJDEP & Watershed Management \\
\hline Thomas Brand & NJDEP & Watershed Management \\
\hline Ambrosia Collier & NJDEP & Watershed Management \\
\hline James Gaffney & NJDEP & Watershed Management \\
\hline Barbara Hirst & NJDEP & Watershed Management \\
\hline Joseph Mattle & NJDEP & Watershed Management \\
\hline Donna Milligan & NJDEP & Watershed Management \\
\hline Harold Nebling & NJDEP & Watershed Management \\
\hline Elizabeth Semple & NJDEP & Watershed Management \\
\hline Steven Nieswand & USGS & Water Resources \\
\hline Jonathan Kennen & USGS & Water Resources \\
\hline Robert Schopp & USGS & Water Resources \\
\hline David Steadfast & USGS & Water Resources \\
\hline Kara Watson & USGS & Water Resources \\
\hline Robert Reiser & USGS & Water Resources \\
\hline Mark Ayers & USGS & Water Resources \\
\hline Steven Tessler & USGS & Water Resources \\
\hline Jacob Gibs & USGS & Water Resources \\
\hline Pierre Lacombe & USGS & Water Resources \\
\hline James Henriksen & USGS & Biological Resources \\
\hline Nicholas Procopio & NJPC & New Jersey Pinelands Commission \\
\hline Robert Zampella & NJPC & New Jersey Pinelands Commission \\
\hline Daniel Van Abs & NJWSA & New Jersey Water Supply Authority \\
\hline Richard Horwitz & ANSP & Academy of Natural Sciences, Philadelphia \\
\hline Camille Finders & ANSP & Academy of Natural Sciences, Philadelphia \\
\hline Leroy Young & PADEP & Fish and Boat Commission \\
\hline
\end{tabular}




\section{Appendix 2. Review of seminal ecological concepts.}

\section{Conceptual models}

The TAC decided to review important stream-ecology concepts that have been presented in the literature over the past 25 years. There was no attempt to identify and review all stream ecological theories and concepts; rather, the review was limited to several well-known and highly regarded concepts with applicability to the current study. This task began with the examination of a series of conceptual models illustrating the generalized view of a stream ecosystem and the many biotic and abiotic factors that influence stream communities and ecological integrity. These conceptual models (for example, figs. 2-1 and 2-2) emphasize the importance of flow regime, and the associated inter- and intra-annual hydrologic variability in influencing distribution, abundance, and diversity of stream communities (stream biotic integrity).
According to these and other conceptual models (figs. 2-1 through 2-6), the structure and function of streams are based on five highly interrelated components: hydrology, geomorphology, biology, water quality, and connectivity. The TAC reviewed five conceptual models of stream biotic integrity:

- River Continuum Concept.

- Intermediate-Disturbance Hypothesis.

- Flood Pulse Concept.

- Hierarchical Framework for Stream Habitat.

- Natural Flow Regime Paradigm.

Each is described briefly below.

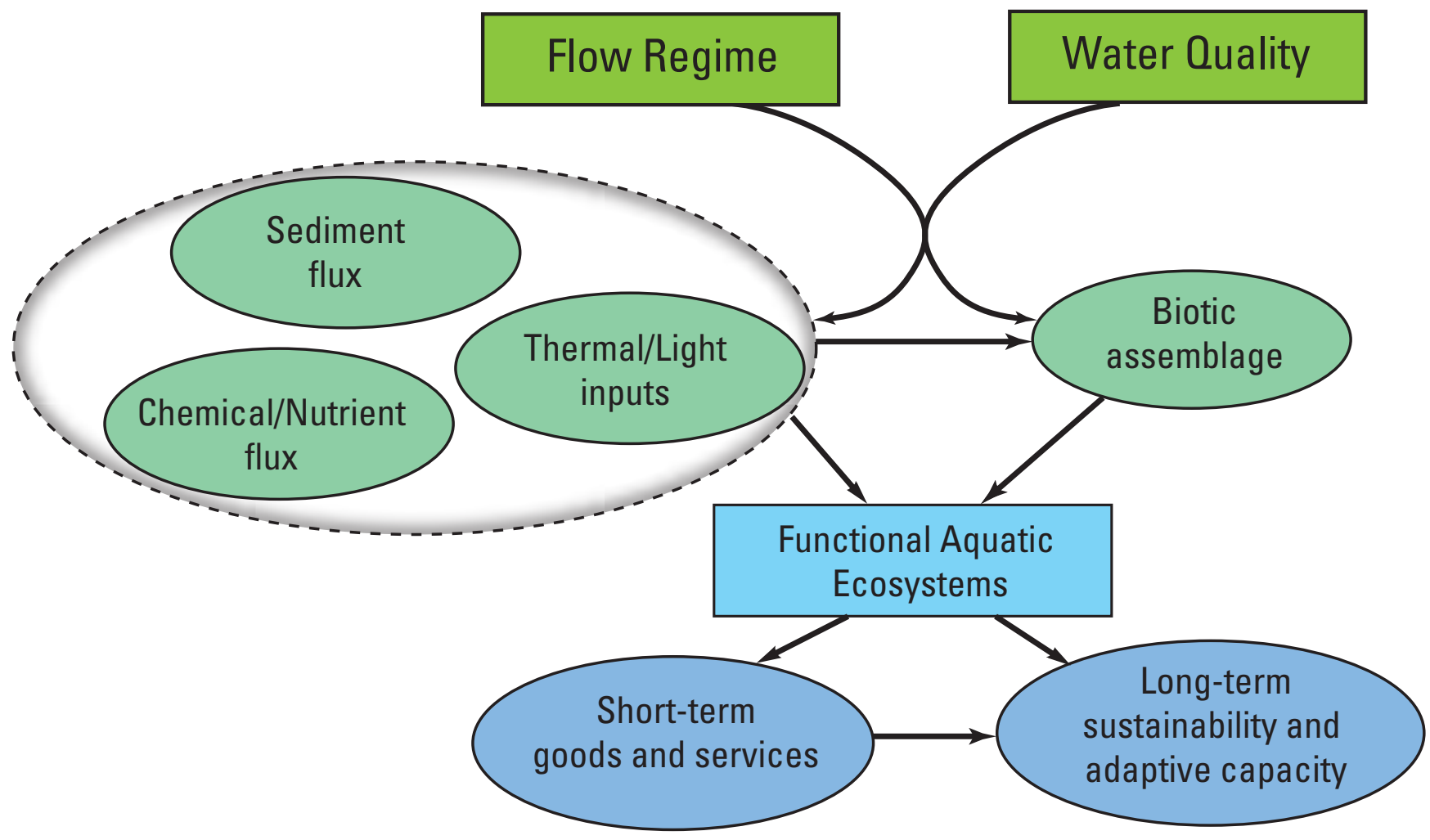

Figure 2-1. Conceptual view of the major interrelated factors that influence the structure and function of freshwater ecosystems. (From Baron and others, 2002) 
The River Continuum Concept (RCC) describes fluvial systems as a continuously integrating series of physical gradients and associated biotic adjustments as a river flows from the headwaters to the mouth (Vannote and others, 1980; fig. 2-3). The physical foundation from which the RCC is derived indicates that the size of the stream and location along the gradient from the headwaters to the mouth influences the type and distribution of the aquatic fauna. It is well established that stream order, discharge, and watershed area are highly correlated. Furthermore, energy inputs along this gradient have profound consequences on the structure and function of the consumer communities, especially those organisms that rely on allochthonous (pertaining to energy sources that were derived from outside the stream - for example, leaves and sticks) and autochthonous (energy sources that are derived from within the lotic system-for example, photosynthesis) inputs and are responsible for processing (breaking down into smaller particles) organic matter in the flowing water along the river continuum. In the context of environmental flows, hydrologic variability and, subsequently, the stream biota are highly dependent on their longitudinal location along the continuum.

One conclusion that can be drawn from the RCC (fig. 2-3) is that as the physical environment and aquatic-community structure and function change from the headwaters (stream orders 1 and 2), to the middle reaches (stream orders 3 through 5), to the lower reaches (stream orders 6 through 10 ), there is a concomitant change in the flow regime. Consequently, quantifying the extent of hydrologic change is important in estimating its effect on the structural and functional integrity of aquatic ecosystems. Therefore, it is necessary to identify which components of the hydrologic regime (for example, magnitude, frequency, duration) are the most influential and what hydrologic measures (statistics and indices) are best suited to evaluate the degree of alteration.

The Intermediate-Disturbance Hypothesis (IDH) predicts that biotic diversity is greatest in communities subjected to moderate levels of disturbance (for example, floods). This hypothesis is consistent with patterns of diversity observed in natural and altered lotic stream ecosystems (Ward and Stanford, 1983; Pickett and White, 1985; Resh and others, 1988). The general view is that diversity is enhanced by the spatial-temporal heterogeneity resulting from the intermediate disturbance, which maintains the communities in a nonequilibrium state. The disturbance can be biotic or abiotic or both, and can fluctuate from severe to moderate to no disturbance. Furthermore, even the sequence of these disturbances influences diversity. Ultimately, community structure is shaped by a myriad of physical, chemical, and biological processes acting synergistically (Ward and Stanford, 1983).

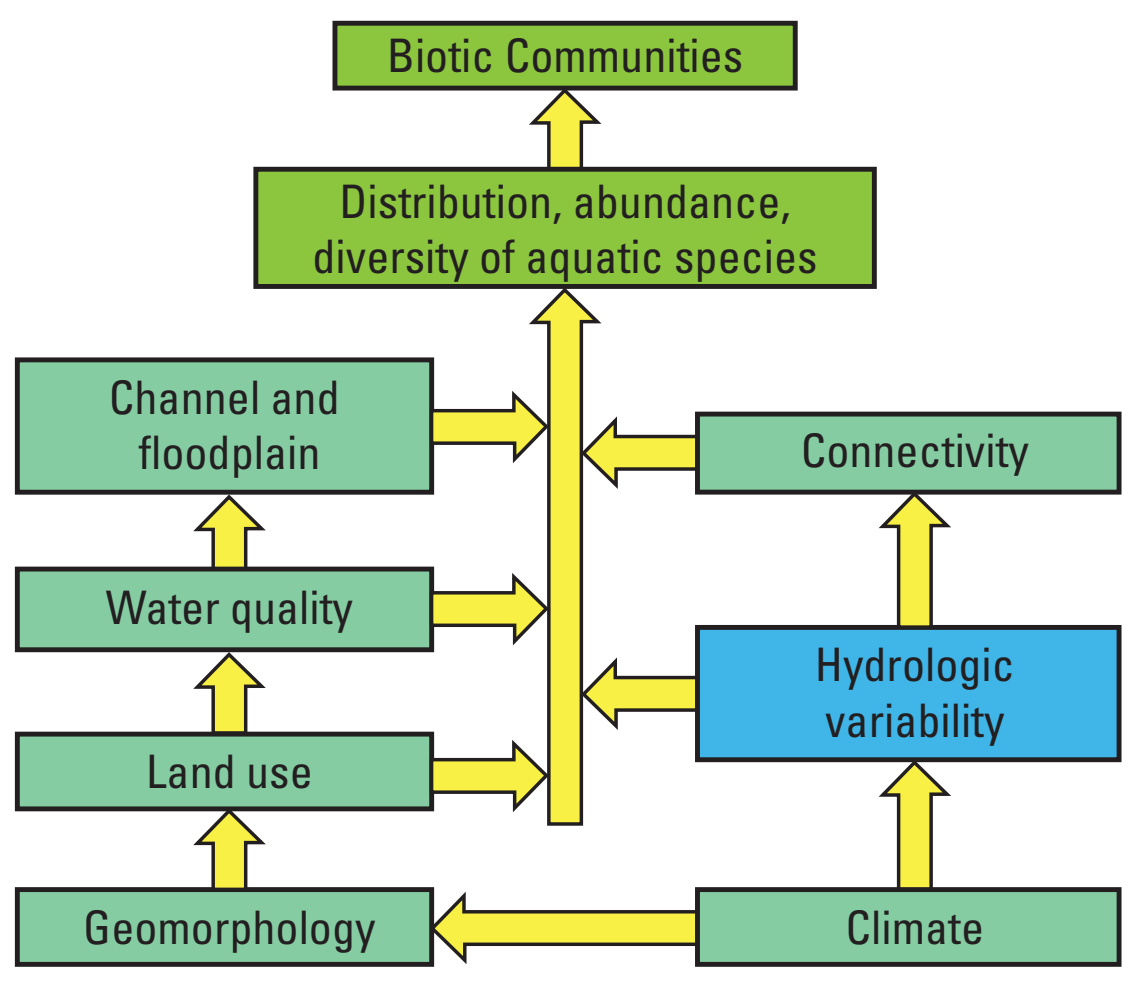

Figure 2-2. Conceptual view of the interrelations between the physical environment and biotic communities. 


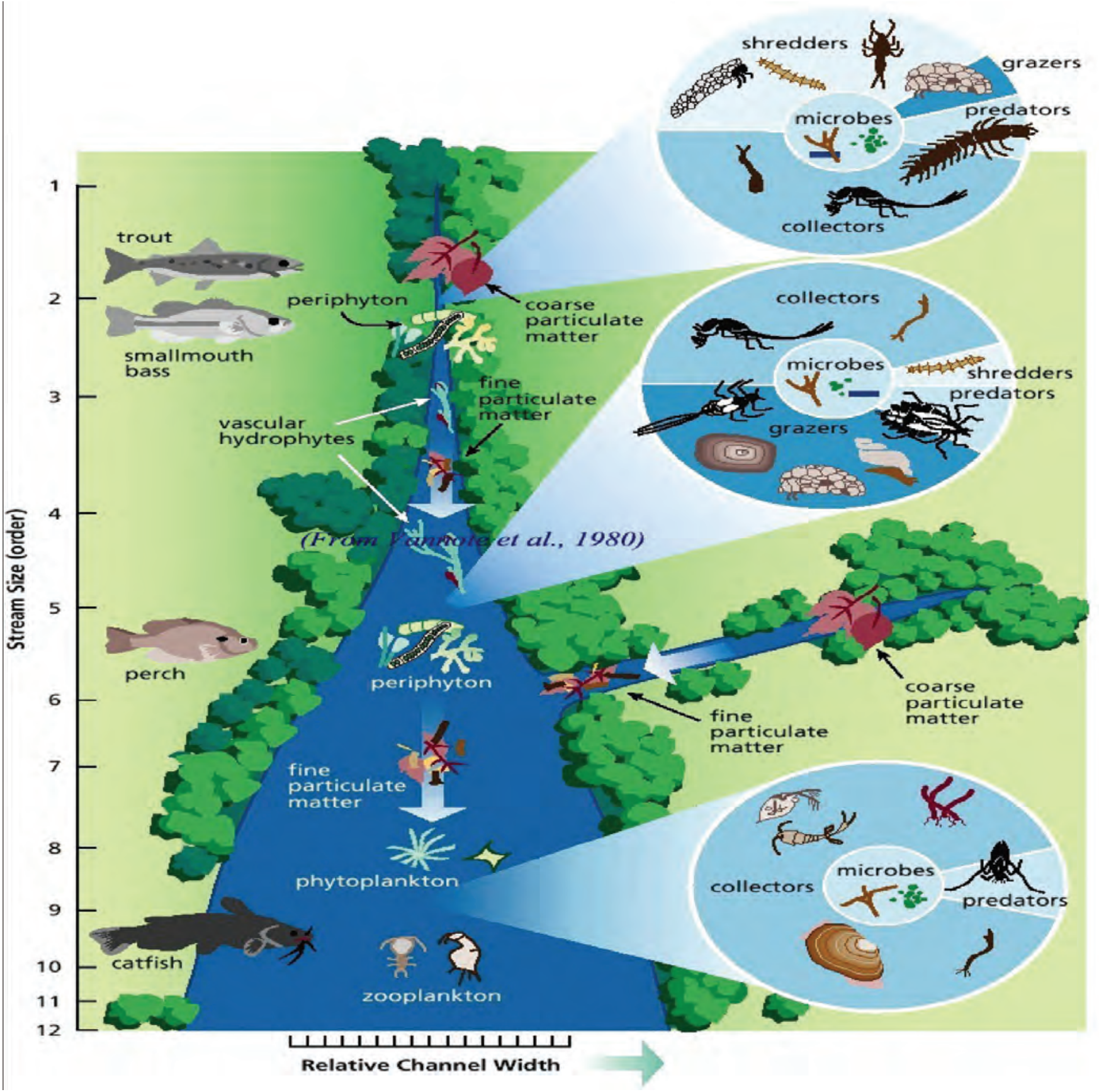

Figure 2-3. Generalized view of the River Continuum Concept. (From Vannote and others, 1980) 
If a moderate level of disturbance is necessary to maintain biodiversity, applying this concept in a way that assists with ecological flow evaluation requires determining what a moderate level of disturbance represents for a stream or class of streams and how it can be measured in terms of magnitude, frequency, and (or) duration of flow events. In addition, one could ask how frequently a moderate-disturbance event occurs, whether the timing of the event is important in terms of life-cycle cues (see Lytle and Poff, 2004), and how such a disturbance affects the life history of longer lived species.

The Flood Pulse Concept (Junk and others, 1989) is further summarized by Bayley (1991). Other authors recognized as contributing to the concept include Brinson and others (1980), Gosselink and Turner (1978), Odum (1984), Ward and Stanford (1989), and Wood (1951). The Flood Pulse Concept recognizes the importance of lateral exchange of water, nutrients, and organisms between the stream channel and the connected floodplain. It focuses on how pulsing hydrology affects the organisms and specific processes in the floodplain. Hydrologic pulsing enhances biological productivity, efficiency of nutrient use, and movement of detritus and sediments, and maintains biodiversity in aquatic systems. Bayley (1991) presents the idea that the flood pulse should not be viewed as a disturbance; rather, only significant departures from the average hydrologic regime, such as the prevention of floods, should be regarded as a disturbance. This perspective is consistent with Ward and Stanford's (1983) suppositions regarding the Intermediate-Disturbance Hypothesis. Most apparent to the TAC, however, was that floods are inextricably part of the natural hydrologic process and are integral to the development of any ecologically based flow method.
The Hierarchical Framework for stream-habitat classification presented by Frissell and others (1986) indicates that structure, operation, and other aspects of the organization and development of stream communities are largely determined by the physical stream habitat, together with the pool of species available for colonization (fig. 2-4). The hierarchical framework itself entails an organized view of the spatial and temporal variation among and within stream systems. Stream systems can be defined as hierarchically organized systems successively related to lower levels - stream segment, reach, pool/riffle, and microhabitat (fig. 2-4).

At each level in the hierarchy, systems can develop and persist predominantly at a specified spatiotemporal scale. According to Frissell and others (1986), "by viewing stream systems as hierarchically organized systems, the framework focuses on a small set of variables at each level that must determine system behaviors within the relevant spatiotemporal frame." This framework represents an integral part of the EFG project because it emphasizes the role of physical processes in determining watershed characteristics at different scales, and how the flow regime determines the relative suitability of habitats for different organisms, which ultimately affects their distribution, abundance, and diversity.

The final concept examined, the Natural Flow Regime Paradigm (Poff and others, 1997), synthesizes existing scientific knowledge to argue that the natural flow regime plays a critical role in sustaining native biodiversity and ecosystem integrity in rivers. Decades of observation of the effects of human alteration of natural flow regimes have resulted in well-established scientific findings indicating that altering the hydrologic regimes in rivers can be ecologically deleterious (for example, Arthington and others, 1991; Castleberry and

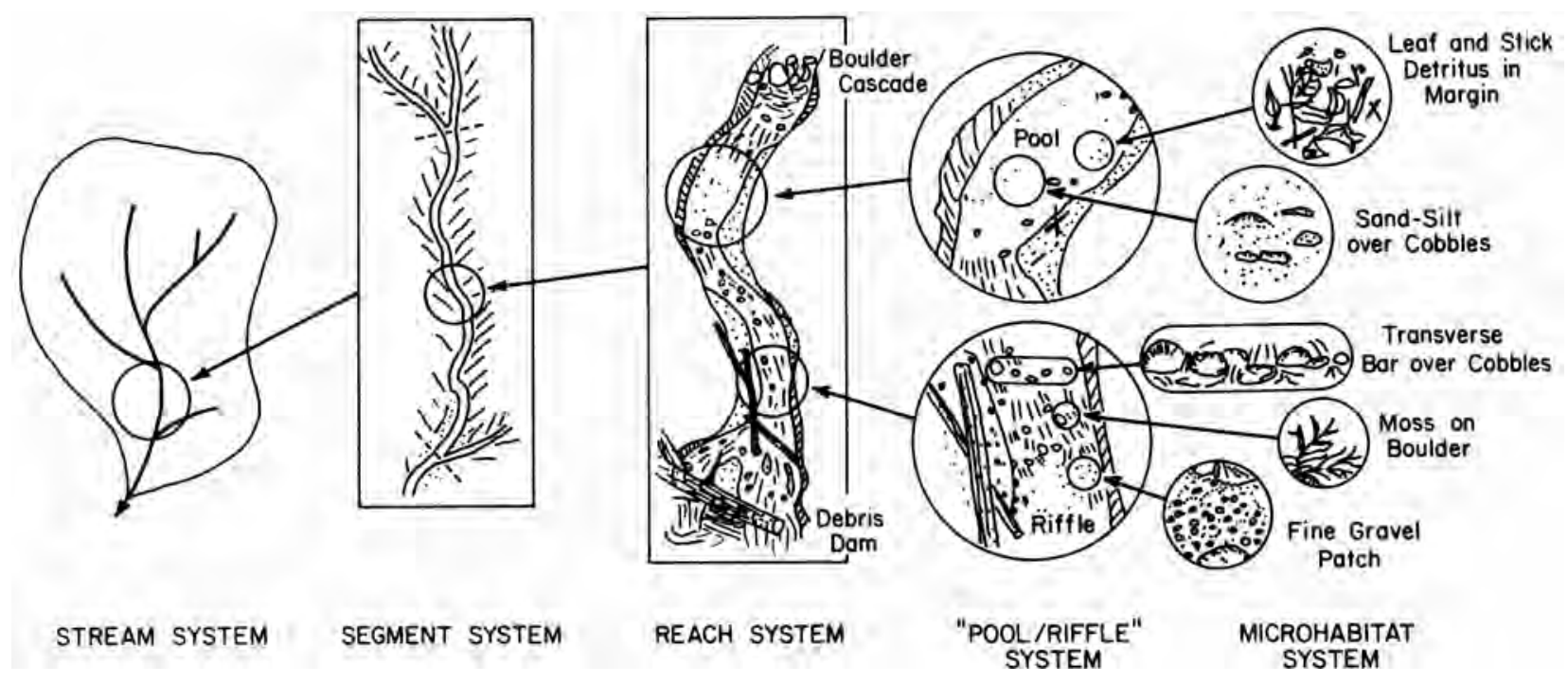

Figure 2-4. Hierarchical organization of a stream system and its habitat subsystem. (From Frissell and others, 1986) 
others, 1996; Hill and others, 1991; Johnson and others, 1976; Richter and others, 1997; Sparks, 1995; Stanford and others, 1996; Toth, 1995; Tyus, 1990). These authors argue that streamflow quantity and timing are critical components affecting the ecological integrity of river systems. Furthermore, streamflow, which is strongly correlated with many critical physiochemical characteristics of rivers, can be considered a "master variable" that limits the distribution and abundance of riverine species (fig. 2-5). In addition, river flow regimes show regional patterns determined by the size of the river and geographic variation in climate, geography, and topography. Thus, all five critical components of the flow regime-magnitude, frequency, duration, timing, and rate of change-must be considered explicitly to characterize the entire range of flows and specific hydrologic phenomena that are critical to maintaining the integrity of river ecosystems. Many studies have documented ecological responses to alterations of the natural flow regime; examples include fish life-cycle disruption, encroachment of vegetation, loss of sensitive invertebrate species, and loss of fish access to backwaters and wetlands (Poff and others, 1997).

The Natural Flow Regime Paradigm approach to flow variability effectively incorporates several concepts that are vital to preserving hydroecological integrity. These concepts are:

- The structure and function of riverine ecosystems varies spatially (longitudinally and laterally) and temporally and is strongly influenced by hydrologic variability in terms of magnitude, frequency, duration, timing, and rate of change.

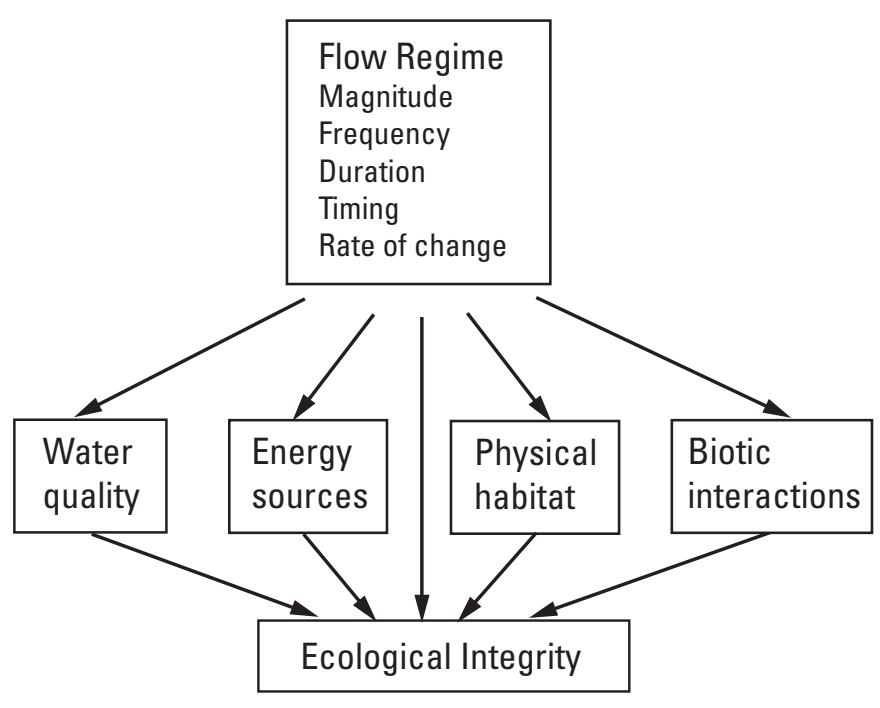

Figure 2-5. Conceptual view of the direct and indirect influence of the five critical components of the flow regime (magnitude, frequency, duration, timing, and rate of change) on the physical environment and biotic communities. (From Poff and others, 1997)
- River ecosystems consist of three templates - physical, chemical, and biological-emphasizing the dynamic spatial and temporal interactions between abiotic and biotic factors.

- Natural flow regimes show regional patterns that represent a gradient of ecological processes that influence the structure and function of the aquatic, plant, and animal communities.

- Magnitude, frequency, duration, timing, and rate of change of flow can be used to characterize streams, the entire range of flows, and the specific hydrologic events critical to maintaining the integrity of river ecosystems.

\section{Critical Hydroecological Research}

Questions that arose as a result of the review of seminal ecological concepts include (1) what specific statistics, indices, and (or) parameters best characterize the hydrologic variability of an unaltered flow regime (that is, what is the natural flow regime)? (2) Alternatively, because streamflow regimes show regional patterns that are determined largely by stream size and variation in climate, geology, topography, vegetation, and land use, which statistics, indices, and (or) parameters best characterize hydrologic variability?

These questions were addressed by detailed examination of several specific studies. According to Poff and Ward (1989), who investigated streamflow variability and community structure at the regional level, patterns of diversity of all major lotic assemblages, including fish, invertebrates, algae, and macrophytes, are related to patterns of temporal variation in flow. Furthermore, a substantial body of evidence (for example, Ward and Stanford (1983)) indicates that high-flow and low-flow disturbances have a central role in structuring stream communities. Different combinations of streamflow variation result in different degrees of physical control over biotic organizations.

Poff and Ward's (1989) research develops an objective and a general quantitative characterization of streamflow variability and predictability. They use 11 summary statistics ( 3 addressing overall flow variability, 6 addressing the pattern of the flood regime, and 2 addressing the degree of flow intermittency) of long-term daily-discharge records from 78 streams across the continental United States to classify streams into nine hydrologically distinct stream types. Thus, the analysis assesses hydrologic similarity among streams using components of the flow regime with ecological significance. They use flow variability, flood patterns, and extent of flow intermittency to develop their conceptual model (fig. 2-6) of stream types. They also recognize that benign or predictable flow environments are more conducive to strong biotic interactions than are unpredictable flow environments. The authors note, however, that in most lotic systems, streamflow regimes 


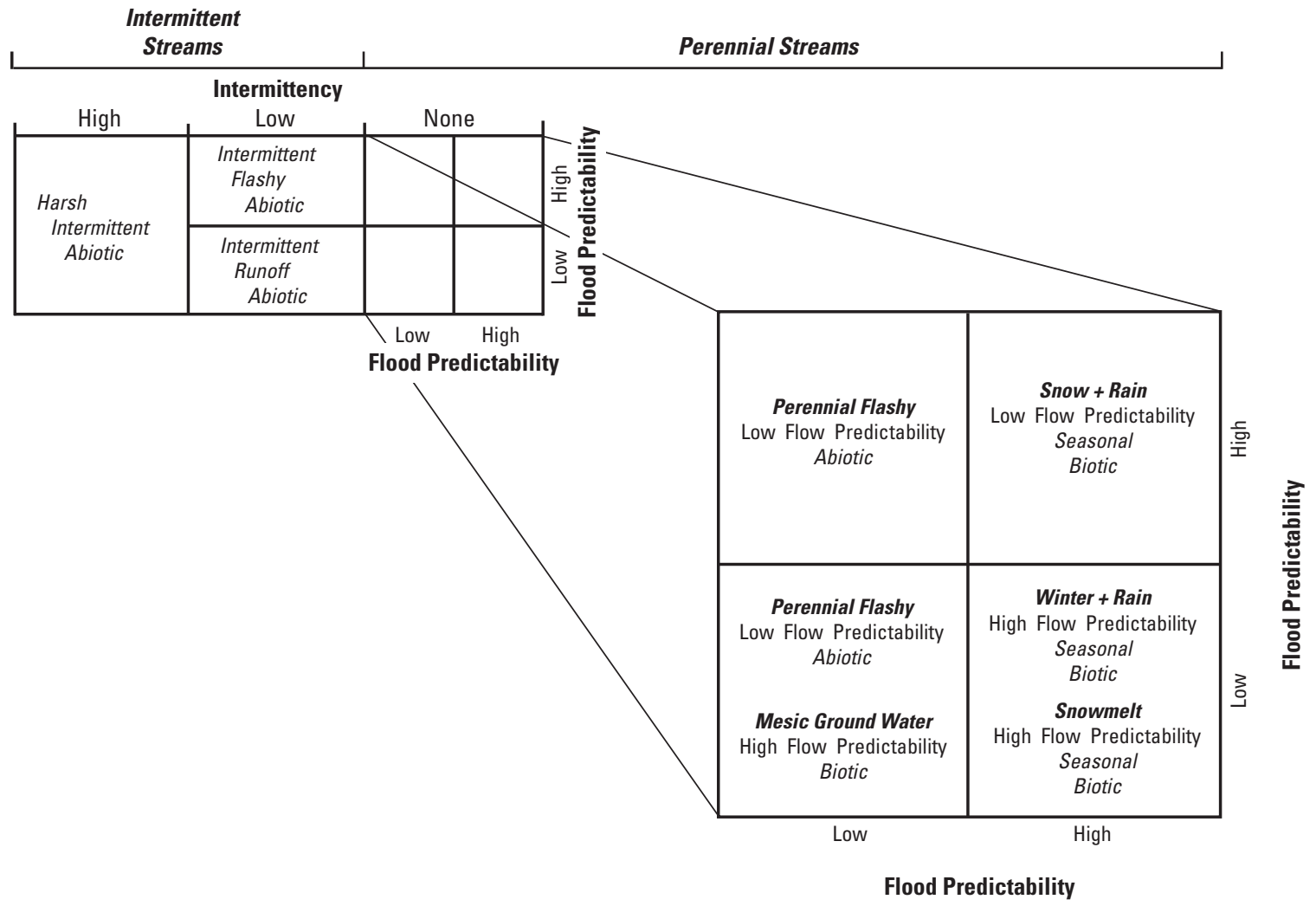

Figure 2-6. Conceptual model of classification of stream clusters based on hierarchical ranking of four temporal components of discharge regime. (From Poff and Ward, 1989)

are intermediate between these extremes and, consequently, abiotic and biotic factors influence community structure at various degrees at various times. They conclude that long-term daily-flow records are valuable sources of information with which to evaluate temporal and spatial patterns of lotic environmental variability and disturbances across physiographic and ecographic regions. Thus, long-term patterns in flow variability need to be evaluated as part of the development of any hydrologically based flow methodology.

Poff (1996) expanded on this research using ecologically relevant hydrologic measures (that is, streamflow indices) to classify streams and examine relations between hydrologic variability and population- and community-level processes and patterns. He used long-term daily- and peak-flow gaging records ( $>36$ years) from 420 relatively undisturbed streams in the conterminous United States to classify streams according to variation in 10 ecologically relevant hydrologic characteristics. Cluster analysis was used to identify 10 distinct stream types which included seven permanent and three intermittent streams. This study established that there are distinct patterns in the hydrological regimes of streams across the United States based on geographic distribution that can be used to identify similar streams for the purpose of broad-scale, comparative ecological research.

Poff and Ward (1989) selected 11 ecologically relevant flow measures to characterize flow variability, flow predictability, flood-regime patterns, and degree of intermittency. The classification analysis $(n=78)$ identified nine stream types. Poff (1996) selected 10 ecologically relevant hydrologic indices to classify streams, only 5 of which differed from those of Poff and Ward (1989). This classification $(n=420)$, however, resulted in the identification of 10 distinct stream types. Many studies have used pre-selected hydrologic variables and flow data from either unclassified or classified streams to seek out biological relations. For example, Clausen and Biggs (1997) selected 34 hydrologic variables and biological data from 83 New Zealand streams. Four of the 34 hydrologic variables were significantly correlated with periphyton biomass, whereas 24 were correlated with periphyton diversity. In contrast, 24 of the hydrologic variables were correlated with total invertebrate density, whereas only 4 were correlated with diversity. Monk and others (2006) classified 83 river basins 
in England and Wales into five classes using a suite of 201 flow-regime descriptors. They found significant correlations with macroinvertebrate community metrics, primarily with two of the variables associated with magnitude of the flow regime. This relation was consistent for all sites and a subset of the flow-regime classes. Poff and Allan (1995) evaluated fish assemblages and hydrologic data from 34 Wisconsin and Michigan streams. They found strong hydrologic-assemblage relations, which indicated that hydrologic factors significantly affect fish assemblage structure.

These examples illustrate many of the issues facing managers attempting to maintain or restore stream integrity through flow management. Hydroecological studies such as those discussed above indicate that flow managers need to be able to account for the connection between hydrologic variability and aquatic-community structure for the three ecosystem templates (physical, chemical, and biological), while simultaneously addressing the dynamic spatial and temporal interactions known to occur between abiotic and biotic factors. It is questionable whether this is actually an attainable goal. Poff (Colorado State University, oral commun., 2006) also recognizes that species have differing, and commonly opposing, environmental requirements. Therefore, it may not be possible to determine a single environmental optimum for all individual species or a community. In addition, the sequence of inter- and intra-annual hydrologic events influences the significance of these relations. Consequently, fluctuations between favorable and unfavorable environmental conditions (that is, hydrologic variability) though space and time are required to sustain the ecological integrity of a stream ecosystem.

In the third study examined, Olden and Poff (2003) recognized that the overarching goal of streamflow characterization and classification is to select hydrologic indices that account for characteristics of streamflow variability that are "biologically relevant." Researchers, however, have used many different ways to characterize streamflow, generally taking a multivariable approach. Moreover, "the use of single indices has been criticized as being overly simplified and lacking biological relevance, and that stream ecologists must now choose from an excess of available hydrologic indices many of which are intercorrelated" (Olden and Poff, 2003).
One of Olden and Poff's (2003) primary goals was to address the question: "Which minimum subset of available hydrologic indices is required to adequately describe the main aspects of the flow regime?" The authors addressed this question by (1) reclassifying the same 420 stream gages ( $>20$ years, unregulated, flow records) analyzed in the Poff (1996) study by using 171 published hydrologic indices that were found to be biologically relevant. This reclassification identified 6 distinctive stream types; identified patterns of redundancy among hydrologic indices; and provided a number of statistically and ecologically based recommendations for the selection of a reduced set of indices that adequately represent all five critical elements of the flow regime (magnitude, frequency, duration, timing, and rate of change) by stream type. Olden and Poff (2003) state that their research provides a statistically based framework that can guide researchers in the selection of non-redundant hydrologic indices that fully characterize the flow regime. Thus, one can reduce the population of indices to a minimal set that incorporates all critical components of the flow regime (for example, app. 6) for all 6 stream types. Appendix 6 represents the quantification of the "natural flow regime," defined in Poff and others (1997) as follows: "A number of ecologically important streamflow characteristics constitute the natural flow regime, including the seasonal patterning of flows; timing of extreme flows; the frequency, predictability, and duration of floods, droughts, and intermittent flows; daily and seasonal, and annual flow variability; and rates of change. These hydrologic indices must be derived from an adequate period of record. Consequently, if, using biological metrics, a stream reach's integrity is declared to be 'healthy' or 'acceptable' currently, or at some previous point in time, it can be attributed in large part to the preceding historic flow regime."

After thorough review, the TAC concluded that: to address stream integrity, one must recognize the importance of stream ecosystem theory and hydrologic-ecologic principles and streams should be classified, at a minimum, based on ecologically relevant indices that incorporate all dimensions of hydrologic variability including magnitude, frequency, duration, timing, and rate of change. 


\section{Appendix 3. Distinctive characteristics of the four stream classes in New Jersey.}
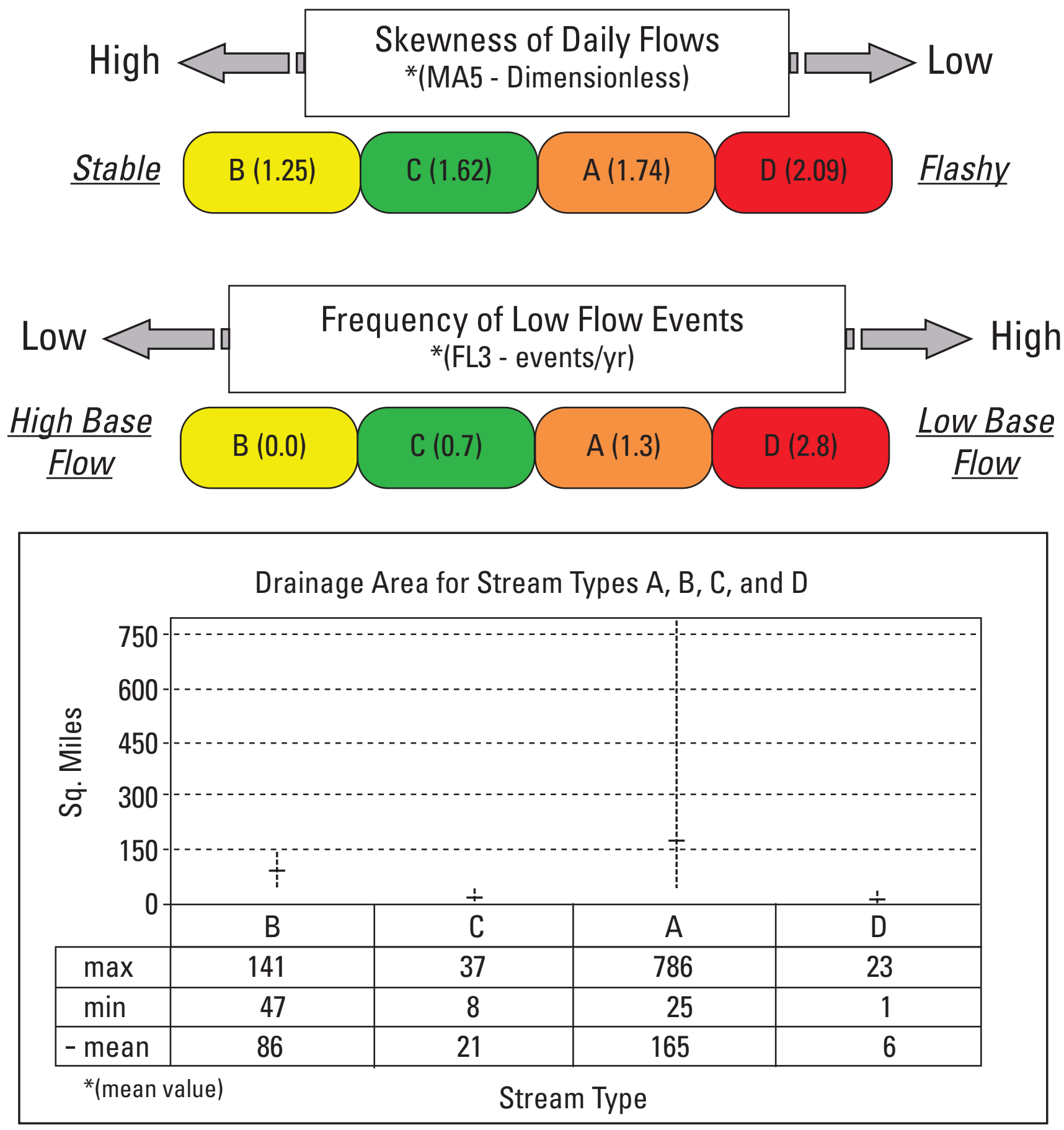


\section{Appendix 4. Stream class and characteristics of gaging stations representing relatively unimpaired basins used to classify New Jersey streams. [Da, drainage area, in square miles]}

\begin{tabular}{|c|c|c|c|c|c|}
\hline Class & Station number & Station name & Da & Record & Years \\
\hline A & 01368000 & Wallkill River near Unionville NY & 140 & $1938-1981$ & 44 \\
\hline A & 01369000 & Pochuck Creek near Pine Island NY & 98 & $1939-1978$ & 39 \\
\hline A & 01379500 & Passaic River near Chatham NJ & 100 & $1938-1960$ & 23 \\
\hline $\mathrm{D}$ & 01379773 & Green Pond Brook at Picatinny Arsenal NJ & 7.65 & $1983-2001$ & 19 \\
\hline A & 01380500 & Rockaway River above Reservoir at Boonton NJ & 116 & $1938-1960$ & 23 \\
\hline $\mathrm{C}$ & 01383500 & Wanaque River at Awosting NJ & 27.1 & $1919-2001$ & 82 \\
\hline A & 01384000 & Wanaque River at Monks NJ & 40.4 & 1935-1985 & 50 \\
\hline $\mathrm{C}$ & 01384500 & Ringwood Creek near Wanaque NJ & 19.1 & $1935-2001$ & 59 \\
\hline $\mathrm{D}$ & 01385000 & Cupsaw Brook Nr Wanaque NJ & 4.37 & $1936-1958$ & 22 \\
\hline $\mathrm{C}$ & 01386000 & West Brook near Wanaque NJ & 11.8 & $1935-1978$ & 43 \\
\hline A & 01387500 & Ramapo River near Mahwah NJ & 120 & $1923-1960$ & 38 \\
\hline A & 01388000 & Ramapo River at Pompton Lakes NJ & 160 & $1922-1950$ & 29 \\
\hline A & 01389500 & Passaic River at Little Falls NJ & 762 & $1898-1927$ & 30 \\
\hline $\mathrm{C}$ & 01390500 & Saddle River at Ridgewood NJ & 21.6 & $1955-1975$ & 20 \\
\hline $\mathrm{C}$ & 01391000 & Hohokus Brook at Ho-Ho-Kus NJ & 16.4 & 1955-1974 & 19 \\
\hline A & 01391500 & Saddle River at Lodi NJ & 54.6 & $1923-1965$ & 43 \\
\hline $\mathrm{D}$ & 01392000 & Weasel Brook at Clifton NJ & 4.45 & $1938-1950$ & 13 \\
\hline $\mathrm{C}$ & 01392210 & Third River at Passaic NJ & 11.8 & 1977-1997 & 21 \\
\hline $\mathrm{C}$ & 01392500 & Second River at Belleville NJ & 11.6 & $1938-1964$ & 28 \\
\hline A & 01396500 & South Branch Raritan River near High Bridge NJ & 65.3 & 1919-2002 & 84 \\
\hline $\mathrm{C}$ & 01398500 & North Branch Raritan River near Far Hills NJ & 26.2 & $1922-1975$ & 54 \\
\hline $\mathrm{D}$ & 01399190 & Lamington (Black) River at Succasunna NJ & 7.37 & $1977-1987$ & 11 \\
\hline $\mathrm{D}$ & 01399200 & Lamington (Black) River near Ironia NJ & 10.9 & $1976-1987$ & 12 \\
\hline $\mathrm{C}$ & 01399500 & Lamington (Black) River near Pottersville NJ & 32.8 & $1922-2001$ & 80 \\
\hline $\mathrm{D}$ & 01399510 & Upper Cold Brook near Pottersville NJ & 2.18 & 1973-1996 & 23 \\
\hline $\mathrm{D}$ & 01399525 & Axle Brook near Pottersville NJ & 1.22 & 1978-1988 & 11 \\
\hline $\mathrm{C}$ & 01399670 & South Branch Rockaway Creek at Whitehouse Station NJ & 12.3 & $1977-2002$ & 25 \\
\hline A & 01400000 & North Branch Raritan River near Raritan NJ & 190 & 1924-1962 & 39 \\
\hline $\mathrm{D}$ & 01400350 & Macs Brook at Somerville NJ & 0.77 & 1983-1995 & 13 \\
\hline A & 01400500 & Raritan River at Manville NJ & 490 & $1922-1963$ & 41 \\
\hline A & 01400730 & Millstone River at Plainsboro NJ & 65.8 & 1964-1975 & 10 \\
\hline A & 01401000 & Stony Brook at Princeton NJ & 44.5 & $1954-2001$ & 48 \\
\hline
\end{tabular}




\begin{tabular}{|c|c|c|c|c|c|}
\hline Class & Station number & Station name & Da & Record & Years \\
\hline A & 01401500 & Millstone River near Kingston NJ & 171 & 1934-1949 & 16 \\
\hline $\mathrm{D}$ & 01401650 & Pike Run at Belle Mead NJ & 5.36 & $1981-2002$ & 21 \\
\hline A & 01403060 & Raritan River Below Calco Dam at Bound Brook NJ & 785 & $1945-1963$ & 18 \\
\hline $\mathrm{D}$ & 01403400 & Green Brook at Seeley Mills NJ & 6.23 & $1980-2001$ & 21 \\
\hline $\mathrm{D}$ & 01403500 & Green Brook at Plainfield NJ & 9.75 & 1939-1984 & 45 \\
\hline $\mathrm{D}$ & 01403540 & Stony Brook at Watchung NJ & 5.51 & $1975-2001$ & 26 \\
\hline A & 01405030 & Lawrence Brook at Weston Mills NJ & 44.9 & 1989-2001 & 13 \\
\hline A & 01405300 & Matchaponix Brook at Spotswood NJ & 43.9 & $1958-1967$ & 10 \\
\hline $\mathrm{D}$ & 01407000 & Matawan Creek at Matawan NJ & 6.11 & 1933-1955 & 22 \\
\hline A & 01408000 & Manasquan River at Squankum NJ & 44 & $1932-1960$ & 29 \\
\hline $\mathrm{D}$ & 01409280 & Westecunk Creek at Stafford Forge NJ & 15.8 & 1974-1988 & 14 \\
\hline $\mathrm{B}$ & 01409400 & Mullica River near Batsto NJ & 46.7 & $1958-2001$ & 43 \\
\hline $\mathrm{B}$ & 01409500 & Batsto River at Batsto NJ & 67.8 & $1940-2001$ & 62 \\
\hline $\mathrm{B}$ & 01409810 & West Branch Wading River near Jenkins NJ & 84.1 & $1975-1996$ & 21 \\
\hline B & 01410000 & Oswego River at Harrisville NJ & 72.5 & $1931-2001$ & 70 \\
\hline $\mathrm{D}$ & 01410150 & East Branch Bass River near New Gretna NJ & 8.11 & 1979-2001 & 22 \\
\hline B & 01411000 & Great Egg Harbor River at Folsom NJ & 57.1 & $1926-1960$ & 35 \\
\hline $\mathrm{C}$ & 01411300 & Tuckahow River at Head Of River NJ & 30.8 & $1971-2001$ & 30 \\
\hline $\mathrm{D}$ & 01411456 & Little Ease Run near Clayton NJ & 9.77 & 1989-2001 & 13 \\
\hline B & 01411500 & Maurice River at Norma NJ & 112 & $1933-2001$ & 68 \\
\hline $\mathrm{C}$ & 01446000 & Beaver Brook near Belvidere NJ & 36.7 & 1923-1961 & 38 \\
\hline $\mathrm{C}$ & 01455200 & Pohatcong Creek at New Village NJ & 33.3 & 1960-1969 & 9 \\
\hline $\mathrm{B}$ & 01456000 & Musconetcong River near Hackettstown NJ & 68.9 & $1922-1973$ & 51 \\
\hline $\mathrm{B}$ & 01457000 & Musconetcong River nears Bloomsbury NJ & 141 & $1922-1960$ & 39 \\
\hline A & 01464000 & Assunpink Creek at Trenton NJ & 90.6 & 1924-1954 & 30 \\
\hline A & 01464500 & Crosswicks Creek at Extonville NJ & 81.5 & $1941-2001$ & 60 \\
\hline B & 01465850 & South Branch Rancocas Creek at Vincentown NJ & 64.5 & $1962-1975$ & 13 \\
\hline $\mathrm{D}$ & 01466000 & Mb Mount Misery Brook In Lebanon State Forest NJ & 2.82 & 1953-1964 & 11 \\
\hline $\mathrm{D}$ & 01466500 & Mcdonalds Branch In Lebanon State Forest NJ & 2.35 & $1954-2001$ & 47 \\
\hline B & 01467000 & North Branch Rancocas Creek at Pemberton NJ & 118 & $1922-2001$ & 79 \\
\hline $\mathrm{C}$ & 01467081 & South Branch Pennsauken Creek at Cherry Hill NJ & 8.98 & $1967-2001$ & 34 \\
\hline $\mathrm{D}$ & 01475000 & Mantua Creek at Pitman NJ & 6.05 & 1942-1976 & 34 \\
\hline
\end{tabular}




\section{Appendix 5. Verification results for the 171 hydrologic indices}

Implementation of mathematical or statistical relations as computer code should be verified as to its proper representation of the relations being computerized. Verification was done for the HIP software (Hydrologic Indices Tool-HIT; New Jersey Hydrologic Assessment Tool-NJHAT; and the National Hydrologic Assessment Tool-NATHAT) by (1) comparing the computer code with the definitions being implemented and (2) comparing the results of applying the same input data set(s) to alternative implementations of the definitions. In this case, inputting the data to alternative, commercially available software - MATLAB, SAS, and EXCEL.

Statistical tests were conducted to verify that the computer code is representative of the formulas being computerized by:

1. Reviewing the computer code and the definitions.

2. Comparing results using the HIP implementation for some indices to results of implementing the index formulation in Microsoft Excel.

3. Comparing the results using the HIP implementation for the remaining indices to results previously generated by Julian D. Olden (Department of Biology, Colorado State University, Fort Collins, Colo.) using MATLAB and SAS.

The criterion for verification was set to a 5-percent difference in index values for the two implementations. For those indices for which the difference was greater than 5 percent, the computer code was again compared to the index definitions. The indices were compared using the formulation:

$$
\text { Absolute percent difference }=\frac{\mid \text { index value }_{\mathrm{HIP}}-\text { index value }_{\mathrm{CAS}} \mid}{\text { average }(\text { index } \mathrm{HIP}, \text { index CAS })_{10}} * 100
$$

where CAS is commercially available software.

Table 5-1 presents the results for the 171 indices. Figure 5-1 shows that there is less than a 5-percent difference for 168 of the indices. For the three remaining indices, subjective adjustment of the index formulation most likely accounted for the larger differences.

Results using the NJHAT implementation for 64 indices were compared with the results of implementing the definitions for those indices using the commercial available software SAS. The index values were calculated using data sets from 19 streamgage sites obtained from the USGS National Water Information System (NWIS) using the formulation:

$$
\text { Percent difference }=\frac{\mid \text { index value }_{\mathrm{NJHAT}}-\text { index value }_{\mathrm{CAS}} \mid}{\text { (index value } \left._{\mathrm{CAS}}\right)} * 100
$$

Table 5-2 lists the indices used and summarizes the results of the comparison. In the initial comparison, the results for four indices were considered problematic. For two indices, FH3 and FH6, the ratios varied from 106 percent to 164 percent for three gage sites. Indices for all other gage sites were within 2 percent. Because NJHAT uses water year (October through September) data and the SAS analysis uses calendar year (January through December) data, the SAS calculations for FH3 and FH6 were recalculated using the water year and the ratios for all stream-gage sites were then within 2 percent. The ratios for ML22 varied from 103 percent to 133 percent, with most values in the 106 percent to 115 percent range. The ratios for DL16 varied from 105 percent to 126 percent, with most being between 110 percent and 126 percent. The definitions for both ML22 and DL16 were checked and the input data reviewed. ML22 was recalculated using the water year and all results were within 2 percent. For DL16, the definition was changed so that the median was used in the calculation rather than the mean. When the ratios were recalculated using the median, 16 of the ratios were within 3 percent; 1 difference was 12.8 percent.

One of the differences between the NJHAT and SAS calculations of the indices was how missing daily streamflow values were handled in the input data. In NJHAT, all available data are used and missing daily values are not used in the calculations. In the SAS calculations, the data for an entire year were not used if there was more than one missing value. This likely explains the small differences between the indices determined using NJHAT and those calculated using SAS.

Because none of the problems in the analysis was associated with the NJHAT software and the issues found using independent calculations of the indices were related to the input data structure, it was concluded that the NJHAT software was performing satisfactorily. 
Table 5-1. Verification results for 171 indices calculated in the Hydrologic Indices Tool.

[USGS, U.S. Geological Survey; CAS, commercially available software; CSU, Colorado State University. Refer to appendix 7 for index definitions]

\begin{tabular}{|c|c|c|c|c|c|}
\hline Index & Verification method ${ }^{1,2,3}$ & $\begin{array}{l}\text { HIT index } \\
\text { value }\end{array}$ & $\begin{array}{c}\text { Verification index } \\
\text { value }\end{array}$ & $\begin{array}{c}\text { Percent } \\
\text { difference }^{4}\end{array}$ & Comments \\
\hline MA1 & USGS-Microsoft Excel (CAS) & 126.29 & 126.29 & 0.00 & \\
\hline MA2 & USGS-Microsoft Excel (CAS) & 126.29 & 126.29 & 0.00 & \\
\hline MA3 & CSU-CAS & 101.70 & 102.20 & 0.12 & \\
\hline MA4 & USGS-Microsoft Excel (CAS) & 15.49 & 15.08 & 0.68 & \\
\hline MA5 & USGS-Microsoft Excel (CAS) & 1.49 & 1.49 & 0.00 & \\
\hline MA6 & CSU-CAS & 7.27 & 7.24 & 0.08 & \\
\hline MA7 & CSU-CAS & 3.87 & 3.87 & 0.00 & \\
\hline MA8 & CSU-CAS & 2.98 & 2.98 & 0.00 & \\
\hline MA9 & CSU-CAS & 0.45 & 0.45 & 0.00 & \\
\hline MA10 & CSU-CAS & 0.30 & 0.30 & 0.00 & \\
\hline MA11 & CSU-CAS & 0.25 & 0.25 & 0.00 & \\
\hline MA12 & USGS-Microsoft Excel (CAS) & 146.52 & 146.52 & 0.00 & \\
\hline MA13 & USGS-Microsoft Excel (CAS) & 167.71 & 167.71 & 0.00 & \\
\hline MA14 & USGS-Microsoft Excel (CAS) & 201.94 & 201.94 & 0.00 & \\
\hline MA15 & USGS-Microsoft Excel (CAS) & 209.95 & 209.95 & 0.00 & \\
\hline MA16 & USGS-Microsoft Excel (CAS) & 147.21 & 147.21 & 0.00 & \\
\hline MA17 & USGS-Microsoft Excel (CAS) & 101.53 & 101.53 & 0.00 & \\
\hline MA18 & USGS-Microsoft Excel (CAS) & 78.39 & 78.39 & 0.00 & \\
\hline MA19 & USGS-Microsoft Excel (CAS) & 73.37 & 73.37 & 0.00 & \\
\hline MA20 & USGS-Microsoft Excel (CAS) & 68.81 & 68.81 & 0.00 & \\
\hline MA21 & USGS-Microsoft Excel (CAS) & 73.25 & 73.25 & 0.00 & \\
\hline MA22 & USGS-Microsoft Excel (CAS) & 106.67 & 106.67 & 0.00 & \\
\hline MA23 & USGS-Microsoft Excel (CAS) & 143.16 & 143.16 & 0.00 & \\
\hline MA24 & USGS-Microsoft Excel (CAS) & 57.23 & 57.23 & 0.00 & \\
\hline MA25 & USGS-Microsoft Excel (CAS) & 71.08 & 71.08 & 0.00 & \\
\hline MA26 & USGS-Microsoft Excel (CAS) & 54.05 & 54.05 & 0.00 & \\
\hline MA27 & USGS-Microsoft Excel (CAS) & 46.48 & 46.48 & 0.00 & \\
\hline MA28 & USGS-Microsoft Excel (CAS) & 51.30 & 51.30 & 0.00 & \\
\hline MA29 & USGS-Microsoft Excel (CAS) & 43.91 & 43.91 & 0.00 & \\
\hline MA30 & USGS-Microsoft Excel (CAS) & 54.06 & 54.06 & 0.00 & \\
\hline MA31 & USGS-Microsoft Excel (CAS) & 60.55 & 60.55 & 0.00 & \\
\hline MA32 & USGS-Microsoft Excel (CAS) & 53.34 & 53.34 & 0.00 & \\
\hline MA33 & USGS-Microsoft Excel (CAS) & 58.13 & 58.13 & 0.00 & \\
\hline MA34 & USGS-Microsoft Excel (CAS) & 64.71 & 64.71 & 0.00 & \\
\hline MA35 & USGS-Microsoft Excel (CAS) & 59.84 & 59.84 & 0.00 & \\
\hline
\end{tabular}


Table 5-1. Verification results for 171 indices calculated in the Hydrologic Indices Tool.—Continued

[USGS, U.S. Geological Survey; CAS, commercially available software; CSU, Colorado State University. Refer to appendix 7 for index definitions]

\begin{tabular}{|c|c|c|c|c|c|}
\hline Index & Verification method ${ }^{1,2,3}$ & $\begin{array}{l}\text { HIT index } \\
\text { value }\end{array}$ & $\begin{array}{c}\text { Verification index } \\
\text { value }\end{array}$ & $\begin{array}{c}\text { Percent } \\
\text { difference }^{4}\end{array}$ & Comments \\
\hline MA36 & CSU-CAS & 4.94 & 4.94 & 0.00 & \\
\hline MA37 & CSU-CAS & 1.07 & 1.07 & 0.09 & \\
\hline MA38 & CSU-CAS & 2.12 & 2.11 & 0.08 & \\
\hline MA39 & CSU-CAS & 66.45 & 66.45 & 0.00 & \\
\hline MA40 & CSU-CAS & 0.23 & 0.23 & 0.00 & \\
\hline MA41 & CSU-CAS & 0.75 & 0.75 & 0.00 & \\
\hline MA42 & CSU-CAS & 1.30 & 1.30 & 0.00 & \\
\hline MA43 & CSU-CAS & 0.60 & 0.57 & 1.03 & HIT percentile calculations are more accurate \\
\hline MA44 & CSU-CAS & 0.91 & 0.75 & 4.66 & HIT percentile calculations are more accurate \\
\hline MA45 & CSU-CAS & 0.04 & 0.04 & 0.00 & \\
\hline ML1 & USGS-Microsoft Excel (CAS) & 71.56 & 71.56 & 0.00 & \\
\hline ML2 & USGS-Microsoft Excel (CAS) & 77.69 & 77.69 & 0.00 & \\
\hline ML3 & USGS-Microsoft Excel (CAS) & 102.06 & 102.06 & 0.00 & \\
\hline ML4 & USGS-Microsoft Excel (CAS) & 110.14 & 110.14 & 0.00 & \\
\hline ML5 & USGS-Microsoft Excel (CAS) & 80.39 & 80.39 & 0.00 & \\
\hline ML6 & USGS-Microsoft Excel (CAS) & 56.28 & 56.28 & 0.00 & \\
\hline ML7 & USGS-Microsoft Excel (CAS) & 42.17 & 42.17 & 0.00 & \\
\hline ML8 & USGS-Microsoft Excel (CAS) & 37.89 & 37.89 & 0.00 & \\
\hline ML9 & USGS-Microsoft Excel (CAS) & 37.75 & 37.75 & 0.00 & \\
\hline ML10 & USGS-Microsoft Excel (CAS) & 40.42 & 40.42 & 0.00 & \\
\hline ML11 & USGS-Microsoft Excel (CAS) & 52.17 & 52.17 & 0.00 & \\
\hline ML12 & USGS-Microsoft Excel (CAS) & 68.78 & 68.78 & 0.00 & \\
\hline ML13 & USGS-Microsoft Excel (CAS) & 55.92 & 55.92 & 0.00 & \\
\hline ML14 & CSU-CAS & 0.34 & 0.35 & 0.36 & \\
\hline ML15 & CSU-CAS & 0.24 & 0.23 & 0.94 & \\
\hline ML16 & CSU-CAS & 0.32 & 0.34 & 1.43 & \\
\hline ML17 & CSU-CAS & 0.27 & 0.26 & 0.47 & \\
\hline ML18 & CSU-CAS & 26.44 & 24.54 & 1.86 & Slight variation in standard deviation formula accounts for this difference \\
\hline ML19 & CSU-CAS & 24.32 & 24.32 & 0.00 & \\
\hline ML20 & CSU-CAS & 0.61 & 0.61 & 0.12 & \\
\hline ML21 & CSU-CAS & 31.39 & 31.39 & 0.00 & \\
\hline ML22 & CSU-CAS & 0.17 & 0.18 & 0.14 & \\
\hline MH1 & USGS-Microsoft Excel (CAS) & 536.39 & 536.39 & 0.00 & \\
\hline MH2 & USGS-Microsoft Excel (CAS) & 629.00 & 629.00 & 0.00 & \\
\hline MH3 & USGS-Microsoft Excel (CAS) & 621.14 & 621.14 & 0.00 & \\
\hline
\end{tabular}


Table 5-1. Verification results for 171 indices calculated in the Hydrologic Indices Tool.—Continued

\begin{tabular}{|c|c|c|c|c|c|}
\hline Index & Verification method ${ }^{1,2,3}$ & $\begin{array}{l}\text { HIT index } \\
\text { value }\end{array}$ & $\begin{array}{c}\text { Verification index } \\
\text { value }\end{array}$ & $\begin{array}{c}\text { Percent } \\
\text { difference }^{4}\end{array}$ & Comments \\
\hline MH4 & USGS-Microsoft Excel (CAS) & 612.25 & 612.25 & 0.00 & \\
\hline MH5 & USGS-Microsoft Excel (CAS) & 466.83 & 466.83 & 0.00 & \\
\hline MH6 & USGS-Microsoft Excel (CAS) & 300.67 & 300.67 & 0.00 & \\
\hline MH7 & USGS-Microsoft Excel (CAS) & 328.47 & 328.47 & 0.00 & \\
\hline MH8 & USGS-Microsoft Excel (CAS) & 319.78 & 319.78 & 0.00 & \\
\hline MH9 & USGS-Microsoft Excel (CAS) & 267.69 & 267.29 & 0.04 & \\
\hline MH10 & USGS-Microsoft Excel (CAS) & 276.50 & 276.50 & 0.00 & \\
\hline MH11 & USGS-Microsoft Excel (CAS) & 409.86 & 409.86 & 0.00 & \\
\hline MH12 & USGS-Microsoft Excel (CAS) & 519.69 & 519.69 & 0.00 & \\
\hline MH13 & USGS-Microsoft Excel (CAS) & 97.90 & 97.90 & 0.00 & \\
\hline MH14 & CSU-CAS & 12.89 & 12.89 & 0.00 & \\
\hline MH15 & CSU-CAS & 8.11 & 8.02 & 0.28 & \\
\hline MH16 & CSU-CAS & 2.91 & 2.88 & 0.19 & \\
\hline MH17 & CSU-CAS & 1.79 & 1.77 & 0.30 & \\
\hline MH18 & CSU-CAS & 6.70 & 6.70 & 0.00 & \\
\hline MH19 & CSU-CAS & -0.01 & -0.01 & 0.00 & \\
\hline MH20 & CSU-CAS & 7.79 & 7.79 & 0.00 & \\
\hline MH21 & CSU-CAS & 17.50 & 17.30 & 0.28 & \\
\hline MH22 & CSU-CAS & 5.73 & 5.71 & 0.07 & \\
\hline MH23 & CSU-CAS & 5.57 & 5.56 & 0.06 & \\
\hline MH24 & CSU-CAS & 3.65 & 3.63 & 0.16 & \\
\hline MH25 & CSU-CAS & 6.36 & 6.37 & 0.03 & \\
\hline MH26 & CSU-CAS & 11.57 & 11.57 & 0.00 & \\
\hline MH27 & CSU-CAS & 4.91 & 4.87 & 0.22 & \\
\hline FL1 & CSU-CAS & 9.25 & 9.00 & 0.69 & \\
\hline FL2 & CSU-CAS & 46.18 & 46.18 & 0.00 & \\
\hline FL3 & CSU-CAS & 0.00 & 0.00 & 0.00 & \\
\hline FH1 & CSU-CAS & 16.33 & 16.33 & 0.00 & \\
\hline $\mathrm{FH} 2$ & CSU-CAS & 33.53 & 33.53 & 0.00 & \\
\hline FH3 & CSU-CAS & 33.92 & 33.14 & 0.58 & \\
\hline FH4 & CSU-CAS & 5.28 & 5.14 & 0.67 & \\
\hline FH5 & CSU-CAS & 14.28 & 14.14 & 0.24 & \\
\hline FH6 & CSU-CAS & 13.36 & 13.03 & 0.63 & \\
\hline FH7 & CSU-CAS & 3.75 & 3.64 & 0.75 & \\
\hline FH8 & CSU-CAS & 16.33 & 16.22 & 0.17 & \\
\hline
\end{tabular}


[USGS, U.S. Geological Survey; CAS, commercially available software; CSU, Colorado State University. Refer to appendix 7 for index definitions]

\begin{tabular}{|c|c|c|c|c|c|}
\hline Index & Verification method ${ }^{1,2,3}$ & $\begin{array}{l}\text { HIT index } \\
\text { value }\end{array}$ & $\begin{array}{c}\text { Verification index } \\
\text { value }\end{array}$ & $\begin{array}{c}\text { Percent } \\
\text { difference }^{4}\end{array}$ & Comments \\
\hline FH9 & CSU-CAS & 9.53 & 8.63 & 2.48 & HIT percentile calculations are more accurate \\
\hline FH10 & CSU-CAS & 3.33 & 2.28 & 9.40 & Computer code checked-OK \\
\hline FH11 & CSU-CAS & 0.86 & 0.76 & 3.15 & Threshold has subjective elements \\
\hline DL1 & CSU-CAS & 29.53 & 29.53 & 0.00 & \\
\hline DL2 & CSU-CAS & 30.35 & 30.25 & 0.08 & \\
\hline DL3 & CSU-CAS & 31.95 & 31.77 & 0.14 & \\
\hline DL4 & CSU-CAS & 40.04 & 38.48 & 0.99 & \\
\hline DL5 & CSU-CAS & 61.24 & 55.04 & 2.67 & Computer code checked-OK \\
\hline DL6 & CSU-CAS & 49.17 & 49.17 & 0.00 & \\
\hline DL7 & CSU-CAS & 30.58 & 30.44 & 0.12 & \\
\hline DL8 & CSU-CAS & 31.94 & 31.75 & 0.15 & \\
\hline DL9 & CSU-CAS & 37.78 & 36.21 & 1.06 & \\
\hline DL10 & CSU-CAS & 49.07 & 43.85 & 2.81 & Computer code checked-OK \\
\hline DL11 & CSU-CAS & 0.35 & 0.35 & 0.00 & \\
\hline DL12 & CSU-CAS & 0.38 & 0.38 & 0.00 & \\
\hline DL13 & CSU-CAS & 0.47 & 0.47 & 0.00 & \\
\hline DL14 & CSU-CAS & 0.60 & 0.60 & 0.00 & \\
\hline DL15 & CSU-CAS & 0.40 & 0.40 & 0.00 & \\
\hline DL16 & CSU-CAS & 8.40 & 8.83 & 1.26 & \\
\hline DL17 & CSU-CAS & 65.30 & 65.30 & 0.00 & \\
\hline DL18 & CSU-CAS & 0.00 & 0.00 & 0.00 & \\
\hline DL19 & CSU-CAS & 0.00 & 0.00 & 0.00 & \\
\hline DL20 & CSU-CAS & 0.00 & 0.00 & 0.00 & \\
\hline DH1 & CSU-CAS & 1318.92 & 1318.92 & 0.00 & \\
\hline DH2 & CSU-CAS & 838.54 & 838.54 & 0.00 & \\
\hline DH3 & CSU-CAS & 553.62 & 553.62 & 0.00 & \\
\hline DH4 & CSU-CAS & 303.16 & 303.16 & 0.00 & \\
\hline DH5 & CSU-CAS & 216.84 & 218.58 & 0.20 & \\
\hline DH6 & CSU-CAS & 49.17 & 49.17 & 0.00 & \\
\hline DH7 & CSU-CAS & 41.07 & 41.07 & 0.00 & \\
\hline DH8 & CSU-CAS & 38.71 & 38.71 & 0.00 & \\
\hline DH9 & CSU-CAS & 31.78 & 31.78 & 0.00 & \\
\hline DH10 & CSU-CAS & 31.97 & 31.11 & 0.68 & \\
\hline DH11 & CSU-CAS & 15.52 & 15.52 & 0.00 & \\
\hline DH12 & CSU-CAS & 6.51 & 6.51 & 0.00 & \\
\hline
\end{tabular}


Table 5-1. Verification results for 171 indices calculated in the Hydrologic Indices Tool.—Continued

[USGS, U.S. Geological Survey; CAS, commercially available software; CSU, Colorado State University. Refer to appendix 7 for index definitions]

\begin{tabular}{|c|c|c|c|c|c|}
\hline Index & Verification method ${ }^{1,2,3}$ & $\begin{array}{c}\text { HIT index } \\
\text { value }\end{array}$ & $\begin{array}{c}\text { Verification index } \\
\text { value }\end{array}$ & $\begin{array}{c}\text { Percent } \\
\text { difference }^{4}\end{array}$ & Comments \\
\hline DH13 & CSU-CAS & 3.57 & 3.57 & 0.00 & \\
\hline DH14 & CSU-CAS & 0.24 & 0.24 & 0.42 & \\
\hline DH15 & USGS Manual Calculation & 4.63 & 4.63 & 0.00 & \\
\hline DH16 & USGS Manual Calculation & 56.72 & 56.72 & 0.00 & \\
\hline DH17 & USGS Manual Calculation & 15.82 & 15.82 & 0.00 & \\
\hline DH18 & CSU-CAS & 2.53 & 2.54 & 0.11 & \\
\hline DH19 & CSU-CAS & 1.43 & 1.41 & 0.26 & \\
\hline DH20 & CSU-CAS & 5.56 & 5.59 & 0.12 & \\
\hline DH21 & USGS Manual Calculation & 45.40 & 45.40 & 0.00 & \\
\hline DH22 & CSU-CAS & 93.98 & 83.00 & 3.10 & Threshold has subjective elements \\
\hline $\mathrm{DH} 23$ & CSU-CAS & 1.70 & 1.53 & 2.63 & Threshold has subjective elements \\
\hline DH24 & USGS Manual Calculation & 116.89 & 116.89 & 0.00 & \\
\hline TA1 & Colwell (1974) table 1 & 0.10 & 0.10 & 0.00 & \\
\hline TA2 & Colwell (1974) table 1 & 0.29 & 0.29 & 0.00 & \\
\hline TA3 & CSU-CAS & 0.21 & 0.30 & 8.65 & Threshold has subjective elements \\
\hline TL1 & CSU-CAS & 261.50 & 260.90 & 0.06 & \\
\hline TL2 & CSU-CAS & 28.44 & 28.30 & 0.12 & \\
\hline TL3 & CSU-CAS & 0.46 & 0.68 & 9.95 & Threshold has subjective elements \\
\hline TL4 & USGS Manual Calculation & 0.04 & 0.04 & 0.00 & \\
\hline TH1 & USGS Manual Calculation & 62.82 & 62.82 & 0.00 & \\
\hline TH2 & USGS Manual Calculation & 61.45 & 61.45 & 0.00 & \\
\hline TH3 & CSU-CAS & 0.08 & 0.07 & 3.59 & Threshold has subjective elements \\
\hline RA1 & CSU-CAS & 70.15 & 70.15 & 0.00 & \\
\hline RA2 & USGS Manual Calculation & 233.73 & 233.73 & 0.00 & \\
\hline RA3 & CSU-CAS & -31.35 & -30.66 & 0.56 & \\
\hline RA4 & USGS Manual Calculation & -290.07 & -290.07 & 0.00 & \\
\hline RA5 & CSU-CAS & 0.28 & 0.31 & 2.37 & \\
\hline RA6 & CSU-CAS & 0.15 & 0.15 & 0.00 & \\
\hline RA7 & CSU-CAS & -0.08 & -0.08 & 0.00 & \\
\hline RA8 & CSU-CAS & 118.08 & 117.94 & 0.03 & \\
\hline RA9 & CSU-CAS & 8.16 & 8.09 & 0.21 & \\
\hline
\end{tabular}

${ }^{1}$ U.S. Geological Survey (Fort Collins Science Center) compared HIT results to results using Microsoft Excel.

${ }^{2}$ Julian D. Olden (Colorado State University) provided previously calculated results using commercially available software - Excel, MATLAB, SAS.

${ }^{3}$ Colwell (1974)

${ }^{4}$ Absolute percent difference $=$ HIP index value-CAS index value/average (HIP value, CAS value $) * 100$ 


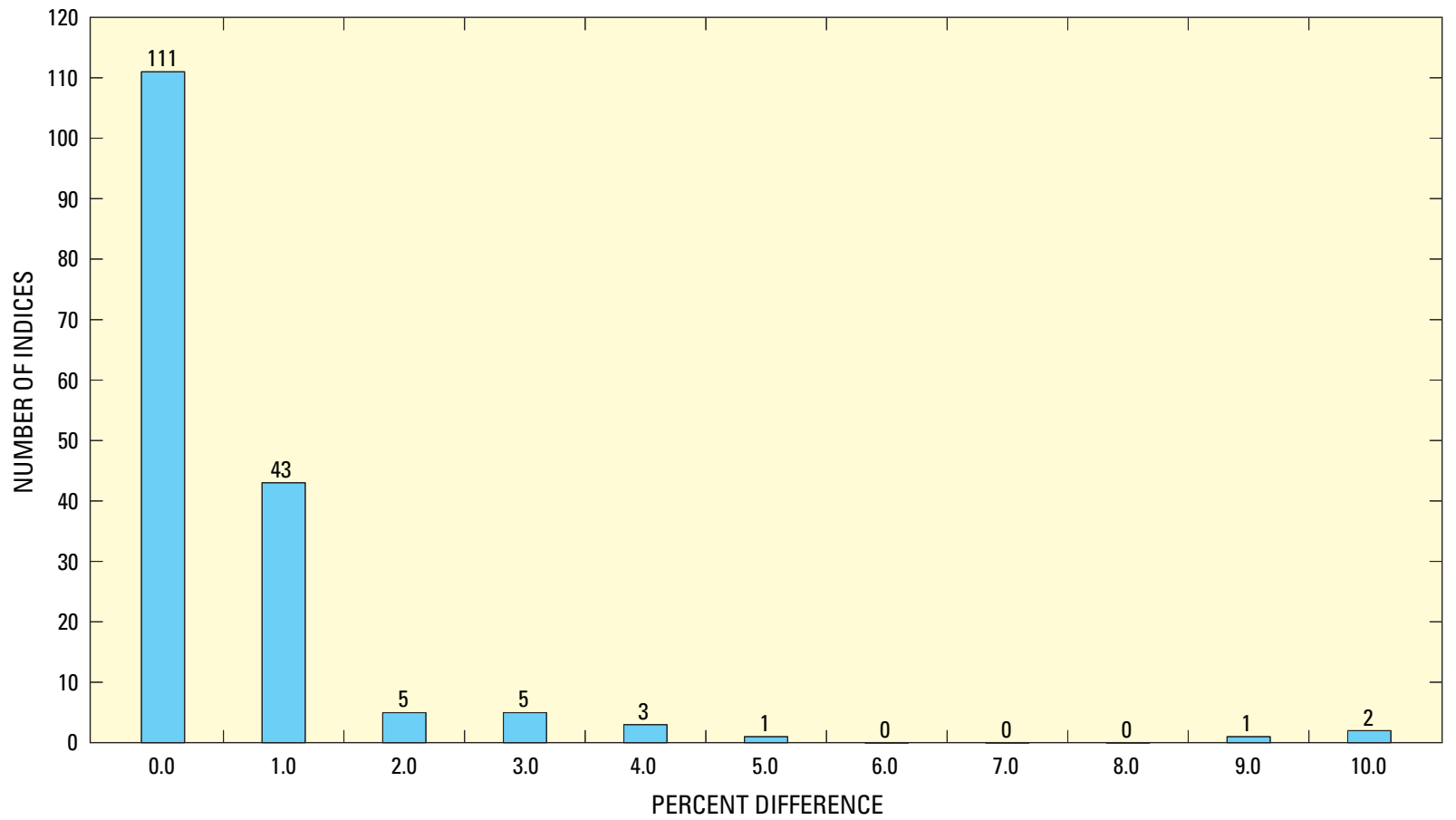

Figure 5-1. Verification results: distribution of percent difference between Hydrologic Indices Tool index values and values calculated using commercially available software.

Table 5-2. Verification results for differences between the New Jersey Hydrologic Assessment Tool index values and values calculated using commercially available software for 64 indices at 19 selected stream-gage sites.

\begin{tabular}{|c|c|}
\hline Index & Results \\
\hline MA1 & All values within 2 percent of NJHAT values \\
\hline MA2 & All values within 3 percent of NJHAT values \\
\hline MA12-MA23 & All values within 2 percent of NJHAT values \\
\hline MA24-MA35 & All values within 3 percent of NJHAT values \\
\hline MA36 & All values within 3 percent of the NJHAT values \\
\hline MA41 & All values within 2 percent of NJHAT values \\
\hline ML22 & All values within 2 percent of NJHAT values \\
\hline MH1-MH12 & All values within 3 percent of NJHAT values \\
\hline MH14 & All values within 3 percent of NJHAT values \\
\hline MH15 & All values within 3 percent of NJHAT values \\
\hline DL3 & All of values within 2 percent of NJHAT values \\
\hline DL14 & All of values within 2 percent of NJHAT values \\
\hline DL16 & 16 values within 3 percent of NJHAT values, 2 values within 5 percent of NJHAT values, and 1 value 12.8 percent different \\
\hline DH3 & All values within 2 percent of NJHAT values. \\
\hline DH8 & 17 values within 2 percent of NJHAT values and, 2 values within 4 percent of NJHAT values \\
\hline RA1 & All values within 3 percent of NJHAT values \\
\hline RA3 & All values within 2 percent of NJHAT values \\
\hline
\end{tabular}


Appendix 6. Hydrologic indices with the largest absolute loading for each of the statistically significant principal component axes for each stream type in the nine sub-components of the flow regime. (From Olden and Poff, 2003)

\begin{tabular}{|c|c|c|c|c|c|c|c|}
\hline \multirow[b]{3}{*}{ Flow component } & \multicolumn{6}{|c|}{ Stream classification } & \multirow[b]{3}{*}{ All streams } \\
\hline & \multicolumn{2}{|c|}{ Intermittent } & \multicolumn{4}{|c|}{ Perennial } & \\
\hline & Harsh intermittent & Intermittent flashy or runoff & Snowmelt & Snow and rain & $\begin{array}{l}\text { Superstable or stable } \\
\text { ground water }\end{array}$ & $\begin{array}{l}\text { Perennial flashy or } \\
\text { runoff }\end{array}$ & \\
\hline \multicolumn{8}{|c|}{ Magnitude of flow events } \\
\hline Average flow conditions & MA34, MA22, MA16 & MA37, MA18, MA21, MA9 & MA29, MA40 & MA3, MA44 & MA3, MA41, MA8 & MA26, MA41, MA10 & MA5, MA41, MA3, MA11 \\
\hline Low flow conditions & ML13, ML15, ML1 & ML16, ML6, ML22, ML15 & ML13, ML22 & ML13, ML14 & ML18, ML14, ML16 & ML17, ML14, ML16 & ML17, ML4, ML21, ML18 \\
\hline High flow conditions & MH23, MH14, MH9 & MH23, MH4, MH14, MH7 & MH1, MH20 & MH17, MH20 & MH17, MH19, MH10 & MH23, MH8, MH14 & MH16, MH8, MH10, MH14 \\
\hline \multicolumn{8}{|c|}{ Frequency of flow events } \\
\hline Low flow conditions & FL2, FL3, FL1 & FL3, FL2, FL1 & FL3, FL2 & FL3, FL2 & FL3, FL1, FL2 & FL3, FL2, FL3 & FL3, FL2, FL3, FL1 \\
\hline High flow conditions & FH2, FH5, FH7 & FH3, FH7, FH2, FH10 & FH8, FH11 & FH3, FH5 & FH3, FH6, FH11 & FH4, FH6, FH7 & FH3, FH6, FH7, FH2 \\
\hline \multicolumn{8}{|c|}{ Duration of flow events } \\
\hline Low flow conditions & DL13, DL1, DL2 & DL18, DL16, DL13, DL1 & DL5, DL16 & DL6, DL13 & DL9, DL11, DL16 & DL10, DL17, DL6 & DL18, DL17, DL16, DL13 \\
\hline High flow conditions & DH10, DH5, DH22 & DH13, DH15, DH12, DH23 & DH19, DH16 & DH12, DH24 & DH11, DH20, DH15 & DH13, DH16, DH24 & DH13, DH16, DH20, DH15 \\
\hline \multicolumn{8}{|c|}{ Timing of flow events } \\
\hline & TH1, TL2, TH2 & TA1, TA2, TL1, TH3 & TA1, TA3 & TA1, TL1 & TA1, TH1, TL2 & TA1, TA3, TH3 & TA1, TH3, TA1, TL2 \\
\hline \multicolumn{8}{|c|}{ Rate of change of flow events } \\
\hline & RA4, RA1, RA5 & RA9, RA6, RA5, RA7 & RA1, RA8 & RA9, RA8 & RA9, RA8, RA5 & RA9, RA7, RA6 & RA9, RA8, RA6, RA5 \\
\hline
\end{tabular}




\section{Appendix 7. Definitions of the 171 hydrologic indices.}

The following information for the 171 hydrologic indices is from Olden and Poff (2003). The USGS revised a limited number of the formulae and (or) definitions when deemed appropriate. These changes are also documented in Henriksen and others (2006). Olden and Poff (2003) contains 12 additional references from which the indices were derived. Two of these articles (Colwell, 1974; Poff, 1996) are referenced here because they provide examples and additional explanation for complex indices.

The alphanumeric code preceding each definition refers to the category of the flow regime (magnitude, frequency, duration, timing, or rate of change) and type of flow event (A, average; L, low; and $\mathrm{H}$, high) the hydrologic index was developed to describe. Indices are numbered successively within each category. For example, MA1 is the first index describing magnitude of the average flow condition.

\begin{tabular}{cl}
\hline MA\# & Magnitude, average flow conditions \\
\hline ML\# & Magnitude, low flow conditions \\
\hline MH\# & Magnitude, high flow conditions \\
\hline FL\# & Frequency, low flow conditions \\
\hline FH\# & Frequency, high flow conditions \\
DL\# & Duration, low flow conditions \\
DH\# & Duration, high flow conditions \\
TA\# & Timing, average flow conditions \\
TL\# & Timing, low flow conditions \\
TH\# & Timing, high flow conditions \\
\hline RA\# & Rate of change, average conditions \\
\hline
\end{tabular}

Following each definition, in parentheses, are (1) the units of the index and (2) the type of data (temporal or spatial), from which the upper and lower percentile limits (for example, 75 th and 25th) are derived. Temporal data are from a multiyear daily-flow record from a single stream gage. For example, index MA1 - mean for the entire flow record - uses 365 mean daily flow values for each year in the flow record to calculate the mean for the entire flow record. Consequently, there are 365 values for each year to calculate upper and lower percentile limits. However, formulas for 60 of the indices do not produce a range of values from which percentile limits can be calculated. MA5 (skewness), for example - the mean for the entire flow record divided by the median for the entire record - results in a single value; therefore, upper and lower percentile limits cannot be calculated. NJHAT uses spatial data, values for each stream gage for all the streams within a stream class, to compute limits. Upper and lower percentile limits are calculated from the 31 MA5 values from the 31 stream gages that were identified from the classification analysis as stream class A.

Exceedence and percentile are used in the calculation for a number of indices. A 90-percent exceedence means that 90 percent of the values are equal to or greater than the 90-percent exceedence value, whereas a 90th percentile means that 10 percent of the values are equal to or greater than the 90th-percentile value.

\begin{tabular}{|c|c|}
\hline Code & Definition \\
\hline MA2 & Median of the daily mean flow values for the entire flow record (cubic feet per second-temporal). \\
\hline MA5 & $\begin{array}{l}\text { The skewness of the entire flow record is computed as the mean for the entire flow record (MA1) divided by the median } \\
\text { (MA2) for the entire flow record (dimensionless-spatial). }\end{array}$ \\
\hline MA7 & $\begin{array}{l}\text { Range in daily flows is computed in the same way as MA6 except using the } 20 \text {-percent and } 80 \text {-percent exceedence val- } \\
\text { ues. Divide the } 20 \text {-percent exceedence value by the } 80 \text {-percent value (dimensionless-spatial). }\end{array}$ \\
\hline
\end{tabular}




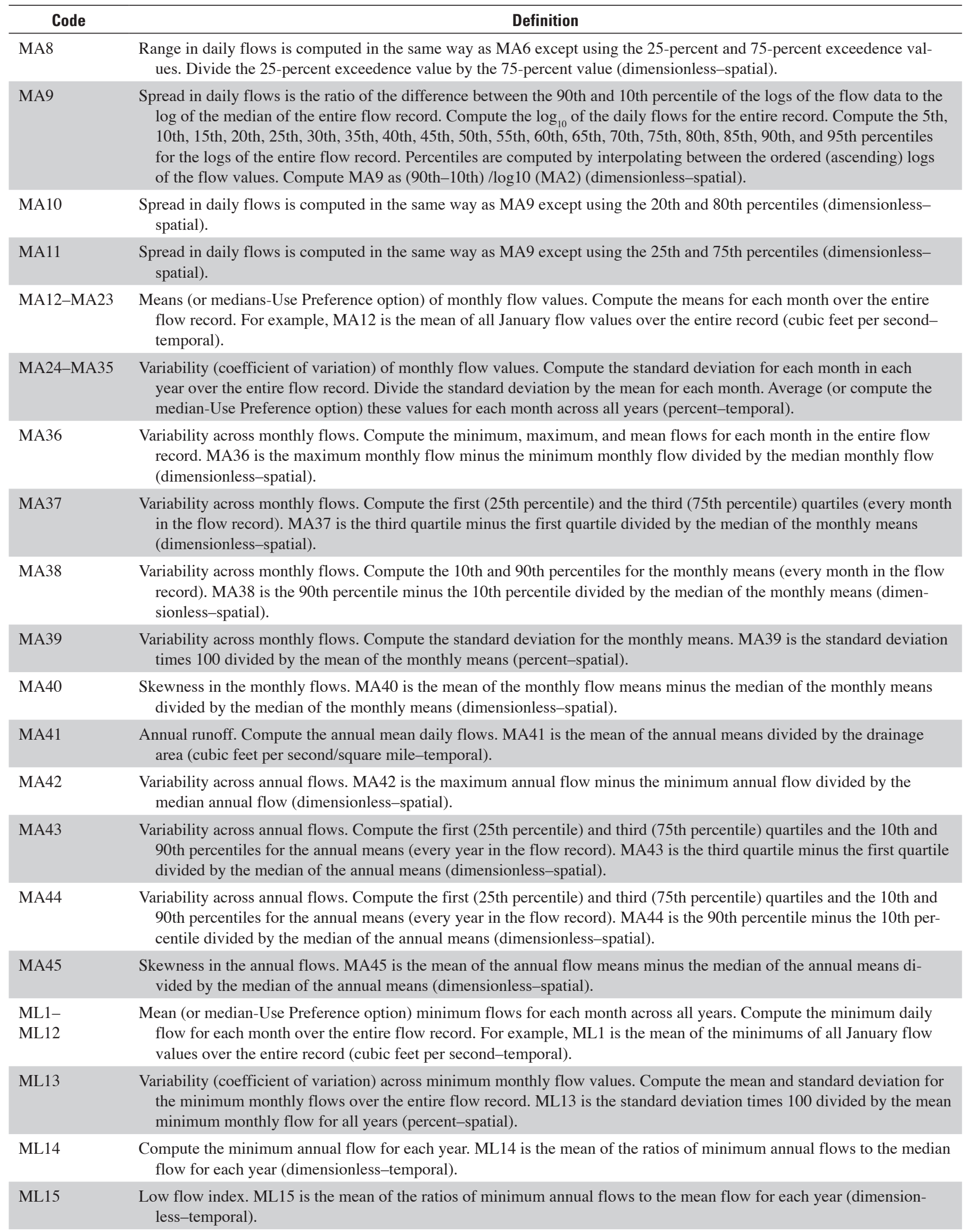




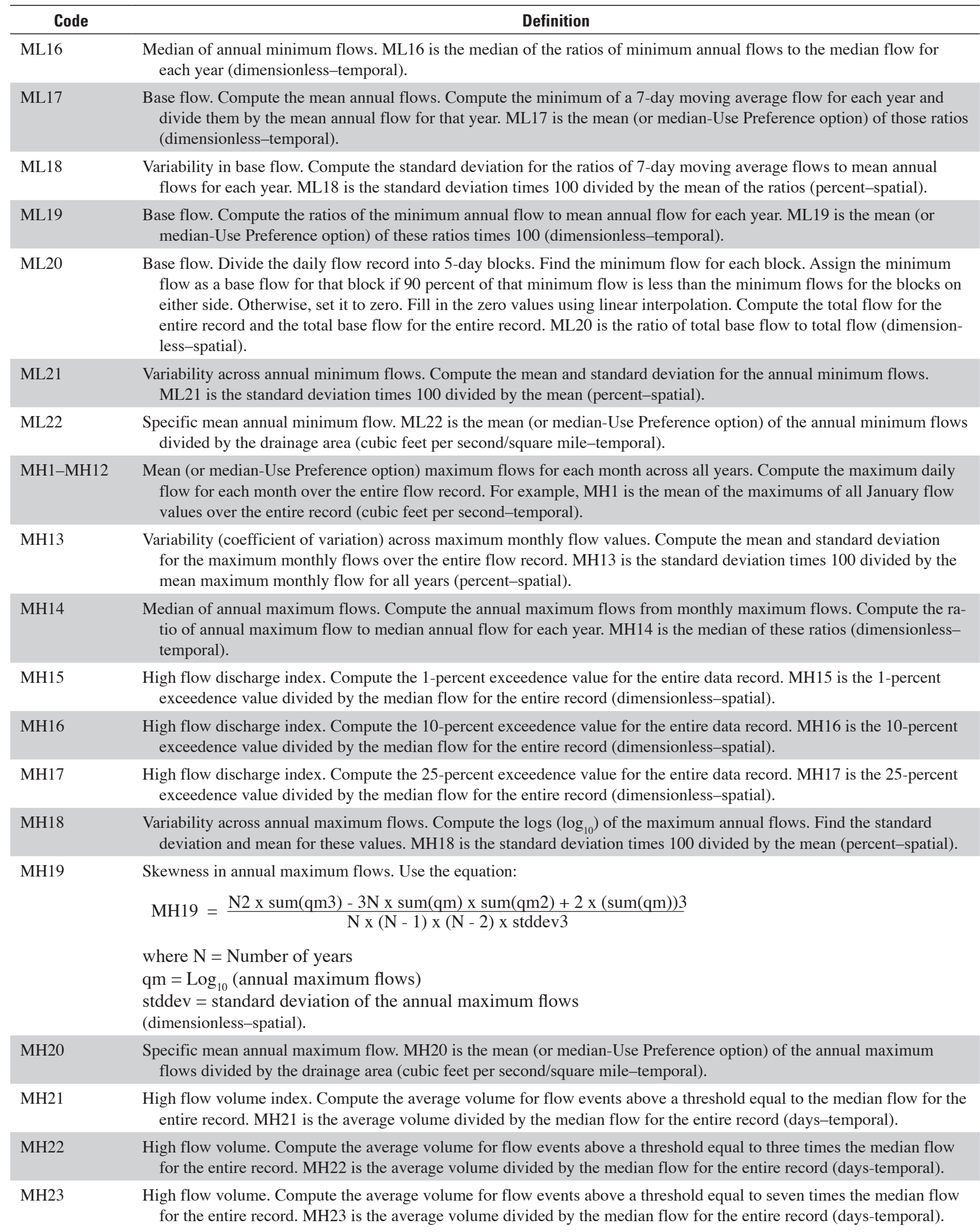




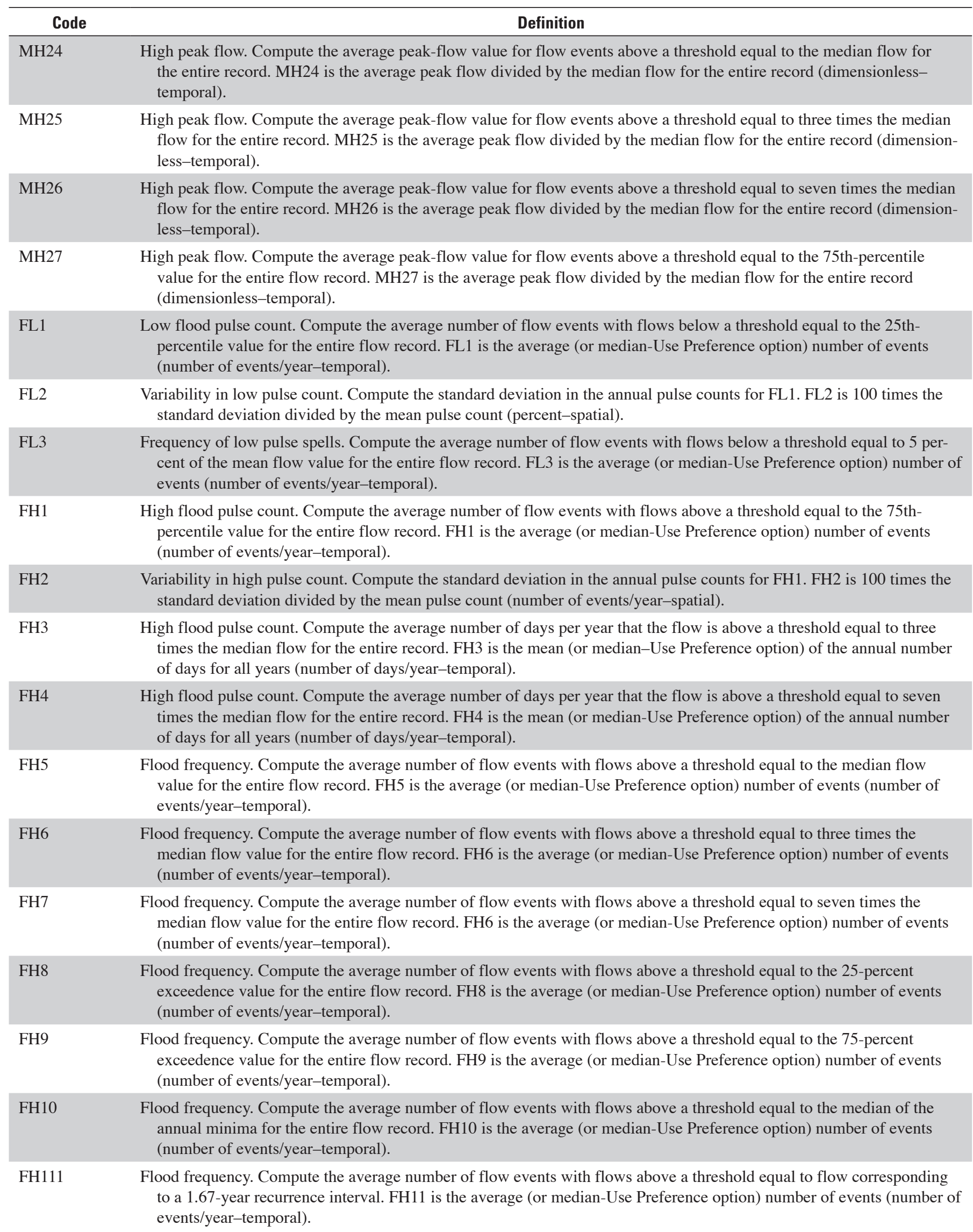




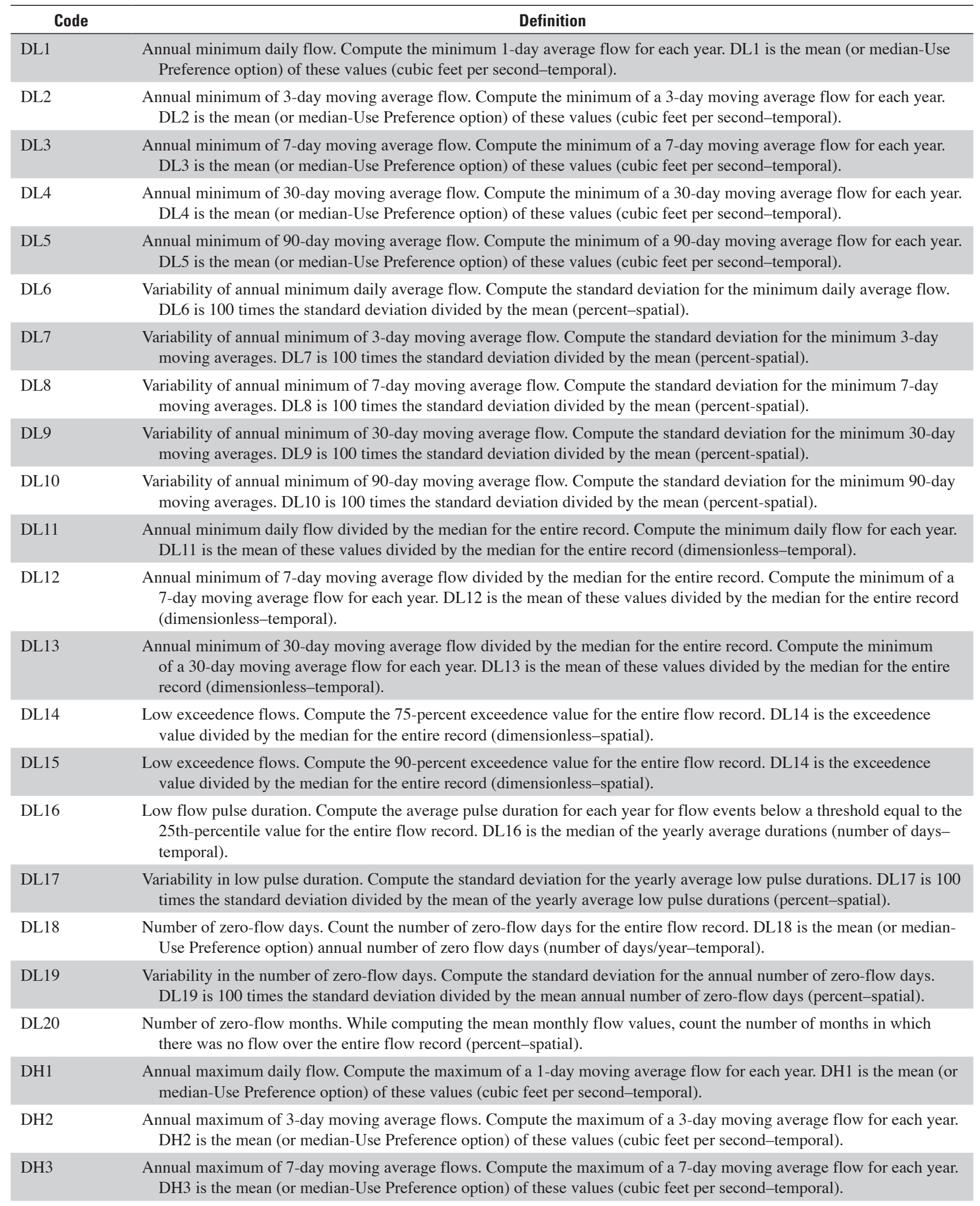




\begin{tabular}{|c|c|}
\hline Code & Definition \\
\hline DH4 & $\begin{array}{l}\text { Annual maximum of 30-day moving average flows. Compute the maximum of } 30 \text {-day moving average flows. Compute } \\
\text { the maximum of a 30-day moving average flow for each year. DH4 is the mean (or median-Use Preference option) of } \\
\text { these values (cubic feet per second-temporal). }\end{array}$ \\
\hline DH5 & $\begin{array}{l}\text { Annual maximum of 90-day moving average flows. Compute the maximum of a 90-day moving average flow for each } \\
\text { year. DH5 is the mean (or median-Use Preference option) of these values (cubic feet per second-temporal). }\end{array}$ \\
\hline DH6 & $\begin{array}{l}\text { Variability of annual maximum daily flows. Compute the standard deviation for the maximum 1-day moving averages. } \\
\text { DH6 is } 100 \text { times the standard deviation divided by the mean (percent-spatial). }\end{array}$ \\
\hline DH7 & $\begin{array}{l}\text { Variability of annual maximum of 3-day moving average flows. Compute the standard deviation for the maximum } 3 \text {-day } \\
\text { moving averages. DH7 is } 100 \text { times the standard deviation divided by the mean (percent-spatial). }\end{array}$ \\
\hline DH8 & $\begin{array}{l}\text { Variability of annual maximum of 7-day moving average flows. Compute the standard deviation for the maximum 7-day } \\
\text { moving averages. DH8 is } 100 \text { times the standard deviation divided by the mean (percent-spatial). }\end{array}$ \\
\hline DH9 & $\begin{array}{l}\text { Variability of annual maximum of } 30 \text {-day moving average flows. Compute the standard deviation for the maximum } 30 \text { - } \\
\text { day moving averages. DH9 is } 100 \text { times the standard deviation divided by the mean (percent-spatial). }\end{array}$ \\
\hline DH11 & $\begin{array}{l}\text { Annual maximum of 1-day moving average flows divided by the median for the entire record. Compute the maximum } \\
\text { of a 1-day moving average flow for each year. DL11 is the mean of these values divided by the median for the entire } \\
\text { record (dimensionless-temporal). }\end{array}$ \\
\hline DH12 & $\begin{array}{l}\text { Annual maximum of 7-day moving average flows divided by the median for the entire record. Compute the maxi- } \\
\text { mum daily average flow for each year. DL12 is the mean of these values divided by the median for the entire record } \\
\text { (dimensionless-temporal). }\end{array}$ \\
\hline DH13 & $\begin{array}{l}\text { Annual maximum of } 30 \text {-day moving average flows divided by the median for the entire record. Compute the maximum } \\
\text { of a } 30 \text {-day moving average flow for each year. DL13 is the mean of these values divided by the median for the entire } \\
\text { record (dimensionless-temporal). }\end{array}$ \\
\hline DH14 & $\begin{array}{l}\text { Flood duration. Compute the mean of the mean monthly flow values. Find the 95th percentile for the mean monthly } \\
\text { flows. DH14 is the } 95 \text { th-percentile value divided by the mean of the monthly means (dimensionless-spatial). }\end{array}$ \\
\hline DH18 & $\begin{array}{l}\text { High flow duration. Compute the average duration of flow events with flows above a threshold equal to three times the } \\
\text { median flow value for the entire flow record. DH18 is the average (or median-Use Preference option) duration of the } \\
\text { events (days-temporal). }\end{array}$ \\
\hline DH19 & $\begin{array}{l}\text { High flow duration. Compute the average duration of flow events with flows above a threshold equal to seven times the } \\
\text { median flow value for the entire flow record. DH19 is the average (or median-Use Preference option) duration of the } \\
\text { events (days-temporal). }\end{array}$ \\
\hline DH20 & $\begin{array}{l}\text { High flow duration. Compute the 75th-percentile value for the entire flow record. Compute the average duration of flow } \\
\text { events with flows above a threshold equal to the } 75 \text { th-percentile value for the median annual flows. DH20 is the aver- } \\
\text { age (or median-Use Preference option) duration of the events (days-temporal). }\end{array}$ \\
\hline $\mathrm{DH} 21$ & $\begin{array}{l}\text { High flow duration. Compute the } 25 \text { th-percentile value for the entire flow record. Compute the average duration of flow } \\
\text { events with flows above a threshold equal to the } 25 \text { th-percentile value for the entire set of flows. DH } 21 \text { is the average } \\
\text { (or median-Use Preference option) duration of the events (days-temporal). }\end{array}$ \\
\hline $\mathrm{DH} 22^{1}$ & $\begin{array}{l}\text { Flood interval. Compute the flood threshold as the flow equivalent for a flood recurrence of } 1.67 \text { years. Determine the } \\
\text { median number of days between flood events for each year. DH22 is the mean (or median-Use Preference option) of } \\
\text { the yearly median number of days between flood events (days-temporal). }\end{array}$ \\
\hline $\mathrm{DH} 23^{1}$ & $\begin{array}{l}\text { Flood duration. Compute the flood threshold as the flow equivalent for a flood recurrence of } 1.67 \text { years. Determine the } \\
\text { number of days each year that the flow remains above the flood threshold. DH23 is the mean (or median-Use Prefer- } \\
\text { ence option) of the number of flood days for years in which floods occur (days-temporal). }\end{array}$ \\
\hline
\end{tabular}




\begin{tabular}{|c|c|}
\hline Code & Definition \\
\hline $\mathrm{DH} 24^{1}$ & $\begin{array}{l}\text { Flood-free days. Compute the flood threshold as the flow equivalent for a flood recurrence of } 1.67 \text { years. Compute the } \\
\text { maximum number of days that the flow is below the threshold for each year. DH24 is the mean (or median-Use Prefer- } \\
\text { ence option) of the maximum yearly no-flood days (days-temporal). }\end{array}$ \\
\hline TA1 & 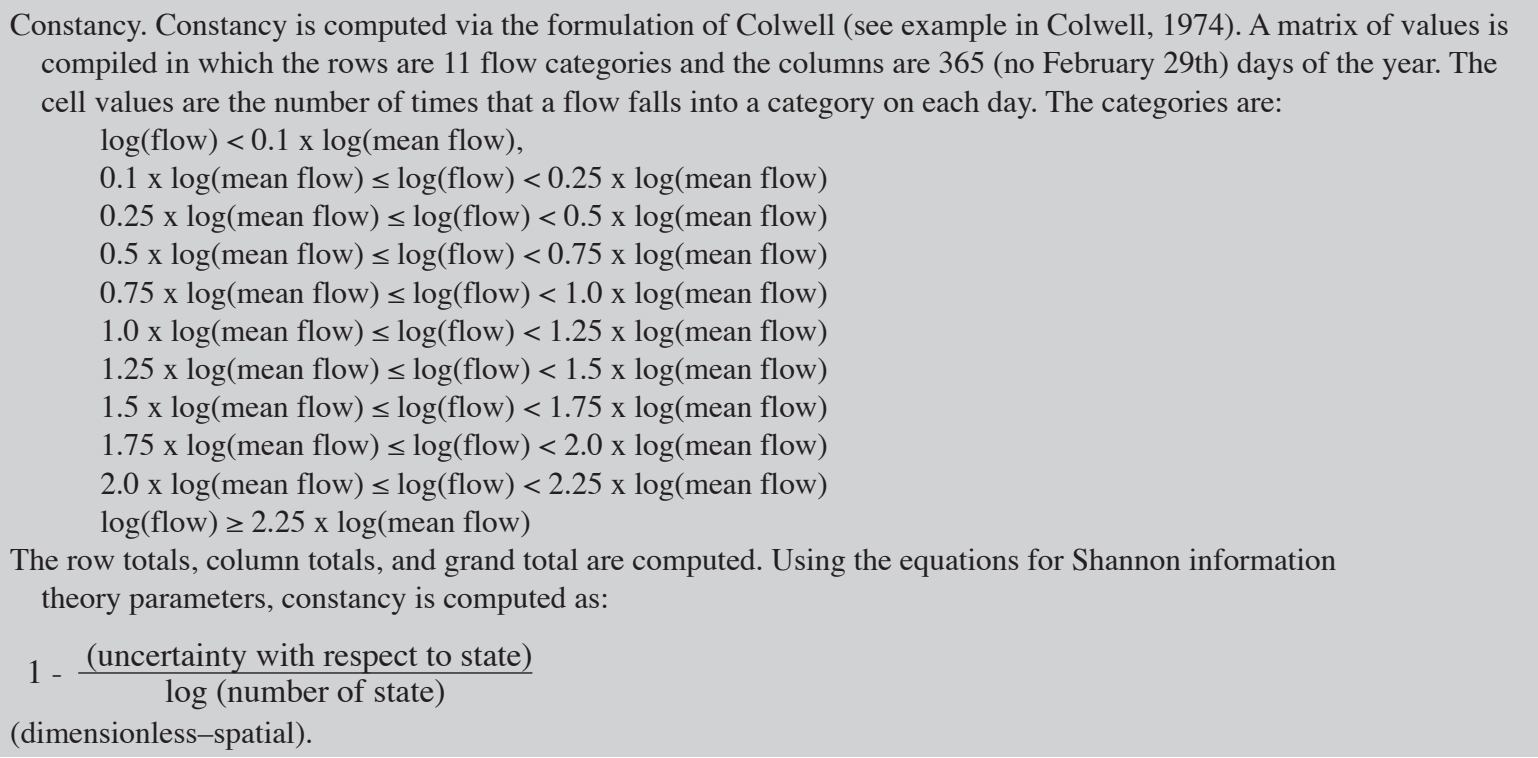 \\
\hline TA2 & $\begin{array}{l}\text { Predictability. Predictability is computed from the same matrix as constancy (see example in Colwell, 1974). It is com- } \\
\text { puted as: } \\
1-\frac{\text { (uncertainty with respect to interaction of time and state - uncertainty with respect to time) }}{\log \text { (number of state) }} \\
\text { (dimensionless-spatial). }\end{array}$ \\
\hline TL2 & $\begin{array}{l}\text { Variability in Julian date of annual minima. Compute the coefficient of variation for the mean } \mathrm{x} \text { and } \mathrm{y} \text { components and } \\
\text { convert to a date (Julian date-spatial). }\end{array}$ \\
\hline TL3 $^{2}$ & $\begin{array}{l}\text { Seasonal predictability of low flow. Divide years into 2-month periods (that is, Oct-Nov, Dec-Jan, and so forth). Count } \\
\text { the number of low flow events (flow events with flows } \leq 5 \text {-year flood threshold) in each period over the entire flow } \\
\text { record. TL3 is the maximum number of low flow events in any one period divided by the total number of low flow } \\
\text { events (dimensionless-spatial). }\end{array}$ \\
\hline $\mathrm{TL}^{2}{ }^{2}$ & $\begin{array}{l}\text { Seasonal predictability of non-low flow. Compute the number of days that flow is above the } 5 \text {-year flood threshold as the } \\
\text { ratio of number of days to } 365 \text { or } 366 \text { (leap year) for each year. TL4 is the maximum of the yearly ratios (dimension- } \\
\text { less-spatial). }\end{array}$ \\
\hline TH1 & $\begin{array}{l}\text { Julian date of annual maximum. Determine the Julian date that the maximum flow occurs for each year. Transform the } \\
\text { dates to relative values on a circular scale (radians or degrees). Compute the } \mathrm{x} \text { and y components for each year and } \\
\text { average them across all years. Compute the mean angle as the arc tangent of y-mean divided by x-mean. Transform the } \\
\text { resultant angle back to Julian date (Julian date-spatial). }\end{array}$ \\
\hline TH2 & $\begin{array}{l}\text { Variability in Julian date of annual maxima. Compute the coefficient of variation for the mean } \mathrm{x} \text { and y components and } \\
\text { convert to a date (Julian date-spatial). }\end{array}$ \\
\hline $\mathrm{TH}^{1}{ }^{1}$ & $\begin{array}{l}\text { Seasonal predictability of nonflooding. Computed as the maximum proportion of a } 365 \text {-day year that the flow is less than } \\
\text { the } 1.67 \text {-year flood threshold and also occurs in all years. Accumulate nonflood days that span all years. TH3 is maxi- } \\
\text { mum length of those flood-free periods divided by } 365 \text { (dimensionless-spatial). }\end{array}$ \\
\hline RA1 & $\begin{array}{l}\text { Rise rate. Compute the change in flow for days in which the change is positive for the entire flow record. RA1 is the } \\
\text { mean (or median-Use Preference option) of these values (cubic feet per second/day-temporal). }\end{array}$ \\
\hline
\end{tabular}




\begin{tabular}{|c|c|}
\hline Code & Definition \\
\hline RA2 & $\begin{array}{l}\text { Variability in rise rate. Compute the standard deviation for the positive flow changes. RA2 is } 100 \text { times the standard } \\
\text { deviation divided by the mean (percent-spatial). }\end{array}$ \\
\hline RA4 & $\begin{array}{l}\text { Variability in fall rate. Compute the standard deviation for the negative flow changes. RA4 is } 100 \text { times the standard } \\
\text { deviation divided by the mean (percent-spatial). }\end{array}$ \\
\hline RA6 & $\begin{array}{l}\text { Change of flow. Compute the } \log _{10} \text { of the flows for the entire flow record. Compute the change in log of flow for days } \\
\text { in which the change is positive for the entire flow record. RA6 is the median of these values (cubic feet per second-- } \\
\text { temporal). }\end{array}$ \\
\hline RA7 & $\begin{array}{l}\text { Change of flow. Compute the } \log _{10} \text { of the flows for the entire flow record. Compute the change in log of flow for days in } \\
\text { which the change is negative for the entire flow record. RA7 is the median of these log values (cubic feet per second/ } \\
\text { day-temporal). }\end{array}$ \\
\hline RA9 & $\begin{array}{l}\text { Variability in reversals. Compute the standard deviation for the yearly reversal values. RA9 is } 100 \text { times the standard } \\
\text { deviation divided by the mean (percent-spatial). }\end{array}$ \\
\hline
\end{tabular}

${ }^{1}$ Note-1.67-year flood threshold (Olden and Poff, 2003)-For indices FH11, DH22, DH23, DH24, TA3, and TH3, compute the $\log _{10}$ of the peak annual flows. Compute the $\log _{10}$ of the daily flows for the peak annual flow days. Calculate the coefficients for a linear regression equation for logs of peak annual flow versus logs of average daily flow for peak days. Using the log peak flow for the 1.67-year recurrence interval (60th percentile) as input to the regression equation, predict the $\log _{10}$ of the average daily flow. The threshold is 10 to the $\log _{10}$ (average daily flow) power (cubic feet per second).

${ }^{2}$ Note-5-year flood threshold (Olden and Poff, 2003)-For TL3 and TL4, compute the $\log _{10}$ of the peak annual flows. Compute the log ${ }_{10}$ of the daily flows for the peak annual flow days. Calculate the coefficients for a linear regression equation for logs of peak annual flow versus logs of average daily flow for peak days. Using the $\log$ peak flow for the 5-year recurrence interval (80th percentile) as input to the regression equation; predict the log ${ }_{10}$ of the average daily flow. The threshold is 10 to the $\log _{10}$ (average daily flow) power (cubic feet per second). 
For additional information, write to:

Director

U.S. Geological Survey

New Jersey Water Science Center

810 Bear Tavern Road, Suite 206

West Trenton, NJ 08628

or visit our Web site at:

http://nj.usgs.gov/

Document prepared by the West Trenton Publishing Service Center 
